\title{
Capillary interactions on soft and textured surfaces
}

\section{Diana Marcela García González}


Capillary interactions on soft and textured surfaces

Diana Marcela García González 
Graduation committee members:

Prof. Dr. Jennifer Herek (chair)

Prof. Dr. Jacco H. Snoeijer (promotor)

Prof. Dr. Hans-Jürgen Butt (promotor)

Dr. Michael Kappl (copromotor)

Prof. Dr. José Bico

Prof. Dr. Anton Darhuber

Prof. Dr. Mireille Claessens

Prof. Dr. Detlef Lohse
University of Twente

University of Twente

Max Planck Institute for Polymer Research Max Planck Institute for Polymer Research

ESPCI, Paris

Eindhoven University of Technology

University of Twente

University of Twente

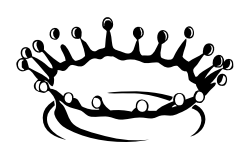

Physics of Fluids

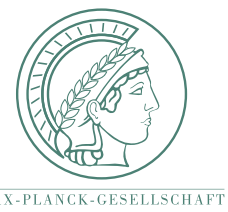

The work in this thesis was carried out at the Physics of Fluids Group of the Faculty of Science and Technology of the University of Twente and the Physics of Interfaces Group of the Max Planck for Polymer Research. This thesis was financially supported by the Max Planck Center for Complex Fluid Dynamics of the University of Twente.

Dutch title:

Capillaire interacties op zachte en gestructureerde oppervlakken

Publisher:

Diana Marcela García González, Physics of Fluids, University of Twente,

P.O. Box 217, 7500 AE Enschede, The Netherlands

www.dmgarciagonzalez.com

Front cover by D.M. García González. A water drop sits on a hydrophobic goose feather.

Copyright () 2021. All rights reserved.

No part of this work may be reproduced or transmitted for commercial purposes, in any form or by any means, electronic or mechanical, including photocopying and recording, or by any information storage or retrieval system, except as expressly permitted by the publisher.

ISBN: $978-90-365-5288-2$

DOI: $10.3990 / 1.9789036552882$ 


\title{
CAPILLARY INTERACTIONS ON SOFT AND TEXTURED SURFACES
}

\author{
DISSERTATION
}

to obtain

the degree of doctor at the University of Twente, on the authority of the rector magnificus,

Prof. Dr. Ir. A. Veldkamp,

on account of the decision of the Doctorate Board,

to be publicly defended

on Friday the 14th of January 2022 at 14:45

by

Diana Marcela García González

Born on the 8th of April 1991

in Bogotá, Colombia 
This dissertation has been approved by the promotors:

Prof. Dr. Jacco H. Snoeijer

Prof. Dr. Hans-Jürgen Butt

and the copromotor:

Dr. Michael Kappl 


\section{Contents}

1 Introduction 1

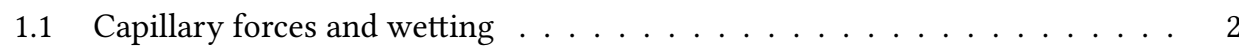

1.2 Textured solids . . . . . . . . . . . . . . . . . . . 4

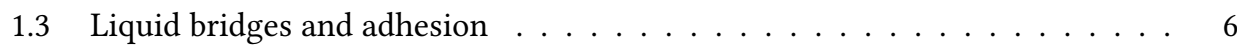

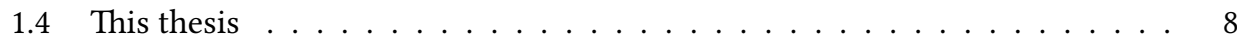

2 Onset of elasto-capillary bundling of micropillar arrays: a direct visualiza$\begin{array}{ll}\text { tion } & 11\end{array}$

2.1 Introduction $\ldots \ldots \ldots \ldots \ldots \ldots \ldots \ldots$

2.2 Experimental section . . . . . . . . . . . . . . . . . . 14

2.2.1 Sample preparation . . . . . . . . . . . . . . . . 14

2.2.2 Experimental data acquisition and analysis . . . . . . . . . 16

2.3 Results ............................ 17

2.3.1 Cassie-to-Wenzel transition of an evaporating drop on an FC-40 infiltrated pillar array . . . . . . . . . . . . . . . . . . 17

2.3.2 Cassie-to-Wenzel transition in air . . . . . . . . . . . . . . . . 19

2.4 Mechanism of symmetry breaking . . . . . . . . . . . . . . . . . . . . . . . . . . . . . . .

2.4 .1 Linear regime . . . . . . . . . . . . . . . . 22

2.4 .2 Nonlinear regime . . . . . . . . . . . . . . . . . . . . . . 23

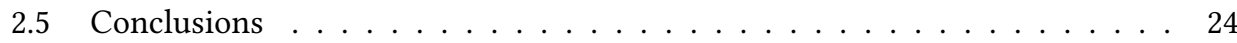

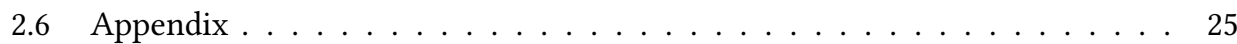

3 Squeezing drops: Force measurements of the Cassie-to-Wenzel transition 29

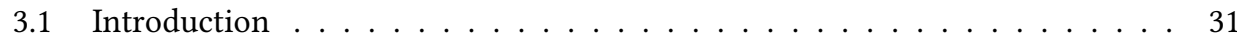

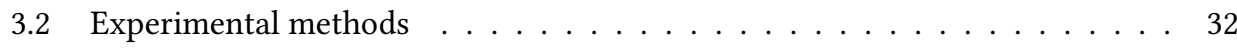

3.3 Results and discussion . . . . . . . . . . . . . . . . . 35

3.3.1 A squeezed drop: Force and area measurements . . . . . . . . . . . 35

3.3 .2 Forces at the transition . . . . . . . . . . . . . . 38

3.3 .3 Impalement pressure . . . . . . . . . . . . . . . . . . . 39

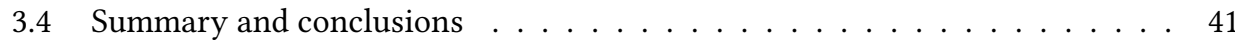


4 Drawing liquid bridges from a thin viscous film 43

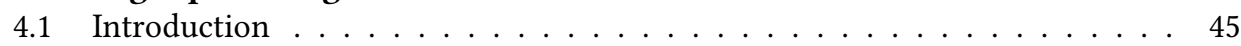

4.2 Experimental methods . . . . . . . . . . . . . . . . 47

4.3 Results . . . . . . . . . . . . . . . . . . . . 49

4.3 .1 The contact radius . . . . . . . . . . . . . . . . 49

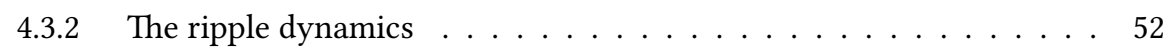

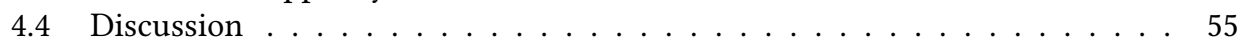

4.4.1 Relating the liquid bridge and the ripple . . . . . . . . . . 55

4.4.2 Contact angles and capillary forces . . . . . . . . . . . . . . 57

4.5 Summary and Conclusions . . . . . . . . . . . . . . . . 60

$\begin{array}{ll}\text { Bibliography } & 61\end{array}$

$\begin{array}{lr}\text { Summary } & 69\end{array}$

$\begin{array}{ll}\text { Síntesis } & 71\end{array}$

$\begin{array}{ll}\text { Samenvatting } & 73\end{array}$

$\begin{array}{ll}\text { Acknowledgements } & 75\end{array}$

$\begin{array}{ll}\text { About the author } & 79\end{array}$ 


\section{1}

\section{Introduction}

"All that you touch, you change. All that you change, changes you. The only lasting truth is change." - this quote, by O. E. Butler [1] was meant to portray the interactions between individuals and the inevitability of change. However, it is also applicable to solid-liquid interactions. Think of the glass that holds your water in the morning (fig. 1.1a). Macroscopically, the shape of the glass determines the shape adopted by the liquid. But when you look close enough, the interaction between the glass and the water is much richer than that. The water's shape close to the glass (the meniscus) depends on the affinity between the water and the glass. Water can creep up the walls, forming a thin film, or it can contact the glass at a finite angle. On the other hand, we can also think about how water influences the glass. Yet, that requires a bit more imagination. Thus, I will elaborate on this point by using another example: hair. When hair is dry, it can deform almost freely; when wet, individual hairs bundle together (fig. 1.1b). The surface tension of the water aims to minimize the water-air interfacial area. As a result, hair, a slender solid, deforms and forms bundles at the expense of its elastic energy, which in turn depends on its deformation. These everyday examples show us the richness of solid-liquid interactions, making it evident that when solids and liquids meet, they influence each other; they change shape, agglomerate, and sometimes adhere to one another [2-6]. The change they experience can depend on the type of solid, liquid, the length-scales involved, and several other aspects of the interaction. However, as long as there is an interaction, there will be a change.

The type of interactions that are at the core of this thesis are capillary interactions: forces due to surface tension. These interactions are more evident in small-scale phenomena and, even though they are mainly visible at small-scales, they have a large impact in industrial processes and everyday life; from powder materials to landslides [6,7]. In this introductory chapter, I would like to show the reader the beauty, complexity of these interactions, and the questions that will be explored in this thesis. So, let us start by discussing some key features that are fundamental to the work presented in the coming chapters. 

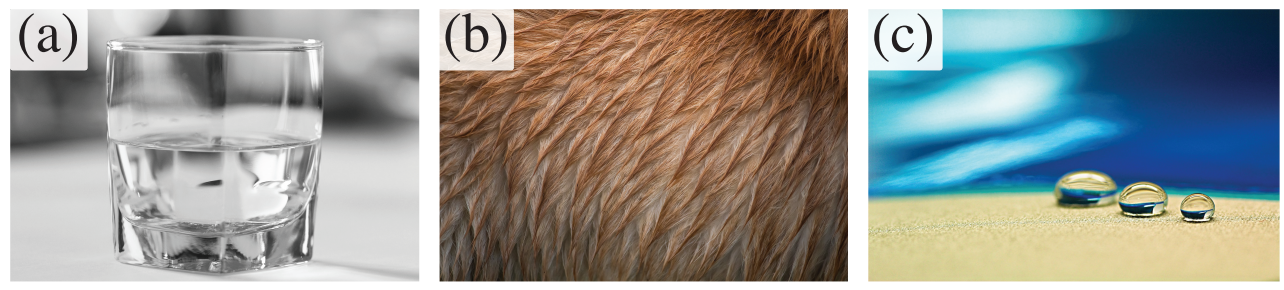

Figure 1.1: (a) Glass of water @Leopold Böttcher [8]. (b) Bundles of wet hair (fur) @Szabolcs Molnar [9]. (c) Drops on a surface $\odot$ Adrian Malec [10]. Sourced freely from pixabay.

\subsection{Capillary forces and wetting}

A key concept in capillarity and wetting phenomena is called surface (or interfacial) tension, $\gamma$. This concept refers to the excess free energy at the interface between two phases [11]. For example, between a liquid and air, or a liquid and a solid. This excess energy can be seen as the energy 'price' needed to generate one new unit of area of a given interface, and thus it can be expressed as an energy per unit area, $J / m^{2}$. Consequently, moving or deforming an interface, comes at a price proportional to $\gamma$.

In fig. 1.2, we sketch a drop of radius $R$ sitting on a smooth flat solid. Notice that solid, liquid, and air phases meet at the edge of the drop forming a contact angle $\theta$. If we think about keeping the drop's volume constant but expanding the three phase contact line such that the radius of the drop changes by $\mathrm{d} R$ (dashed line), we would be decreasing the solidair interface while increasing the solid-liquid interface. As a result, the free energy of the substrate changes by $2 \pi R\left(\gamma_{S L}-\gamma_{S A}\right) \mathrm{d} R$, where the subscripts stand for each interface. The surface free energy of the drop would also change by an amount $2 \pi R \gamma_{L A} \cos \theta \mathrm{d} R$. Thus, the work of expanding this contact line $\mathrm{d} W$ reads:

$$
\mathrm{d} W=2 \pi R\left(\gamma_{S L}-\gamma_{S A}\right) \mathrm{d} R+2 \pi R \gamma_{L A} \cos \theta \mathrm{d} R .
$$

At equillibrium $\mathrm{d} W=0$, and we recover Young's law [12]:

$$
\gamma_{S A}-\gamma_{S L}=\gamma_{L A} \cos \theta
$$

This relation can also be interpreted as a force balance, projected in the horizontal direction. More generally, surface tension gives rise to capillary forces that act parallel to the interface.

We encounter the effects of surface tension forces in a wide range of situations in our everyday life, not only in solitary drops on a solid. After all, fluids and interfaces, are everywhere. Capillary forces, however, depend on the length-scale as we have seen from the example of the drop. In particular, the length-scale beyond which gravitational effects become dominant is called the capillary length $\left(\lambda_{c}\right)$. This can be seen directly from the different sizes and shapes of the drops in fig. 1.1c; the smallest drop is almost a perfect sphere 


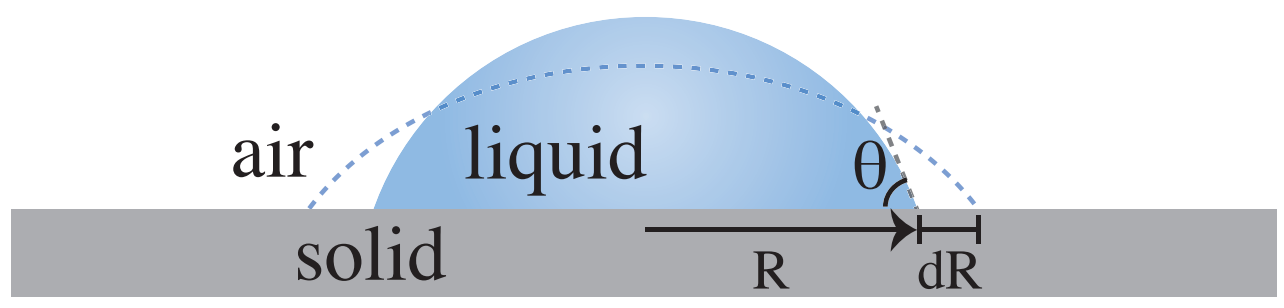

Figure 1.2: Sketch of a drop sitting on a smooth flat solid. The contact angle $\theta$ is determined by the surface tensions at the solid-air, solid-liquid, and liquid-air interfaces; $\gamma_{S A}, \gamma_{S L}$, and $\gamma_{L A}$, respectively.

as surface tension tries to minimize its surface area, while the biggest one is flattened by gravity. Explicitly, the capillary length is given by the ratio of surface tension forces and gravity:

$$
\lambda_{c}=\left(\frac{\gamma}{\rho g}\right)^{1 / 2}
$$

In this expression $\gamma, \rho$, and $g$ are the surface tension and density of the liquid, and the acceleration due to gravity, respectively. For the case of water $\lambda_{c} \approx 2.7 \mathrm{~mm}$. Throughout this thesis we will study systems where the typical length is smaller than $\lambda_{c}$. Thus, we consider systems where the effects of gravity can be safely neglected.

While the capillary length accounts for the competition between surface tension and gravity, another length-scale is of particular importance to us: the elasto-capillary length, $\lambda_{e c}$. This is the length at which capillary and elastic forces are of the same magnitude [13-17]. It determines, for instance, why the glass in the morning does not deform while holding the water (fig. 1.1a), but hair [3] and fur do deform under the effect of surface tension (fig. 1.1b). Particularly, for slender solids, the bending elasto-capillary length,

$$
\lambda_{e c}=\left(\frac{B}{\gamma}\right)^{1 / 2}
$$

depends on the ratio of the solid's bending rigidity $(B)$ and the liquid's surface tension. When the typical length-scale of a slender solid is larger than $\lambda_{e c}$ it is likely that capillary forces are able to deform the solid significantly. Thus, this length-scale is relevant when liquids interact with slender solids such as hairy (textured) solids $[3,4,18]$, feathers and fibres [19-22], and elastic beams and sheets [23,24]. 
INTRODUCTION

\subsection{Textured solids}

From experience, we know that solids are often not flat and smooth. In fact, we continuously find naturally textured solids; solids with ridges, hairs, pillars, and other structures. In fig. 1.3a, we show an example of a hairy solid in contact with a water drop; a leaf of Solanum quitoense. This plant, indigenous to the South American tropics, presents two types of structures in its upper (adaxial) surface; hairs, and thorns. When in contact with a water drop, the leaves may present non-wetting and imbibition scenarios. Like this, many other plants present textures which influence their wetting properties [25,26], and in general textured solids exhibit different wettability as compared to flat solids [27-33].

Textured solids can hold air-pockets between their texture as shown in the first image of fig. 1.3b, where a water drop (blue) is shown on top of a micropillar-textured substrate [34]. Initially, the drop hovers on top of the texture being supported by the pillars (yellow). Then, the drop impales onto the surface (second image in fig. 1.3b). The process is illustrated by the red contours in the third image of fig. $1.3 \mathrm{~b}$, which show the contact line progression between the pillars. The hovering and impaled states, are the so-called 'Cassie-Baxter', and 'Wenzel' states, respectively. When the liquid is water, the Cassie state is also called superhydrophobic, and it is characterised by large apparent contact angles $\left(>150^{\circ}\right)$, and low roll-off angles $\left(<10^{\circ}\right)$. This means that water tends to be repelled by the surface, due to the presence of air-pockets in between the structures. Conversely, when water is in the Wenzel state, it displays lower contact angles, and higher roll-off angles as compared to those of the Cassie state. Thus, giving the water a much stronger affinity with the surface.

The design principles of superhydrophobic solids rely on low surface energies of the surface, as well as micro- and nanotexturing [30,31,35-38]. However, preserving this superhydrophobic state is a challenge $[30,39,40]$ as it has been observed that the Cassie state is metastable; a transition to the Wenzel state can occur in many applications. Consequently, much research has been conducted aiming to generate robust, stable, and durable superhydrophobic surfaces [36,41-44]. One of the challenges of designing these surfaces is precisely to prevent the liquid from transitioning from the Cassie to the Wenzel state. This transition is expected to occur when the pressure exerted by the liquid increases beyond a critical value $[34,45,46]$. The increase in pressure in systems like a sessile drop may be due to drop shrinkage; while in fully submerged systems, for example in underwater applications, may be due to hydrostatic pressure, or the dissolution of gas into the liquid.

Another approach to understanding the Cassie-to-Wenzel transition is by compressing a water drop between two identical superhydrophobic surfaces; this is shown in fig. 1.3c [47]. The capillary pressure on the drop increases as the separation between the surfaces decreases. As a result, the water drop impales onto the surface. This is shown as the change in contact angle seen from the first to the last image of fig. 1.3c. With these experiments, one could gain valuable insights into the transition as well as characterize the wetting resistance of a particular surface. The compression of a drop between two superhydrophobic surfaces will be discussed further in Chapter 3 of this thesis.

A way to circumvent losing the superhydrophobic state, or to recover it once the liquid 

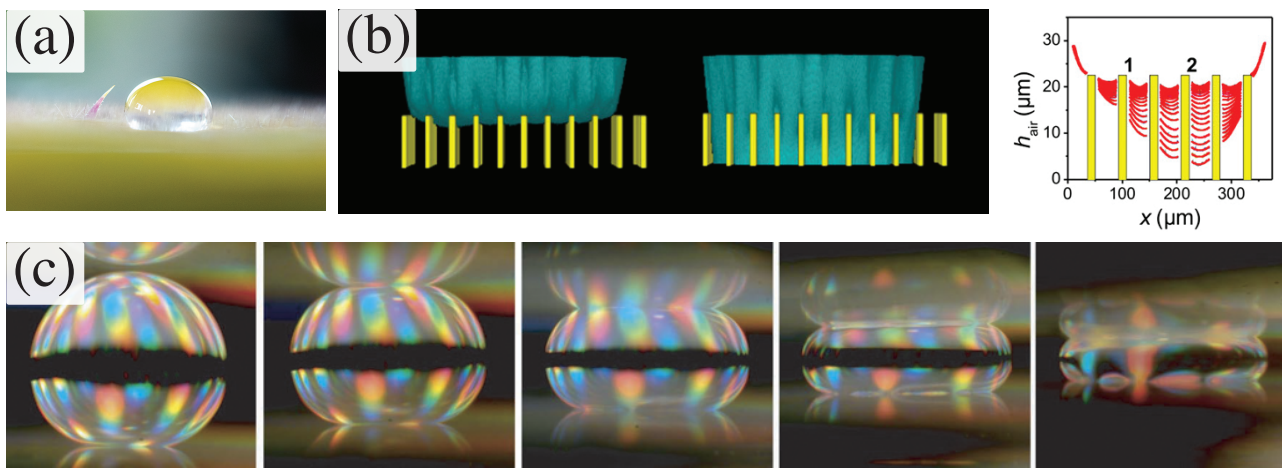

Figure 1.3: (a) Example of a water drop on a textured surface. The surface is a leaf of Solanum quitoense (traditionally referred to as Lulo, from Quechua). (b) Cassie-to-Wenzel transition imaged via laser scanning confocal microscopy, the height profiles of the air cushion are shown in the last panel of the image. Image reproduced with permission from Papadopoulos et al. [34]. (c) Compression of a millimetric water drop between two identical microtextured hydrophobic surfaces. Image reproduced with permission from Lafuma and Quéré [47].

is in the Wenzel state, could be to create superhydrophobic surfaces with deformable structures. The structures can bend in response to the surface tension forces from the drop [48], and thus, prevent impalement. However, this would require the size of the structures be larger or comparable to the bending elasto-capillary length. Therefore, we now turn our attention to capillary interactions with slender structures.

In figures 1.4a and b, we present experimental images from Bico et al. [3] and Duprat et al. [19], respectively. These images illustrate the multiple configurations in which liquid can interact with textured (hairy) solids. We note that the liquid can cause the structures to agglomerate and cluster together (fig. 1.4a), it can remain in between pairs of structures creating a liquid bridge in between (red arrow in fig. 1.4b), or it can sit at the base of the hairs in the previously mentioned Wenzel state.

The interplay between capillary forces and the elastic response of the solid is not only of fundamental interest $[13,15]$, but it also plays a key role in industrial applications involving micro- and nanotechnologies [4, 5, 14, 17, 49-51]. The fabrication of many Micro Electro Mechanical Systems (MEMS) involves wet lithography to produce structures of controllable size and order. This, in turn, involves micrometric structures subjected to capillary forces. Consequently, at such scales, structural collapse is caused by surface tension forces rather than gravitational effects like in buildings and bridges. Uncontrolled structural collapse can lead to defects on the MEMS as the internal structures bend and break (see, e.g. fig. 1.4c, [5]). However, controlled collapse can yield beautiful, self-assembled bundles of different sizes and shapes [4,52,53] (fig. 1.4d, [4]). Harvesting the potential of elasto-capillarity to control the formation of these bundles lies at the forefront of new technological possibilities $[17,49,50,52,53]$. Thus, we must understand how and under which conditions these bundles 

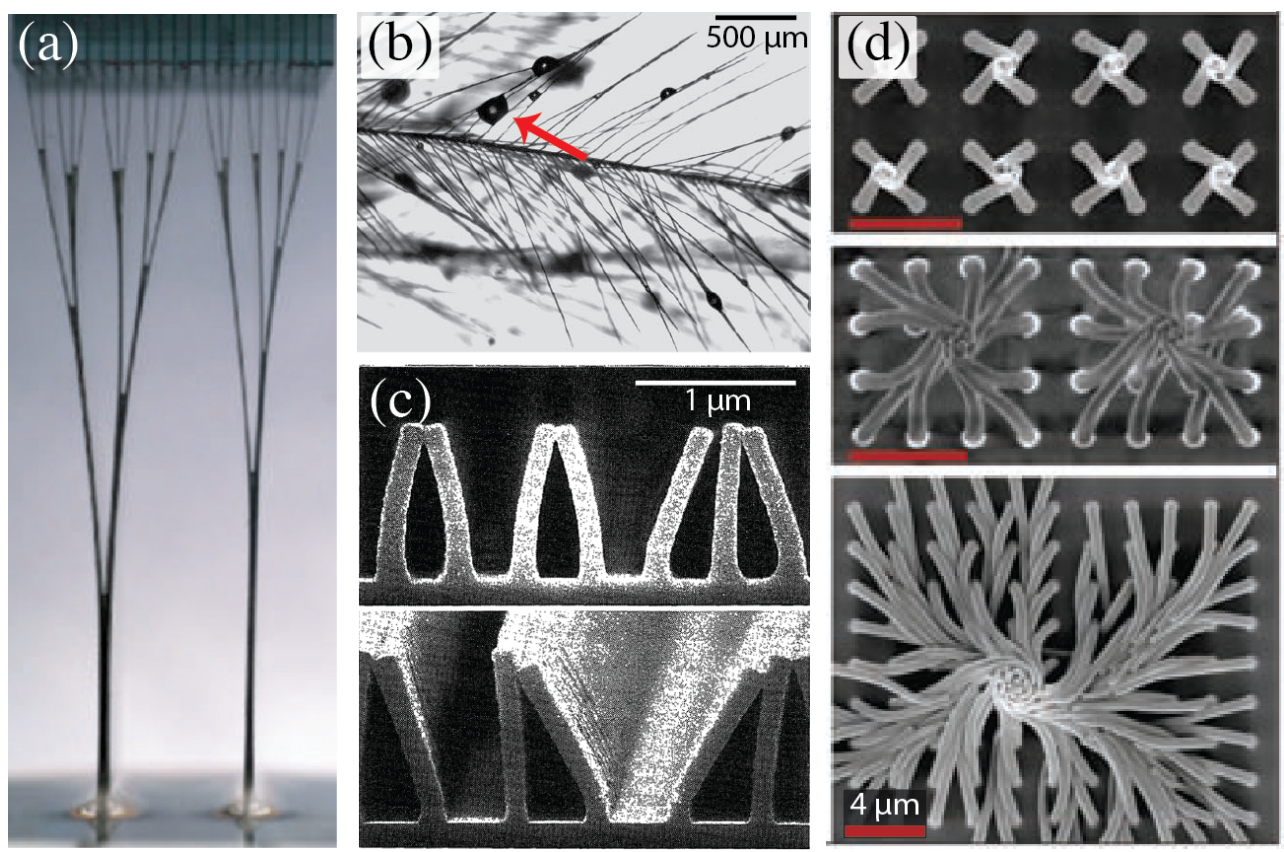

Figure 1.4: Examples of slender structures deformed by the solid-liquid interaction. (a) Regularly spaced, flexible lamellae progressively withdrawn from a liquid bath. Image reproduced with permission from Bico et al. [3]. (b) Microscope pictures of goose feathers sprayed with oil. Image reproduced with permission from Duprat et al. [19]. (c) Examples of photoresist pattern collapse; bending and breaking. Image reproduced with permission from Tanaka et al. [5]. (d) Scanning electron microscopy (SEM) images showing different types of nanobristle bundles. Image from Pokroy et al. [4], reproduced with permission from AAAS.

form. This will be the central motivation for Chapter 2 of this thesis.

\subsection{Liquid bridges and adhesion}

Up to now we have seen how liquids can create beautiful shapes, deform solids, and impale into textured surfaces. In this section, we will discuss how a thin liquid layer can induce adhesion between two solids and sometimes even act as a cohesive factor for granular materials; the reason why sandcastles are build with wet sand and not with dry sand [58]. In the same manner, surface tension can be responsible for making glitter-and powder-'sticky' 

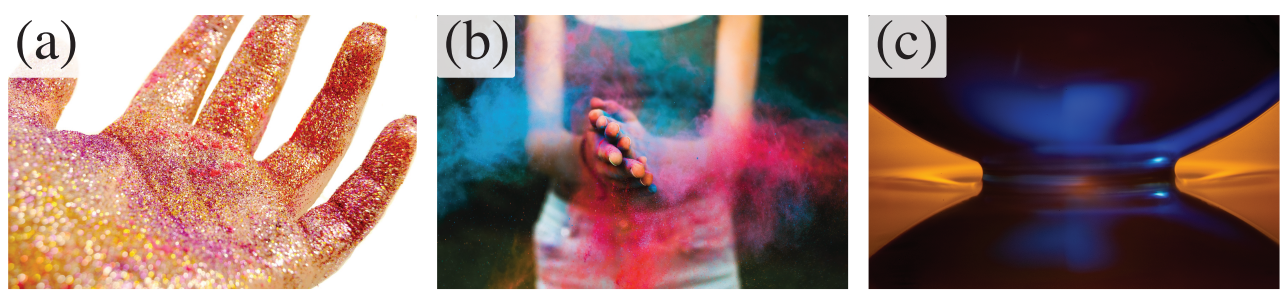

Figure 1.5: Liquid bridges trap (a) glitter (@Maryamassimi [54]), and (b) powder [55] on skin (๔Jan Cigánek). (c) A glass sphere contacting a thin viscous oil film. (a) and (b) sourced freely from pixabay.
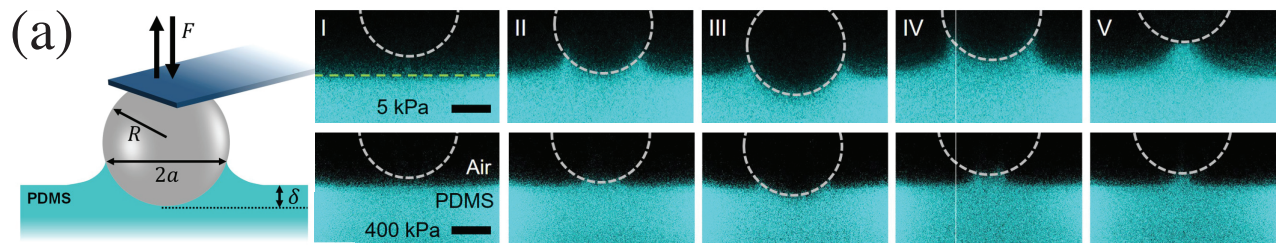

(b)
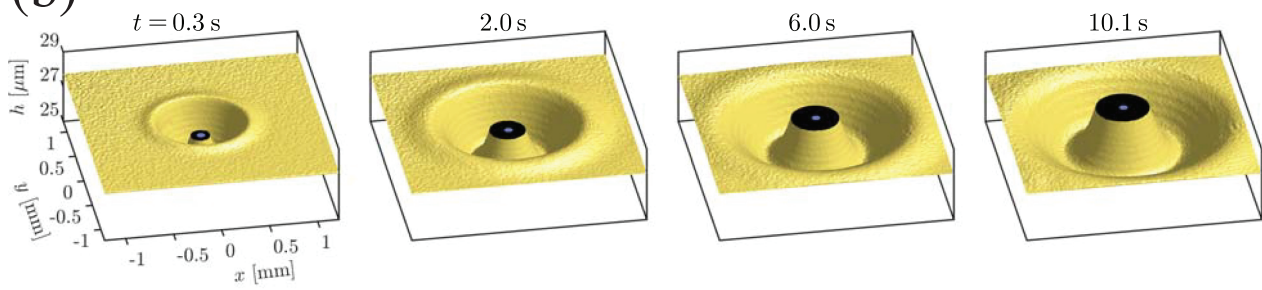

Figure 1.6: (a) Quasistatic measurements of the force-indentation curve of a colloidal probe on a soft polymer. The confocal images show the deformation of the soft polymer in contact with the probe. The shape of the polymer resembles the shape of a liquid bridge. Two elastic moduli are shown 5 , and $400 \mathrm{kPa}$; top and bottom panels, respectively. Image reproduced with permission from Pham et al. [56]. (b) Dynamics of a thin viscous layer upon contacting a micrometric drop $(R=45 \mu \mathrm{m})$. The surface profile shows a clear dependence on time. Image reproduced with permission from Hack et al. [57].

(see, e.g. figs. 1.5a,b). These particles often adhere to our skin due to a superficial thin liquid layer of sweat or humidity. Small liquid bridges such as the one shown in fig. $1.5 \mathrm{c}$ are created between the particle and our skin leading to capillary adhesion, and it is this capillary adhesion that we try to break when we try to 'brush off' glitter from our hands.

Liquid bridges are not only relevant for glitter in your hands. They also appear in technological applications [59-61], granular materials [7,62,63], and they are fundamental to 
the study of adhesion forces on liquid layers $[64,65]$. Similar 'bridge' structures are encountered during the detachment of particles on soft solids [56,66-68]. An example of a particle indenting a soft material is shown in fig. 1.6a, where a colloidal probe indents a PDMS gel while simultaneously imaging the process with a confocal microscope [56]. The confocal images reveal the change in the surface of the soft substrate while the probe indents the gel. We can see the difference between the soft and the hard gel; top and bottom panels, 5 and $400 \mathrm{kPa}$, respectively. For the soft gel, we find a shape that resembles that of a liquid bridge, while for the hard gel the shape is much less pronounced. Moreover, in [56], they find that for softer gels the presence of free polymer chains can induce a significant change in the force-indentation curves as compared to that of harder gels with less free polymer chains. On the other hand, previous work [57,69-73] has shown that liquid layers respond dynamically to perturbations. This is illustrated in fig. 1.6 [57], where they show surface profiles of a thin viscous film after being in contact with a liquid drop (the position of the drop is roughly that of the dark circle in the image). We can see how the contact induces surface deformations which propagate on the oil film. Thus, motivated by the indentation tests, and the dynamics found in thin films we explore in Chapter 4 of this thesis the dynamics of a liquid bridge growing between a glass sphere and a thin viscous film.

\subsection{This thesis}

In this thesis, we explore three different systems where capillary interactions play a key role; an evaporating drop on a soft micropillared substrate, a drop being squeezed between two superhydrophobic surfaces, and a glass sphere in contact with a thin oil film.

In Chapter 2, we start by investigating microstructure collapse in soft textured materials resulting from capillary interactions. While many studies were previously addressed this collapse $[4,17,49,50,52,53,74]$, the kinematics of this process has remained relatively unexplored due to the difficulty to image the capillary menisci between the pillars. Here, we visualize the collapse through confocal microscopy and find that a key ingredient in capillary self-assembly and collapse is the local contact angle of the meniscus between the structures. Based on our observations we develop a simple model including the local contact angle, stiffness of the pillars, and interfacial tension to predict the onset of the collapse.

In Chapter 3, we turn to rigid superhydrophobic micropillared surfaces. We focus on compression tests of a drop between two superhydrophobic surfaces. With a combination of top-view imaging and compression force measurements we investigate the Cassie-toWenzel transition. The transition is evident in our experiments both from optical imaging and force sensing measurements. This allows us to discuss our results with the current views on impalement pressure of superhydrophobic surfaces, finding that our results lie below the current predictions.

In Chapter 4, we move on to smooth solids where we study the formation and evolution of a liquid bridge between a sphere and a flat solid covered by a thin viscous film. We investigate the radial growth of the liquid bridge and its correlation with the dynamics present 
in the thin viscous film. We do this by a combination of imaging techniques; bright-field and digital holographic microscopy. This allows us to describe in detail the rich dynamics at play when a liquid bridge is forming from a thin viscous layer. A key finding is that the liquid bridge dynamics gives rise to intricate time-dependent capillary adhesion forces. 


\section{Onset of elasto-capillary bundling of micropillar arrays: a direct visualization ${ }^{\dagger}$}

When a liquid drop gets into contact with a soft array of microstructures, capillary forces at the three-phase contact lines can lead to critical deformations. Microstructures may collapse, form bundles or even patterns. So far a view at the scale of the menisci of the kinetics of bundling has remained elusive. Here, we use laser scanning confocal microscopy to directly image the menisci between the micropillars. We image structural changes in polydimethylsiloxane micropillar arrays during the Cassie-to-Wenzel transitions of a water drop evaporating on top of the array. With this, we show how the regular pillar array undergoes a spontaneous symmetry breaking as the first step to the formation of pillar bundles. A comparison of the Cassie-to-Wenzel transition in air and FC-40 indicates that the local contact angle determines the outcome of the bundling process. Based on these observations we develop a simple model using the local contact angle, stiffness of the pillars, and interfacial tension of the liquid to predict the onset of the symmetry breaking.

\footnotetext{
${ }^{\dagger}$ Published as: Garcia-Gonzalez, D., Snoeijer, J., Kappl, M., and Butt, H. J. (2020). Onset of elastocapillary bundling of micropillar arrays: a direct visualization. Langmuir, 36(39), 11581-11588.
} 


\subsection{Introduction}

Capillary forces play a role in diverse natural settings. Usually, capillary forces have more impact on the small scale. For example, when a water drop sits on a so-called superhydrophobic surface. A good model for superhydrophobic surfaces are arrays of hydrophobic micrometric pillars $[37,47]$. In this scenario, one encounters that the drop remains spherical as it is dominated by capillary forces that allow it to minimize its surface energy and thus, not wet the surface (Cassie-Baxter state [75]). However, if the drop wets the array of micrometric pillars (Wenzel state), the pillars in the array may bend and collapse upon draining or evaporation of the liquid $[5,51,76,77]$. The response of the pillars depends on its height and material as well as the surface tension of the drop [74,78].

The collapse of the pillars is analogous to a paintbrush which is dipped in liquid [13, 19,21-23]. When the brush is pulled out of the liquid, its bristles aggregate because of the interplay between the capillary and elastic forces. The elastic forces, directly related to the material properties of the solid, try to straighten the bent bristles. In contrast, capillarity pulls the bristles together. This joint effect is called elasto-capillarity and has been studied extensively, $[13,14]$ in a wide range of scenarios; from clumps of wet bristles [4], feathers [19] or hairs [3], to carbon nanotubes [53].

Elasto-capillarity is of particular importance for the fabrication of Micro Electro Mechanical Systems (MEMS), where wet lithography is used to produce micrometric structures of controllable size and order. In wet lithography, the last step involves rinsing the sample with a developing agent. This step is both vital for the structures to be finalized and very delicate for slender structures, like pillars, since the pattern can collapse when draining the developing agent [5]. Once the structures have collapsed, sticking occurs due to adhesion forces which render the process irreversible in most cases. Uncontrolled structural collapse is not desirable as it damages the quality of the MEMS. However, controlled collapse can lead to patterns of self-assembled bundles of different sizes and shapes [4]. In fact, the elasto-capillary interactions in the lithography processes open up the possibility of producing higher aspect ratio structures and even three-dimensional lithography $[17,53]$. So far, it has been possible to control the clustering process by varying different parameters like the geometry of the sample, its tilting angle when evaporating a fluid [52], or at the nanometric scale, by locally varying the relative positions between pillars [79].

A global fabrication strategy is still obscured by the lack of information regarding the onset of the process at the scale of the microstructures. Directly observing the capillary menisci between the pillars is key to understand the onset of the bundling process, yet in this context, it has only been done by using top-view images $[49,52,78,80]$. These images show the movement and final position of the top of the structures. Such observations are valuable to classify the different bundling geometries, but do not capture the shape of the menisci-which ultimately determines the capillary force applied on each pillar. To resolve this, previous studies have focused on setups that are conceptually simpler than micropillar arrays. For example, a beam piercing a liquid surface [76], the multiple states of equilibrium of a pair of beams holding fluid in between [24], or the capillary rise between two 
slender lamellae [21,23]. There have also been many studies regarding the agglomeration of multiple high aspect ratio structures. Like the case of multiple lamellae forced to pierce a liquid's interface [81] and numerical studies where they used multiple spring block elements to model the cluster size and dynamics on a two-dimensional system $[77,82]$. To our knowledge, however, time-resolved images of the menisci in micropillar arrays, during the entire process of bundling, have remained elusive.

In this chapter, we directly image the onset of the three-dimensional self-assembly of micropillars. We image both top-view and cross-section videos of the process by using a Laser Scanning Confocal Microscope (LSCM). We acquire critical information regarding the time-resolved shape of the interpillar meniscus between the micrometric array of soft pillars. In particular, we show how the menisci evolve during the bundling process. Our work focusses on the onset of the bundling, where the initially regular pillar array undergoes a symmetry breaking. By comparing pillar arrays filled with air or with FC-40, it is found that the symmetry breaking of the pillar array is sensitive to the contact angle of the menisci on the pillars. We devise a simple two-dimensional model in which we incorporate elasticity and capillarity effects. While previous studies focus on the conditions necessary for bundles to stick $[3,22]$, we here consider the initial breaking of symmetry of the pillar array. Comparing the results of the model to the experiment, we confirm the importance of the contact angle.

\subsection{Experimental section}

\subsubsection{Sample preparation}

Polydimethylsiloxane (PDMS) pillar arrays were patterned onto a $170 \mu \mathrm{m}$ thick glass slide. The final arrays were superhydrophobic due to the combination of structure and hydrophobicity from the PDMS. The typical apparent advancing and receding contact angles of the surface were measured by moving the drop on the surface and observing the contact angle change via LSCM. The values were $150^{\circ}$ and $140^{\circ}$, respectively. The cylindrical pillars, ordered in a square grid, had the following dimensions: height, $h=40 \mu \mathrm{m}$, diameter, $d=20 \mu \mathrm{m}$, and the center-to-center spacing between pillars, $w=40 \mu \mathrm{m}$.

The pillars were fabricated via a two-step photolithography process [83]. First, a template was prepared by exposing a spin-coated layer of negative SU-8 photoresist on a $1 \mathrm{~mm}$ thick glass slide to UV light through a chromium mask with circular holes. The sample was rinsed with the developer solution (Microchem), followed by isopropyl alcohol, and dried under a stream of nitrogen gas. The resulting template with the SU-8 pillar structure was silanized for $1 \mathrm{~h}$ with $1 \mathrm{H}, 1 \mathrm{H}, 2 \mathrm{H}, 2 \mathrm{H}$-perfluorooctyl-trichlorosilane via chemical vapour deposition under vacuum. The template was used to create a negative elastomeric stamp of the target structure. For that, PDMS (crosslinker to base ratio, 1:10) was poured on the SU-8 
template and crosslinked in an oven at $150{ }^{\circ} \mathrm{C}$ for $1 \mathrm{~h}$. The PDMS stamp (with holes) was mechanically detached from the SU-8 template; the silane layer helped release the PDMS structure from the SU-8 template.

Next, the PDMS stamp was silanized with $1 \mathrm{H}, 1 \mathrm{H}, 2 \mathrm{H}, 2 \mathrm{H}$-perfluorooctyl-trichlorosilane via chemical vapor deposition. A new mixture of PDMS (cross-linker to base ratio, 1:10) was fluorescently labelled with Coumarin $6(0.04 \mathrm{mg} / \mathrm{mL})$ for imaging later by confocal microscopy. The stained PDMS was spin-coated onto a $170 \mu \mathrm{m}$ thick glass slide (No. $1.5 \mathrm{H}$ from Marienfeld Superior). The PDMS coated glass substrate was pressed into contact with the silanized PDMS stamp and placed into a vacuum chamber to remove any residual air pockets and ensure complete filling. The stained PDMS was then crosslinked at $60{ }^{\circ} \mathrm{C}$ for $15 \mathrm{~h}$. Finally, the stamp and the sample were mechanically separated from each other by peeling.

A key element in this study is the flexibility of the pillars. Using beam theory, one obtains a linear relation between the pillar deflection $x$ and a horizontal point force $F_{x}$ applied at the end of the pillar [84],

$$
F_{x}=\frac{3 \pi E d^{4}}{64 h^{3}} x
$$

as was validated experimentally by Ref. [48]. Thus, the pillars react to a horizontal end load as a linear spring with a spring constant of $k=\frac{3 \pi E d^{4}}{64 h^{3}}$. Here, the Young's modulus of the PDMS substrate, $E=0.54 \pm 0.04 \mathrm{MPa}$, was determined using a home-built indenter system, in which a $2 \mathrm{~mm}$ radius ruby sphere was used as indenter. With these parameters, the elasto-capillary length [13] $\sqrt{E r^{3} / 8 \gamma}$ is approximately $36 \mu \mathrm{m}$, which is comparable to the pillar height so that pillar deformations can be expected. On the contrary, the pillars are not expected to bend due to the pressure force within a $4 \mu \mathrm{L}$ drop. Since the pressure force is around two orders of magnitude smaller as compared to Euler's critical load for our pillars $(8 \mu \mathrm{N})$.

To measure the Young's modulus, the sample was placed on a glass slide that was mounted on top of a force sensor (GSO10 load cell, Transducer Techniques, Temecula, CA). The ruby sphere was connected to a piezo translation stage with $1500 \mu \mathrm{m}$ movement range (P-629.1CD, Physik Instrumente, Karlsruhe, Germany). The sphere was moved towards the sample with a linear motion at a speed of $10 \mu \mathrm{m} / \mathrm{s}$ until a predefined contact force of 5 $10 \mathrm{mN}$ was reached. The movement of the piezo stage was then reversed until complete separation was achieved again. Both piezo position and force were recorded by a computer equipped with an AD board (NI6052, National Instruments, Austin, TX). The force versus indentation curves obtained were fitted using the JKR model $[85,86]$ to determine the Young's modulus of the samples. Assuming a PDMS Poisson ratio of 0.5, a work of adhesion of $W_{a}=0.10 \pm 0.01 \mathrm{~J} / \mathrm{m}^{2}$ was obtained. 


\subsubsection{Experimental data acquisition and analysis}

For all measurements, we used drops of ultra-pure (Milli-Q) water dyed with Alexa 647 at a concentration of $0.1 \mathrm{mg} / \mathrm{mL}$. The surface tension of the Alexa-dyed water was $65.4 \pm$ $0.3 \mathrm{mN} / \mathrm{m}$ as measured using a Wilhelmy plate. In part of the experiments, the PDMS pillars were infused with FC-40, a fluorinated oil with a surface tension of $14.2 \pm 0.3 \mathrm{mN} / \mathrm{m}$. FC-40 was used because it combines index matching (see below) with low water solubility ( $7 \mathrm{ppm}$ ). The interfacial tension between FC-40 and water is $52.1 \pm 0.2 \mathrm{mN} / \mathrm{m}$, and FC-40 does not swell PDMS within the time frame of our experiments.

The LSCM used was a Leica TCS SP8 based on an inverted optical microscope. The LSCM allowed to record 3D images. However, for increased time resolution, we did not record full 3D images but rather cross-sections of the evaporating water drop on top of the pillar array. The horizontal cross-sections $(x y)$ are parallel to the circular sections of the pillars, while the vertical $(x z)$ cross-sections are perpendicular to them. The acquisition time of each cross-section ( $3.5 \mathrm{~s})$ was shorter compared to the evaporation timescale of the water drops (40 min).

For imaging the $x y$ and $x z$ cross-sections in the infused case we used a $20 \times / 0.75$ multi-immersion (water) objective, while for the dry case we used a $40 \times / 0.85$ dry objective. The refractive indices of the different materials are: $1.50,1.43,1.29$, and 1.33 for glass, PDMS [87], FC-40, and water, respectively. Therefore, FC-40 acts as an index matching liquid when infusing the PDMS pillar array, improving image quality in these experiments. A combination of 458, 476 and $633 \mathrm{~nm}$ laser excitation lines were used. Besides from brightfield top-view images, three different signals were recorded simultaneously. The signals were: reflection and two fluorescence signals. The reflected light, highest at the interfaces with a large change in refractive indices was measured with a photomultiplier (PMT) detector in the range of 455-460 $\mathrm{nm}$. The fluorescence of the Alexa-dyed water and the Coumarin-dyed pillars were measured with two different PMTs in the ranges of 690-750 $\mathrm{nm}$ and 490-555 $\mathrm{nm}$, respectively.

For each experiment, a $4 \mu \mathrm{L}$ Alexa-dyed water drop was manually deposited on top of the pillar array. For the experiments with FC-40, the sample was infused before with FC-40 by depositing the oil and tilting the substrate. Prior to the experiment, the height of the FC-40 layer was similar to that of the pillars, this, was checked with the reflection signal from $x z$ cross-sections. The sample was surrounded by a ring-shaped container with optical access from the top to minimize any airflow from the surroundings. The evaporating drop was imaged by the LSCM at approximately $24^{\circ} \mathrm{C}$ and a relative humidity of $40 \%$. 


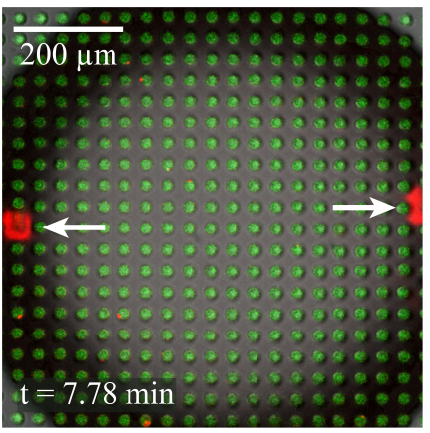

(a)

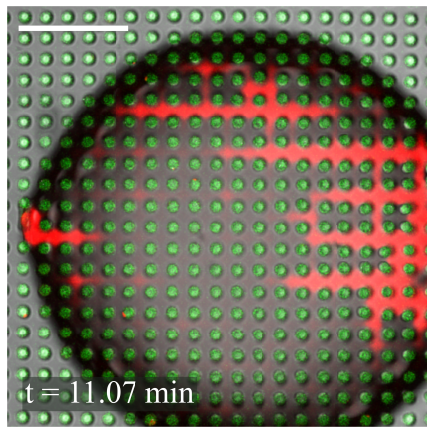

(b)

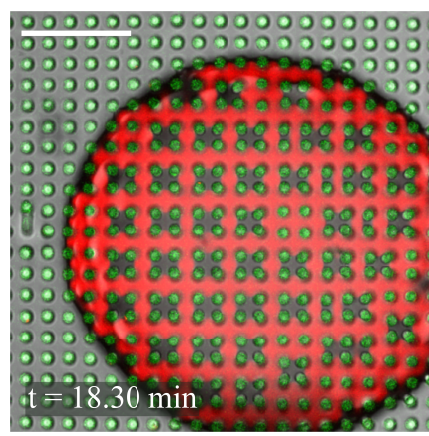

(c)

Figure 2.1: Time series of an evaporating drop on a PDMS pillar array infused with FC-40 (Movie S1). The images are overlays of the confocal images taken $1 \mu \mathrm{m}$ below the pillar top faces. Greyscale represents the brightfield top-view images, $x y$ fluorescence cross-sections from PDMS pillars are shown in green, and water is shown in red. Darker regions of the greyscale image are covered by water, red regions indicate impalement of water by at least 1 $\mu \mathrm{m}$. The FC-40 is not visible. (a) The onset of water impalement, signalled by white arrows, (b) propagation and first bundling events, and (c) formation of regular bundles of pillars. By the last stage, the drop is in a complete Wenzel (impaled) state.

\subsection{Results}

\subsubsection{Cassie-to-Wenzel transition of an evaporating drop on an FC-40 infiltrated pillar array}

A time series of a drop evaporating on top of an FC-40-infiltrated PDMS pillar array is shown in fig. 2.1. Each image is a composite of the greyscale top-view image and both fluorescence signals from the drop (red), and the PDMS pillars (green). When the water drop evaporates, its Laplace pressure increases as its radius decreases. In our experiments, the water drop impales when its radius reaches $370 \pm 47 \mu \mathrm{m}$. We can identify the onset of impalement as the red signal from the Alexa-dyed water starts to become visible on the horizontal crosssections imaged $1 \mu \mathrm{m}$ below the pillar tops. The first impalement sites between pillars are indicated by white arrows in fig. 2.1a.

Impalement starts at the rim and propagates along either direction of the array. Once a certain gap had been impaled, water did not impale its consecutive parallel gap. Rather the second one in line is impaled (fig. 2.1b). The reason for which a line is skipped is the bending of the pillars, as will be demonstrated below. During the impalement process, FC40 is displaced by the water and the neighbouring pillars bend. When the drop has impaled 
completely, most of the pillars in contact with it display the same four-pillar bundle geometry (fig. 2.1c). Eventually, when the water has completely evaporated, some of the bundles open up while some others remain in place. So, even if the bundling is triggered, the bundles can still return to upright pillars, depending on the pillar-to-pillar adhesion. Note that in contrast to other elasto-capillary problems, the water has completely evaporated at the end of the process so that sticking is only due to adhesion between pillars.

The onset of the impalement transition and symmetry breaking occurs simultaneously. However, they relate two different processes; (i) the transition from the Cassie-to-Wenzel state (impalement), and (ii) the breaking of symmetry of the initially regular array of pillars. When the water impales the surface, the wetting transition has been triggered; the local contact angle is higher than the advancing local contact angle-usually measured between the liquid and the surface with a goniometer. However, the impalement transition is independent from the symmetry breaking. The symmetry breaking involves the local contact angle between the water meniscus and the vertical wall of the PDMS micropillar, as it influences the capillary force on the micropillar. Notice that the pillars only bend when the capillary force pulling at the pillar top is stronger than its restoring elastic force. Here we focus on the symmetry breaking that leads the pillars to bundle.

To reveal the assembly mechanism of the bundles, we recorded vertical cross-sections at the rim of the water drop (blue plane in fig. 2.2a). The FC-40-infused regions are represented in black while the fluorescence signals from the drop and the PDMS pillars are red and green, respectively (figs. 2.2b,c). In the vertical cross-sections, optical artefacts are visible over the pillars. Scattering of light causes a decrease in the intensity of the detected light. Thus, for clarity, we have marked the approximate position of some of the pillar top faces in yellow.

At the onset of symmetry breaking, below the drop, only the pillar directly at the edge of the drop was slightly bent inwards (rightmost pillar in fig. 2.2b). As evaporation progresses, pairs of pillars bent towards-or away-from each other, further breaking the symmetry of the structure (fig. 2.2c, and Movie S2). The experiments show a correlation between the deformation of the pillars and the shape of the liquid menisci such that where the meniscus was deeper (shallower), the pillar spacing became wider (narrower). This observation shows that bundling is a collective process. The bending of one pillar influences the bending of its neighbours via the capillary interaction mediated by water.

In the experiments, bundling always started from the outer edge of the water drop, or near a defect in the pillar array. Slight deviations from the mean spacing between pillars act as a perturbation to the symmetry of the array and cause the water to start penetrating between the pillars. Then, the pillars bend away from each other allowing the water surface to bulge even lower. As a result, the gap between the pillars widens, which facilitates further penetration of water. Ultimately the process ends in a complete Wenzel state.

Horizontal and vertical images (figs. 2.1, 2.2) demonstrate that bundles of pillars are formed while individual water menisci between pairs of pillars infiltrate the surface. Bundling is due to a spontaneous symmetry breaking underneath the water drop leading to a collective impalement pattern. 


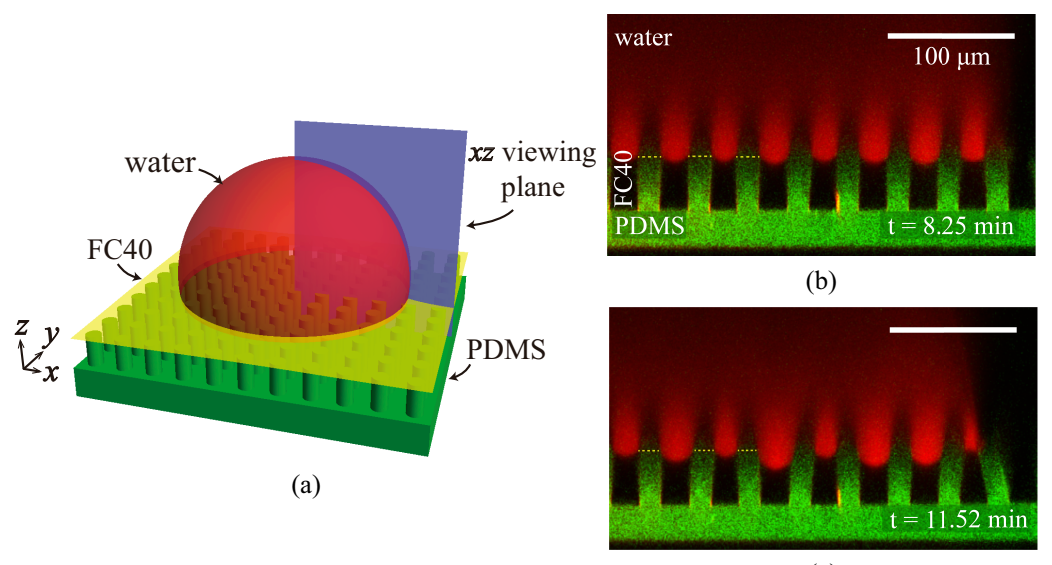

(c)

Figure 2.2: Vertical confocal cross-sections of the FC-40 infiltrated structures as the PDMS pillars bundle (Movie S2). The blue cross-section in the sketch (a) indicates the position at which (b) and (c) are recorded. In (b), the onset of the symmetry breaking takes place. The local menisci are all similar to one another. (c) Shows the spontaneous symmetry breaking as the menisci between each pair of pillars changes. Deeper (shallower) menisci are present when the pillars bend away (towards) from each other.

\subsubsection{Cassie-to-Wenzel transition in air}

The effect of replacing FC-40 with air was twofold: First, the interpillar menisci were flatter than in FC-40-infused arrays; the contact angle of the water menisci on the PDMS pillars was around $90^{\circ}$ (fig. 2.3). Second, no significant pillar bending was observed. We observed impalement, but not symmetry breaking of consecutive menisci. There was no bundling of the micropillars during the impalement of water, showing that bundling and impalement are different processes. In air, the Cassie-to-Wenzel transitions either led to a complete filling of the substrate by water, or to the formation of an air pocket (Movie S3). The air pockets agree with those observed by Papadopoulos et al. [34]; they were only slightly larger as our pillars $(40 \mu \mathrm{m})$ were taller than theirs $(25 \mu \mathrm{m})$.

\subsection{Mechanism of symmetry breaking}

We now wish to explain the mechanism of symmetry breaking; the onset of bundling. For this, we consider the two competing effects: capillarity and elasticity. From the capillary perspective, having alternating deep and shallow menisci is energetically more favourable 


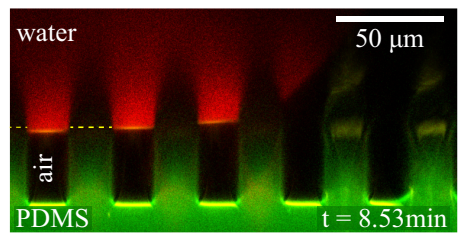

Figure 2.3: Vertical cross-section of a water drop (red) on a superhydrophobic pillar array surface (green) at the onset of the Cassie-to-Wenzel transition (Movie S4). The waterair and PDMS-air interfaces are visible as reflections (shown in yellow), due to the high difference in refractive index between water and air.

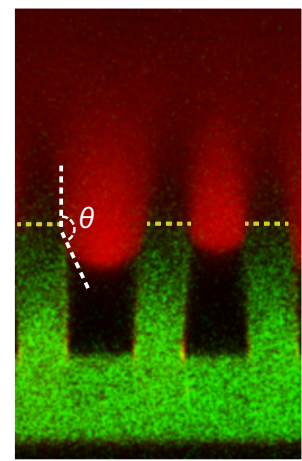

(a)

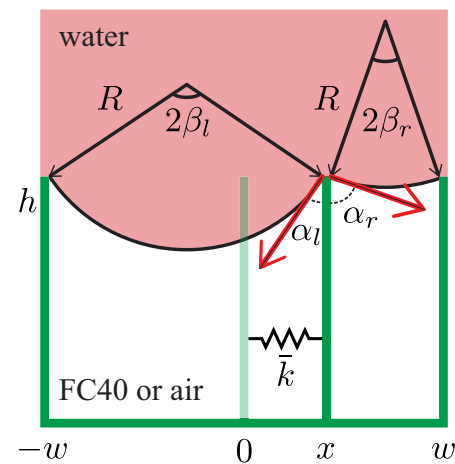

(b)

Figure 2.4: (a) A fraction of the water drop's interface with the PDMS pillars from fig. 2.2b. (b) Sketch of the two-dimensional model representing the experiment. The flexibility of the pillars is represented by a moving central pillar connected to its original position by a linear elastic spring with spring constant $\bar{k}$. The effect of capillarity is accounted for by the contact line forces, indicated by red arrows.

as compared to having two symmetric menisci. Elasticity plays the reverse role as capillarity since it opposes deformation. A similar balance has been used to describe the sticking condition, predicting the condition for bundles to stay together $[3,13,22]$. Here, we rather focus on the symmetry breaking of the initially regular periodic array of pillars. The reason why the pillars start to bend in the first place. In what follows, we explain the mechanism of symmetry breaking in terms of the forces rather than in terms of the energy which is discussed in the appendix.

We develop a simplified model where we consider the balance between capillary and elastic forces. Inspired by the analysis by Ref. [77], we consider a simplified setting; the complex system of periodic three-dimensional pillars are reduced to a set of two-dimensional pillars of height $h$, and centre-to-centre spacing $w$ (fig. 2.4a). In the model, the outer pillars are kept fixed in place while the central one can be displaced laterally, mimicking the flexible behaviour of the real pillars by a linear spring connected to the central position. 


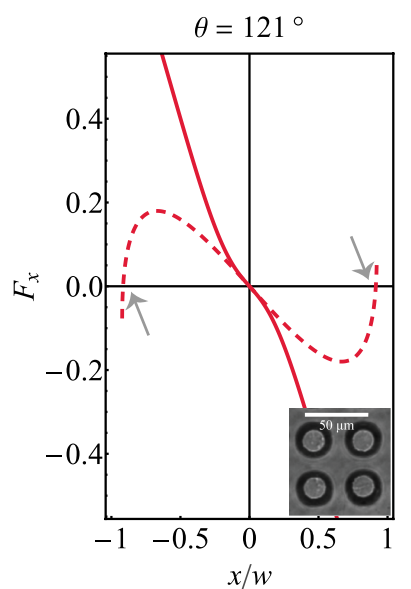

(a)

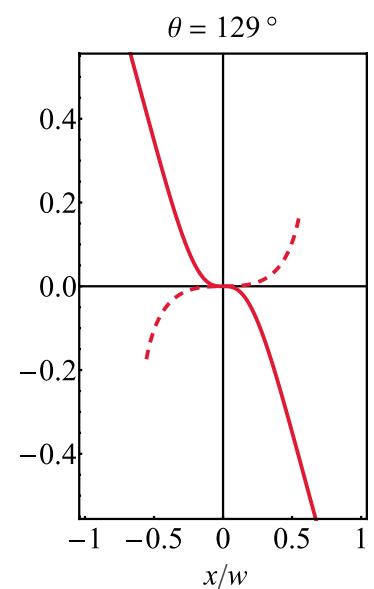

(b)

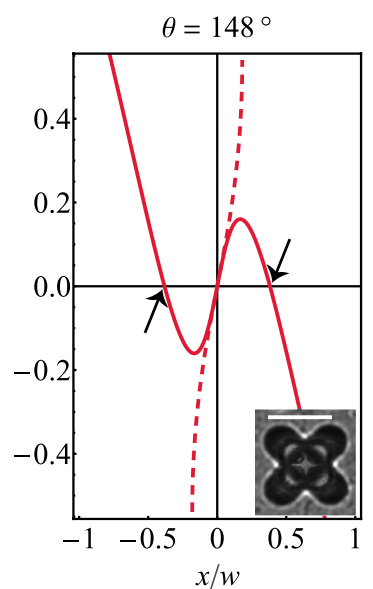

(c)

Figure 2.5: The force on the central pillar calculated assuming constant area (solid line), and constant pressure (dashed line) for a critical contact angle $\theta_{c}=129^{\circ}$, assuming for convenience, $\bar{k} w / \gamma=1$. Notice that both calculations coincide in the linear regime $(x \rightarrow 0)$.

The displacement is denoted $x . \bar{k}$ is the equivalent elastic constant of the pillars in the two-dimensional case; $\bar{k}=k / w\left([\mathrm{~N}] /\left[\mathrm{m}^{2}\right]\right)$, and capillarity is accounted for by the menisci (radius $R$ ) in between the pillars.

Importantly, at the onset of the symmetry breaking in the experiment (fig. 2.2a), the contact line is still pinned to the pillar tops. Therefore, the sidewalls in fig. $2.4 \mathrm{~b}$ remain fully wetted by the liquid below as long as impalement does not occur. Impalement occurs only when the static advancing angle of the top liquid is reached. Thus, as long as the contact angle on the pillar does not exceed this static advancing angle, the point force can still be considered to act at the top of the pillar. With this, the total horizontal force per unit length on the central pillar reads

$$
\begin{aligned}
F_{x} & =-\bar{k} x+\gamma\left[\sin \alpha_{r}-\sin \alpha_{l}\right] \\
& =-\bar{k} x+\gamma\left[\sqrt{1-\left[\frac{w-x}{2 R}\right]^{2}}-\sqrt{1-\left[\frac{w+x}{2 R}\right]^{2}}\right] .
\end{aligned}
$$

Here we have used that $\alpha_{l, r}=\pi / 2-\beta_{l, r}$, with $\sin \beta_{l, r}=\frac{w \pm x}{2 R}$, given by the geometry sketched in fig. $2.4 \mathrm{~b}$. With this force, we will see below that the effect of capillarity is to promote the breaking of symmetry, while the effect of elasticity is to resist it.

First, we focus on the linear range of the force as we are most interested in the onset of the symmetry breaking. Then, we discuss the non-linear response of the system. While below we discuss the results in terms of forces, the equivalent energetic derivation is provided in the Appendix. 


\subsubsection{Linear regime}

We start by considering small deformations of the central pillar. For this, we linearize eq. 2.2 around $x=0$,

$$
F_{x} \approx\left[-\bar{k}+\frac{\gamma w}{R \sqrt{4 R^{2}-w^{2}}}\right] x .
$$

The opposite signs of the terms on the right nicely illustrate the opposing characters of capillarity and elasticity. The linearized form of the force, eq. 2.3, is such that when elasticity is dominant, its prefactor is negative. In that case, the resultant force is restoring, having the opposite sign of the displacement, which renders $x=0$ a stable equilibrium. In contrast, when capillarity is dominant, the prefactor is positive. Then, the total force has the same sign as the displacement such that the symmetric situation where $x=0$, becomes unstable. Thus, the criteria for spontaneous symmetry breaking is: $-\bar{k}+\frac{\gamma w}{R \sqrt{4 R^{2}-w^{2}}} \geq 0$, or, in terms of the contact angle $(\theta)$ :

$$
\frac{\cos \theta}{|\tan \theta|} \leq-\frac{\bar{k} w}{2 \gamma},
$$

where we have used that $\theta=\pi / 2+\arcsin (w / 2 R)$. In terms of the material properties of the pillars, this gives a critical contact angle $\theta_{c}$ defined by

$$
\frac{\cos \theta_{c}}{\left|\tan \theta_{c}\right|}=-\frac{3 \pi}{128} \frac{E d^{4}}{\gamma h^{3}}
$$

Interestingly, the critical value of the contact angle is independent from the pillar-to-pillar distance. This is because the breaking of symmetry appears at the onset of the bundling, where the pillar deflection is initially infinitesimal: whether or not an initial perturbation is amplified depends only on the projection of the capillary force, and does not involve the spacing. This is in stark contrast with the sticking conditions discussed in Ref. [22] and Ref. [13]. In that case, the deflection of the pillars is decisive, and hence the distance between the pillars appears as a key parameter.

We remark that in the model the contact line is assumed to remain pinned at the top of the pillar. In reality, the contact line will move once the liquid's contact angle exceeds the static advancing contact angle $\left(\theta_{a}\right)$. Whether or not symmetry breaking occurs prior to impalement, therefore, depends on the magnitude of $\theta_{a}$ and $\theta_{c}$. If $\theta_{a}>\theta_{c}$ the symmetry breaking occurs prior to impalement. On the other hand, if $\theta_{a}<\theta_{c}$ liquid will fill the gaps of the array without triggering the symmetry breaking.

In practice, since the pressure inside the drop is positive, we only need to consider $\theta \geq 90^{\circ}$. From eq. 2.4, we then infer that the system will typically be below the threshold of symmetry breaking for angles close to $90^{\circ}$, even for very soft pillars. However, the increase of $\theta$ due to the increase of pressure inside the drop could indeed cause a change in sign in eq. 2.4 , and hence a breaking of symmetry. 
The proposed mechanism for symmetry breaking, associated with a large contact angle of the menisci, is indeed supported by our experiments. We measured the maximum contact angles (the advancing contact angles, $\theta_{a}$ ), from the vertical cross-sections for the non-bundling and bundling cases. These are $91^{\circ}$ for air, and $131^{\circ}$ for FC-40. So indeed, for the air-filled case, the interface remains almost perpendicular to the pillar walls throughout the impalement process and bending is not observed. By contrast, the FC-40-infused case exhibits large bulges, and bending is observed.

Despite the simplifying assumptions of the model, we can go one step further and quantitatively estimate the stability threshold, $\theta_{c}$, corresponding to both the FC-40 and air-filled surfaces. The spring constant, $\bar{k}$, is the same for both cases; with $k \approx 200 \mathrm{mN} / \mathrm{m}$ and $w=40 \mu \mathrm{m}$, while the surface tensions are slightly different. Therefore, eq. 2.5 gives slightly different values for the critical angle, namely $\theta_{c}^{F C-40} \approx 144^{\circ}$ for the FC-40-infused surface, and $\theta_{c}^{a i r} \approx 139^{\circ}$ for the air-filled surface. So, the maximum contact angle mentioned before for FC-40 $\left(\theta_{a}=131^{\circ}\right)$ is indeed close to the predicted onset $\left(\theta_{c}=144^{\circ}\right)$. As opposed to the air-filled menisci $\left(\theta_{a}=91^{\circ}\right)$ which are too shallow to cause any symmetry breaking, in line with the proposed mechanism for bundling.

\subsubsection{Nonlinear regime}

We now examine the predictions of the model in the nonlinear regime, where the displacement $x$ no longer remains small. Interestingly, it is necessary to distinguish between two possible scenarios, depending on whether the impalement occurs at constant pressure or at constant volume. In the first scenario, we assume that the pressure inside the lubricant layer (FC-40 or air) is the same as that of the surrounding air, and thus is kept constant as the system equilibrates. In this case, the value of $R$ appearing in eq. 2.2 follows from the imposed value of $\theta$. In the second scenario, we assume that the equilibration of $x$ occurs at constant volume-e.g. the transport of lubricant induces a pressure difference with respect to the air pressure. In that case, $R$ has to be treated as a function of $x$, for the imposed lubricant volume which in our two-dimensional model is actually, the total area of the menisci. This relation is obtained numerically, as explained in the Appendix.

Figure 5 shows the nonlinear force-displacement curves, for typical examples: (a) below the threshold of symmetry breaking $\left(\theta<\theta_{c}\right)$, (b) at the threshold of symmetry breaking $(\theta=$ $\theta_{c}$ ), and (c) above the threshold of symmetry breaking $\left(\theta>\theta_{c}\right)$. This is achieved by assuming $\bar{k} w / \gamma=1$ and increasing the value of theta. Indeed, we see that the two approaches, constant pressure (dashed line) and constant area (solid line) give different results.

As expected, we find the transition between a stable and an unstable spring at the threshold value calculated with eq. $2.5 ; \theta_{c} \approx 129^{\circ}$ (fig. $2.5 \mathrm{~b}$ ). This transition is illustrated by comparing the slope of the force in the vicinity of $x=0$ for different contact angles. Below the threshold, fig. 2.5a, this slope is negative, while above the threshold, fig. $2.5 \mathrm{c}$, it is positive. A negative slope yields no spontaneous symmetry breaking, as any deformation from the spring is counteracted by the elastic force. The contrary is true for a positive slope, where a symmetry breaking is expected since any spring deformation will be amplified. 
Both approaches, constant area and pressure, show the predicted symmetry breaking. However, we find two different types of transition since we find different stable and unstable equilibria for each approach. Below the critical contact angle $\left(\theta<\theta_{c}=129^{\circ}\right)$, the constant area approach (solid line in fig. 2.5a) shows only one stable equilibrium at $x=0$; the force and displacement have opposite signs. In contrast, the constant pressure approach shows one stable equilibrium $(x=0$ ), and two unstable equilibria as $x \rightarrow w$ (grey arrows in fig. 2.5a). Therefore, the symmetric configuration with upright pillars (inset fig. 2.5a) is expected in this case, since any other configuration would be unstable.

Above the critical contact angle $\left(\theta>\theta_{c}\right.$, fig. 2.5c), the constant area approach shows two new stable equilibria (dark arrows). In contrast, the constant pressure approach shows only unstable configurations; the force and displacements always have the same sign.

For the constant area approach, the transition towards bending is continuous, and for the constant pressure approach, it is discontinuous. In the first case, when the contact angle grows larger, we identify new stable equilibria like in a second-order phase transition. In the second case, there are no new stable equilibria and the spring goes from being stable to unstable like in a first-order phase transition. The value of $x$ jumps to its maximum value immediately above the threshold of symmetry breaking. In experiments, when the pillars are infused with FC-40, we see the pillars deform slowly to form the bundles (see e.g. fig 2.4a, movie S2). This gradual shift from upright to bundled pillars suggests a continuous transition with stable equilibria different than $x=0$, in line with the constant area approach. However, it can also be the case that in the quasi-static evolution of the system, the evaporating drop imposes a pressure jump across the interface and if the pressure in the bottom liquid remains constant (as in the air case), the transition would be discontinuous (first-order).

\subsection{Conclusions}

We studied the formation of bundles of soft, hydrophobic micropillars under an evaporating water drop. A comparison between the Cassie-to-Wenzel transition in air and FC-40 shows that the local contact angle is fundamental for the onset of the bundling process. We observe that bundling starts as a spontaneous breaking of symmetry in the consecutive menisci below the water drop. Experimentally, a point defect-e.g. a missing pillar in the array, slight shifts in pillar positions, or the bending of the pillar at the rim of the drop, serves as an initial perturbation of the meniscus symmetry which is later on amplified by the interplay between capillary and elastic forces.

We find that a fundamental parameter in the onset of the symmetry breaking is $\theta$ : the local contact angle of the liquid with respect to the pillar wall. As the water-PDMS contact angle becomes higher, the pillar array becomes mechanically more unstable and likely to bundle. We propose a simple two-dimensional model, where the breaking of symmetry emerges from a balance of capillarity and elasticity. In particular, we recover that the symmetry breaking requires large contact angles, in good agreement with the experiments. 
Interestingly, in the model, the behaviour above the threshold can be continuous or discontinuous. That is, the pillar deformation can show new local equilibria, or suffer a sharp transition from upright to bent. Experimentally, the transition is continuous, which suggests that the pressure inside the lubricant is not in quasi-static equilibrium with the air pressure according to our model.

The model consists of only three consecutive pillars rather than a periodic array. Therefore, a natural path for the following research is to incorporate the meniscus contact angle into more elaborate models with more than three pillars, and the possibility of pillar stiction to predict larger bundles of taller (or softer) pillars. However, the simple model is sufficient for the purpose of describing the symmetry breaking of the initially periodic pattern. Indeed, the essential ingredients in the simple spring-pillar model reproduce the symmetry breaking of the real PDMS micropillars and predict a threshold contact angle in good qualitative agreement with our experimental results.

\subsection{Appendix}

In the main text, we presented the mechanism of symmetry breaking in the context of the forces involved. However, this symmetry breaking can also be analysed in terms of the energy of the system. In this appendix, we will show the energy-based approach and will find that both force and energy approaches are equivalent. So, we consider the energy per unit length of the system as the sum of the capillary, elastic energies, and in the case of constant pressure add the work done on the top liquid $(W=-\delta P A)$. With this, the energy of the system as the liquid infiltrates into the surface reads

$$
E=2 \gamma R\left[\sin ^{-1}\left(\frac{w-x}{2 R}\right)+\sin ^{-1}\left(\frac{w+x}{2 R}\right)\right]+\frac{1}{2} \bar{k} x^{2}+W
$$

The first two terms of the equation are related to the length of the menisci, while the third accounts for the energy stored by deforming the spring connected to the central pillar.

As noted previously, we examine two scenarios in the quasi-static evolution of the system; an isobaric, and an isochoric process. In the first scenario, the work done by the pressure is non-zero as the liquid area that sags into the interpillar gaps is not fixed. In the second scenario, the liquid area sagging into the gaps is the control variable. Keeping the area constant implies that the total work is zero and, therefore, the equation reduces to two contributions; capillarity and elasticity.

For either approach, we must compute the area of the sagging menisci (instead of the volume, since this is a two-dimensional model). For this, we compute the sum of the area 


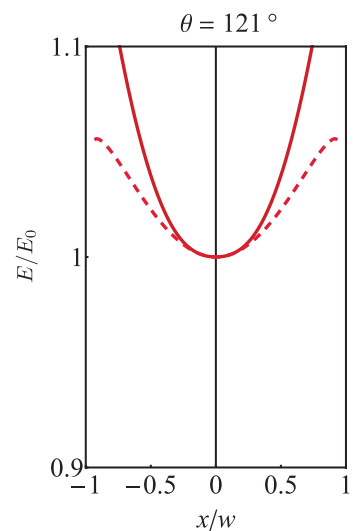

(a)

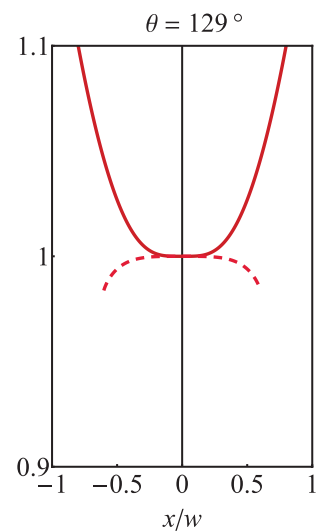

(b)

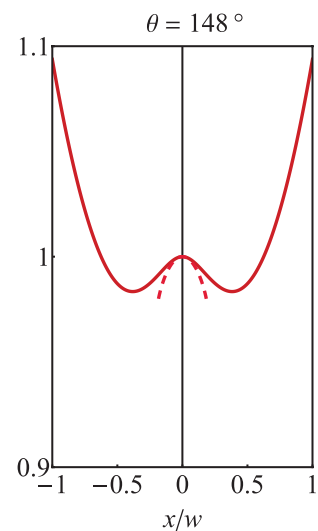

(c)

Figure 2.6: Energy calculated at constant area (solid lines), and constant pressure (dashed lines) for increasing values of contact angle. The calculations were performed considering $\bar{k} w / \gamma=1$.

of two circular segments of radius $R$ as sketched in fig. 2.4b;

$$
\begin{aligned}
A=R^{2} & {\left[\sin ^{-1}\left(\frac{w-x}{2 R}\right)+\sin ^{-1}\left(\frac{w+x}{2 R}\right)\right.} \\
& \left.-\frac{w-x}{2 R} \sqrt{1-\left[\frac{w-x}{2 R}\right]^{2}}-\frac{w+x}{2 R} \sqrt{1-\left[\frac{w+x}{2 R}\right]^{2}}\right] .
\end{aligned}
$$

For the isochoric process, we find the radius of the meniscus as a function of the area by numerically solving eq. 2.7 via Newton's method. The same method was used to calculate $R(x, A)$, for the force curves presented in fig. 2.5. Eq. 2.7, was solved under the constraint $0 \leq A \leq 0.79$, where the maximum value of this range was computed as the area at zero deformation and minimum possible radius; $x=0$, and $R=\frac{w}{2}$. Notice that if $x=0$, and the liquid is pinned at the top of the pillars, the radius of the meniscus is strictly larger than half the separation between the consecutive pillars; $R \geq \frac{w}{2}$. For the isobaric process, we compute the total energy (with $W \neq 0$ ), assuming the radius of the meniscus to be a constant such that $R \geq \frac{w}{2}$.

The predictions of the model are now presented in the form of an energy landscape, in fig. 2.6 for both isochoric (solid lines), and isobaric scenarios (dashed lines). The force diagram of fig. 2.5 is simply recovered by the connection $F=-d E / d x$.

As in the force case, the transition from stable to unstable, fig. 2.6b, is found at the critical value calculated with eq. $2.4 ; \theta=129^{\circ}$. Below the transition, fig. $2.6 \mathrm{a}$, both the isochoric and isobaric scenarios are stable at $x=0$. This is illustrated by the concave energy landscape with a minimum at $x=0$. Above the transition, fig. 2.6c, the energy landscape is convex 
with a local maximum at $x=0$. As anticipated by the force approach, we find two types of transitions. The isobaric scenario yields a first-order transition where the energy changes from a concave to a convex landscape at the transition value given by eq. 2.4. In contrast, the isochoric scenario yields a second-order transition where the energy landscape changes to a double-well configuration, creating two new stable states at $x \neq 0$. 


\section{Supplementary movies}

All movies can be found in the supplementary information linked in the following QR-code.

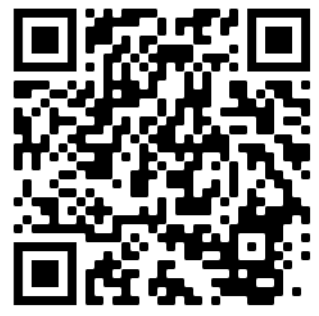




\section{Squeezing drops: Force measurements of the Cassie-to-Wenzel transition ${ }^{\ddagger}$}

Superhydrophobic surfaces have long been the centre of attention of many researchers due to their unique liquid repellency and self-cleaning properties. However, these unique properties rely on the stability of the so-called Cassie state with air-filled microstructures, which is metastable and tends to transit to the stable Wenzel state, where the inside of the microstructures gets wetted. For potential industrial applications, it is therefore critical to maintain the Cassie state. In this chapter, we investigate the Cassie-to-Wenzel transition on superhydrophobic micropillar surfaces by squeezing a water drop between the surface and a transparent superhydrophobic force probe. This probe allows the use of top-view imaging to monitor the area of the drop as it is squeezed between the probe and the micropillared surface. The impalement, Cassie-to-Wenzel transition, is identified as a sharp decrease in force accompanied by an abrupt change in the drop's contact area. We compare the force measured by the sensor with the capillary pressure force calculated from the observed drop shape and find a good agreement between both quantities. We also study the force and pressure at impalement as a function of the pillar's slenderness ratio. Finally, we compare the impalement pressure with three predictions from the literature and find that our experimental values are consistently lower than the theoretical predictions. We find that a possible cause of this earlier Cassie-to-Wenzel transition may be the coalescence of the squeezed drop with micro-drops nucleated on the micropillared surface.

\footnotetext{
${ }^{\ddagger}$ In preparation: Garcia-Gonzalez, D., Corrales, T.P., D’Acunzi, M. , and Kappl, M. Squeezing drops: Force measurements of the Cassie-to-Wenzel transition.
} 


\subsection{Introduction}

The wetting properties of superhydrophobic materials are of great interest due to their potential industrial applications [88,89], and widespread presence in nature [25,26]. Properties such as: self-cleaning [26], antifouling [88,90], water-harvesting [91] and antifogging [92], among others [93-95] have been inspired by the natural superhydrophobicity found in animals and plants. In fact, many surfaces have been created to generate the desired superhydrophobic states [96-100], and much research has been conducted to recognize the basic design principles of superhydrophobicity; micro-texturing and low surface energy materials $[31,32,36,37,47]$. Yet all of the properties mentioned rely on the surface's ability to maintain its superhydrophobicity, the so-called "Cassie-Baxter" state.

In the Cassie state, water drops lay on top of the surface, entrapping an air pocket between the texture [75]. The presence of the air pocket leads to large apparent contact angles $\left(>150^{\circ}\right)$ and low drop adhesion, leading to low roll-off angles $\left(<10^{\circ}\right)$. However, the Cassie state is only metastable; penetration of the liquid into the surface texture can lead to the complete displacement of the air pockets with the liquid reaching the bottom of the surface. This impaled state is the so-called "Wenzel" state. This means that once the drop impales in the surface texture, the superhydrophobic properties are lost. For a drop resting on a superhydrophobic surface, impalement is expected to occur when the pressure exerted by the drop increases beyond a critical impalement pressure which lets the airwater interface bulge far enough into the surface texture. Such a pressure increase can be due to an external force on the drop or by an increase of the Laplace pressure of a shrinking droplet during evaporation. The point at which the transition occurs can depend on the shape of the surface texture and the local contact angles, but also on how strong the airwater interface may be pinned at the edges of surface structures. Thus, characterizing the Cassie-to-Wenzel transition and measuring the critical impalement pressure can contribute to further optimize superhydrophobic materials for potential industrial applications.

Previous studies have approached this question by observing a drop as it is squeezed between two superhydrophobic surfaces [47, 101, 102], as sketched in fig. 3.1. When the drop impales, the air trapped between the texture (micropillars) is displaced, and the water penetrates within the structure (fig. 3.1c). Thus, when impalement occurs, a sudden change in apparent contact angle can be measured from side view images [47,101]. Further studies $[102,103]$ have incorporated force sensors to characterize the transition. In [103], they present an experimental setup where a drop is squeezed between two superhydrophobic surfaces while simultaneously measuring the displacement of the top plate and the force applied on the bottom plate. In this work, they showed that the transition is detectable by force sensing methods but did not find evidence of a sharp transition. In a more recent work [102], it was shown that the force exhibits a sharp change at the transition when squeezing a drop between two superhydrophobic surfaces. They measured force and separation of the surfaces and calculated the experimental impalement pressure. However, the experimental impalement pressure values were in disagreement with their adopted model. This difference was attributed to the nanoscopic pillar roughness, a byproduct of the fabri- 
(a)

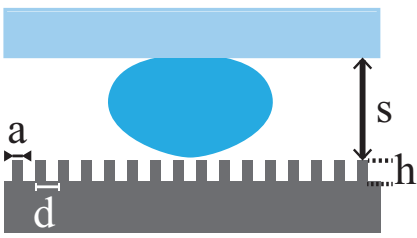

(b)

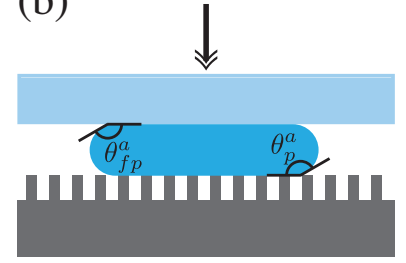

(c)

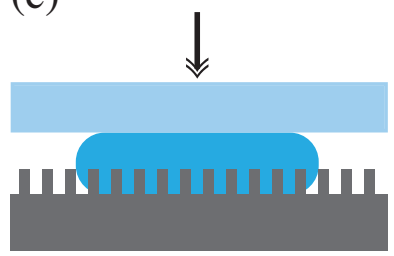

Figure 3.1: Drop squeeze tests. (a) A micrometric water drop is attached to the top plate separated by a variable distance $s$ from the superhydrophobic micropillar array. The pillar width, center-to-center distance and height are $a, d$ and $h$, respectively. (b) The drop is squeezed between both surfaces, forming advancing contact angles $\theta_{f p}^{a}$ and $\theta_{p}^{a}$ with the top and bottom surfaces, respectively. Finally, in (c), the drop is shown in the Wenzel state; the drop is impaled on the micropillar array.

cation method.

In this chapter, we revisit the squeeze test to characterize the Cassie-to-Wenzel transition. We compress a water drop between a planar superhydrophobic force probe and a superhydrophobic micropillar array, and measure the force on the probe while simultaneously recording top-view videos of the process. Using video-tracking analysis, we are able to directly measure the geometric change in the drop's radius and contact area. With this, we compare the force measured at the transition with the one calculated using the geometrical parameters and further discuss the impalement pressure in relation to the pillar's dimensions and spacing.

\subsection{Experimental methods}

We measured the force necessary to squeeze a water drop between two parallel surfaces: a superhydrophobic glass slide connected to a force sensor (acting as the force probe) and a superhydrophobic micropillar array. Meanwhile, we recorded top-view videos of the process to determine the drop shape. In this section, we discuss the methods used to prepare the force probe, the micropillar arrays, and the data acquisition of the experimental results.

\section{Preparation of the force probe}

Prior to the experiments, each transparent force probe was made superhydrophobic. The probes were made from a microscope glass slide $\left(76 \times 26 \mathrm{~mm}^{2}\right.$, Thermo Scientific MenzelGläser) with a hole of approximately $3.4 \mathrm{~mm}$ diameter for mounting the force sensor (with a screw, as sketched in fig. 3.2). Superhydrophobicity was achieved by coating the glass slides with a layer of silicone nanofilaments as described in the literature [95,104]. The procedure 
to apply the silicone nanofilament layer was as follows: first, the slides were cleaned by oxygen plasma for 2 minutes at $120 \mathrm{~W}$ (using a Diener Electronic Femto BLS). Then, they were immersed for 3 hours in a solution of $400 \mu \mathrm{L}$ of trichloromethylsilane (99\%, Sigma-Aldrich) in $100 \mathrm{~mL}$ toluene ( $\geq 99.5 \%$ Sigma Aldrich) with a water content of $150 \mathrm{ppm}$ as measured by a coulometer (Mettler Toledo C20 Compact Karl Fischer coulometer). This treatment leads to the formation of a few micrometre thick, transparent silicone nanofilament layer. Finally, the slides were rinsed with n-hexane (95\%, Fisher Chemicals) to remove unreacted silane, and dried under nitrogen flow.

Once the probe was coated, a hydrophilic defect (or "sticky" spot) was created on the surface by exposing a circular section to oxygen plasma ( 2 minutes at $150 \mathrm{~W}$ ). This was achieved by masking the surface using an aluminium plate with a $1.5 \mathrm{~mm}$ hole. The mask was gently placed on the superhydrophobic force probe and fixed tightly with two clamps. The plasma treatment procedure produces a small hydrophilic region on the force probe surrounded by the superhydrophobic nanofilaments. This hydrophilic defect acts as a pinning site to attach small liquid drops onto the superhydrophobic probe. It should be noted that the impalement pressure of the nanofilament coating was always higher than that of the pillar array due to its nanoscale roughness.

\section{Preparation of the samples: SU-8 micropillar arrays}

The samples used were superhydrophobic round and square pillar arrays. The lithography process is as follows: first, a glass slide was covered by a $25 \mu \mathrm{m}$ layer of SU-8, a negative photoresist. Then, the layer was exposed to UV light through a chromium mask with either round or square holes. We used a mask with holes of width $a$ organized in a square lattice with centre-to-centre distance $d$. The sample was then rinsed with developer (Microchem) to remove the non-crosslinked SU-8, followed by rinsing with isopropyl alcohol, and dried under a stream of nitrogen gas. Finally, after the fabrication steps, the pillars were plasma-treated for 2 minutes at $120 \mathrm{~W}$, and coated with a $(1 \mathrm{H}, 1 \mathrm{H}, 2 \mathrm{H}, 2 \mathrm{H})$-perfluorooctyltrichlorosilane layer by chemical vapour deposition. This rendered the pillar arrays superhydrophobic.

In the following table, we specify the dimensions of the micropillar arrays as well as the slenderness ratio $(\xi)$ of the round and square pillars. This quantity, proposed in [105], relates the pillar's height, perimeter, and cross-section area: $h, p$, and $A_{p}$, respectively. For pillars of square and round cross-sections, $\xi=h p / A_{p}=4 h / a$, with $h=25 \mu \mathrm{m}$ for all our samples.

\begin{tabular}{|c||c|c|c|c|c|c|c|}
\hline $\mathrm{a}[\mu \mathrm{m}]$ & 5 & 9 & 47 & 25 & 87 & 45 & 90 \\
\hline $\mathrm{d}[\mu \mathrm{m}]$ & 18 & 35 & 95 & 95 & 175 & 90 & 175 \\
\hline$\xi$ & 20.0 & 11.1 & 2.1 & 4.0 & 1.1 & 2.2 & 1.1 \\
\hline
\end{tabular}

Table 3.1: List of width $(a)$, center-to-center distance $(d)$, and slenderness ratio $(\xi)$ of the micropillar arrays. $\xi$ relates the pillar's height, perimeter, and cross-section are such that $\xi=h p / A_{p}=4 h / a$ for pillars of square and circular cross-sections [105]. 


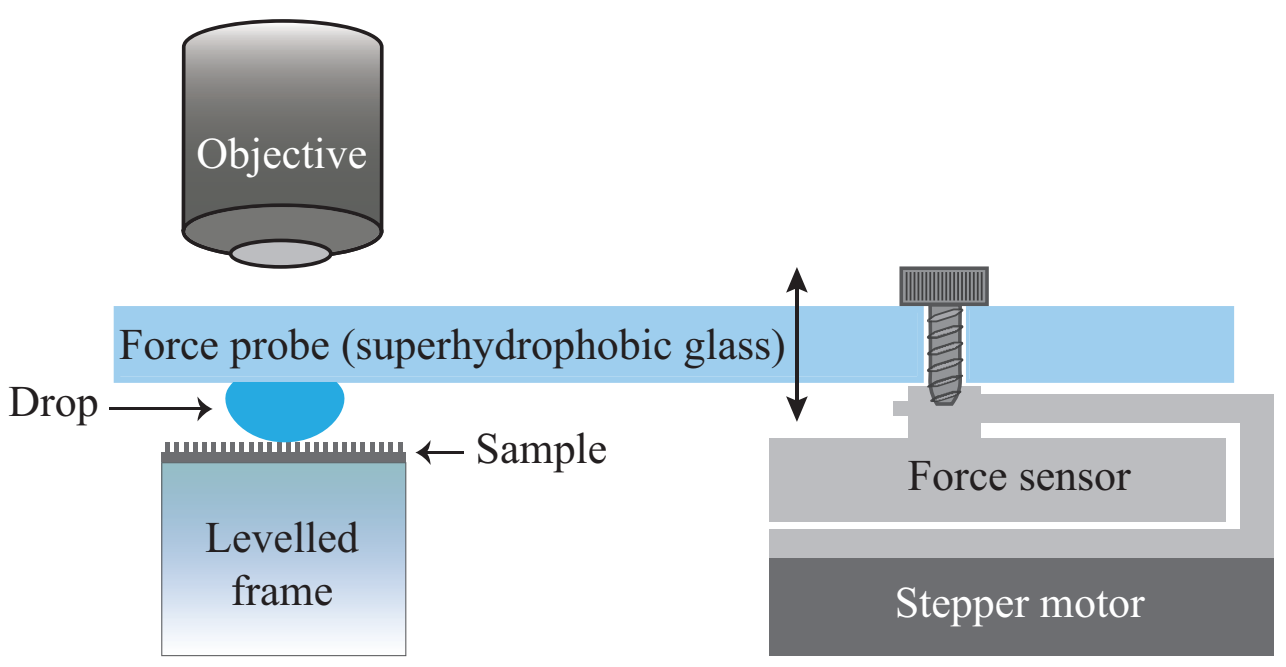

Figure 3.2: Sketch of the experimental setup. The force probe (superhydrophobic glass slide and force sensor) is moved by the vertical translation stage. Top-view images were recorded using a uEye CMOS USB video camera coupled to a Navitar optical system. This set-up can capture the water-pillars contact line position as the superhydrophobic glass retains its transparency. The pillar arrays are placed on a levelled aluminium frame to prevent having an angle between the sample and the force probe.

\section{Experimental data acquisition}

A $2 \mu \mathrm{L}$ water drop was placed on the "sticky" spot on the transparent superhydrophobic glass. Transparency was needed to capture top-view images, while superhydrophobicity ensures symmetric contact lines (in contact with the top and bottom surfaces). The "sticky" spot pins the drop such that when drop compression starts, it will not move laterally. Then, the superhydrophobic glass is mounted horizontally with a screw onto a strain gauge force sensor (GSO-10 load cell, Transducer Techniques, Temecula, CA) as sketched in fig. 3.2. The sensor is connected to a corresponding load cell signal conditioner (TMO-2) with an analogue output voltage $(0-10 \mathrm{~V})$ proportional to the applied force on the load cell. The output voltage was recorded with an AD board (National Instruments NI PCIe-6321) installed on a computer. This combination of load cell and signal conditioner can measure forces up to $10 \mathrm{mN}$ with a standard deviation of approximately $10 \mu \mathrm{N}$. Calibration of the force sensor was done by placing known weights on the glass slide and measuring the output of the signal conditioner. The force probe is attached to a motorized vertical translation stage (HVM10030-HDS Owis, Staufen, Germany) with a minimum step size of $9 \mathrm{~nm}$. The movement of the stage was controlled by a PCI motor controller card (PS30, Owis, Staufen, Germany).

In the experiments, the two surfaces were approached in steps of $0.8 \mu \mathrm{m}$, while recording the force signal and the top-view video. Note that each micropillar array sample was placed on a levelled aluminium frame to make sure the probe and the micropillar array were 
parallel to each other. Levelling was achieved prior to each experiment by approaching the aluminium frame without a drop on the probe and iteratively correcting the orientation of the frame. The video acquisition is triggered with the first movement of the translation stage to synchronize the videos with the force recordings. The video system consisted of a Navitar $6.5 \times$ zoom lens with a $2 \times$ extension tube, and a $2 \times$ Mitotuyo objective, mounted to a uEye USB camera (IDS, Obersulm, Germany). It was then focused on top of the pillars with the drop.

The acquisition frequency of the top-view videos and the force measurements was 4.5 and $2.4 \mathrm{~Hz}$, respectively. Therefore, given that the video and force sensing are recorded at different rates, we linearly interpolate the force curve by using a standard MATLAB function (interp1), generating a time-dependent force curve that is sampled at the same rate as the video recording.

\subsection{Results and discussion}

\subsubsection{A squeezed drop: Force and area measurements}

We start by examining fig. 3.3a, a typical force curve, where the force is shown as a function of the separation $(s)$ between the micropillar array and the force probe. The experiment starts at point $\mathrm{A}$ and follows the progression shown by the arrows until finishing at point $\mathrm{F}$, where the drop finally detaches from the micropillar array. At $A$, the drop does not yet touch the array. Therefore, the force measured by the sensor is zero. From A to B, the separation between the surfaces decreases, but the drop does not yet touch the lower surface.

From $B$ to $C$, the drop touches both the top and bottom surfaces and is being compressed. At $\mathrm{C}$, there is a sudden fall in the force curve, which coincides with the drop impaling the micropillar array. We show this transition in more detail in fig. 3.3b (left axis). From C to $\mathrm{D}$, the drop continues to be squeezed between the surfaces, and the force increases further. At $D$, the vertical translation stage starts reversing its motion, thus gradually increasing the distance between the force probe and the micropillar array. We see this as a decrease in the force until E. From $\mathrm{E}$ to $\mathrm{F}$, the force increases again until, at point $\mathrm{F}$, the drop and the probe are detached from the array. We find that in some experiments, the drop ruptures: one part remains on the micropillar array while the other is detached with the probe. 


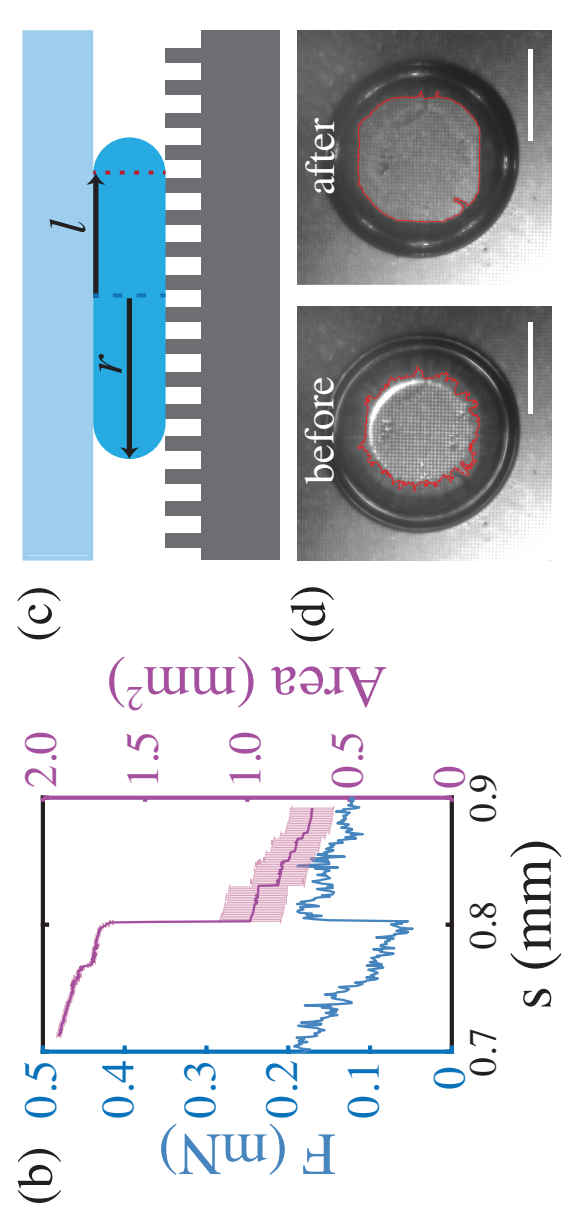

를ㄹㅀ

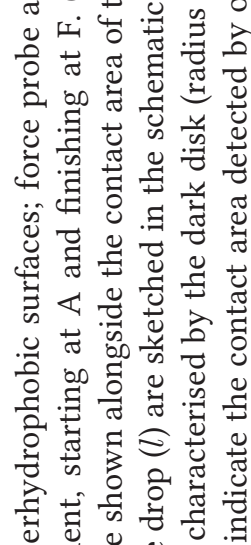

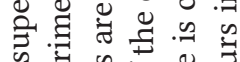

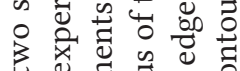
- $\Xi$ is 0

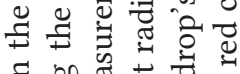
ปี

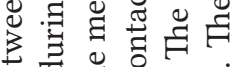

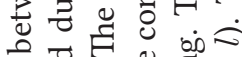

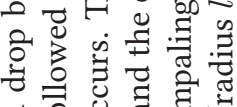

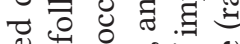

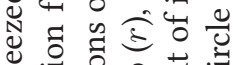

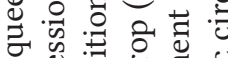

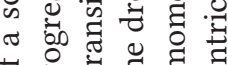
Чั \&

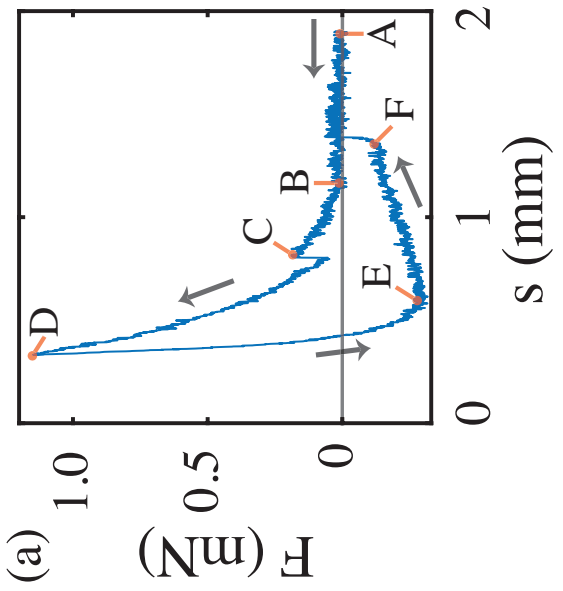

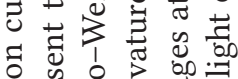
. ป 준 150.5

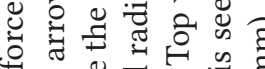

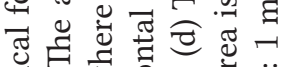
帘范

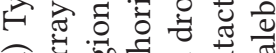

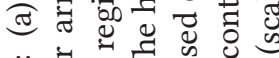

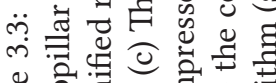

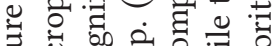

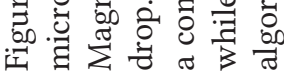


The Cassie-to-Wenzel transition coincides with the fall in the force-separation curve. This can be seen in fig. 3.3b, where we show the contact area (calculated from the top view images) along with the force measurements. In fig. 3.3c, we show a schematic of the drop's geometry while being squeezed between the surfaces. Both the radius of the drop $r$, and the contact radius with the surface $l$ are indicated. In fig. 3.3d, we show top-view images of the drop before and after impalement. When looking at these images, we see the edge of the drop as a dark disk of radius $r$, and a concentric light circle of radius $l$ in the middle. The light region corresponds to the contact area of the drop with the pillared surface $\left(\approx \pi l^{2}\right)$, while the red contours correspond to the area detected by our MATLAB algorithm. Before impalement, this region is circular; the drop is axisymmetric. However, after impalement, the central region resembles a polygon. Note that prior to the impalement event, our MATLAB algorithm encounters difficulties in the detection of the contact area due to light scattering. This is seen as the jagged edge in the red contour of fig. $3.3 \mathrm{~d}$, left. When the drop transitions to the Wenzel state, the images present less scattering, and therefore, the contour detection is more accurate (fig. 3.3d, right). The error bars in the area (fig. 3.3b) represent the difference between the area detected by the algorithm and an estimated value obtained by tracing the boundary of the light region in each of the snapshots of fig. 3.3d.

The geometrical change (circular to polygon) observed in the snapshots of fig. $3.3 \mathrm{~d}$ shows the effect of the underlying pillar's square lattice on the impaled area. This is illustrated in more detail in fig. 3.4a, where we show the contact line of a partially impaled drop. Here, we see a snapshot while the impaled section of the drop moves (from left to right) on the pillared surface; the shape of the contact line is influenced by pinning to the rows of pillars, leading to the polygon shape of the impaled area [46, 106, 107]. Moreover, in fig. 3.4a, we notice the presence of small water drops ahead of the impalement front at the bottom of the pillared surface, which are more evident in the zoom-in picture fig. $3.4 \mathrm{~b}$ (a higher magnification snapshot of fig. 3.4a). In this magnified image of the pillars, we can observe micro-drops of diverse sizes, the largest ones around $5 \mu \mathrm{m}$. These micro-drops have formed beneath the drop in the Cassie state by evaporation from the drop and condensation on the bottom and probably sides of the pillars. These micro-drops will facilitate the movement of the advancing front as they coalesce with it, and it is likely that they also facilitate Cassie-to-Wenzel transition. Similar micro-drops were reported in [43], where they show that small water drops shorten the lifespan of the Cassie state for their cylindrical micropores substrates. We believe that much like in the asymmetric collapse of [43], the micro-drops condensate on small defects on the surface. In our case, the source of these defects might be traces of SU-8 remaining from the developing step of the lithography process. However, further cleaning steps to remove any residual SU-8 could induce detachment of pillars on our surface. 
(a)

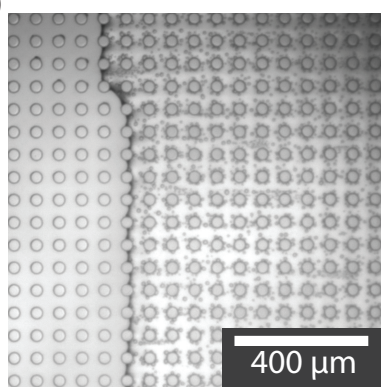

(b)

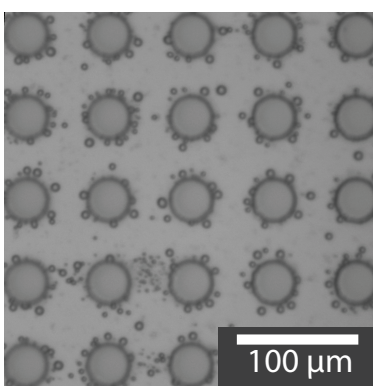

Figure 3.4: (a) A partially impaled drop advances on the pillared surface. The left side of the image shows the drop in a Wenzel state, while the right side of the image is still in the Cassie state. (b) Micro-drops of liquid condense near the pillars prior to the Cassie-toWenzel transition.

\subsubsection{Forces at the transition}

The force measured by the sensor is given as a combination of the drop's capillary pressure, and the line tension [37,102], expressed as:

$$
F=\pi l^{2} \gamma\left(\frac{1}{r}-\frac{2 \cos \theta}{s}\right)-2 \pi l \gamma \sin \theta,
$$

with $l, r$ and $s$ parameters concerning the geometry of the drop (fig. 3.3c), and $\theta=\theta_{f p}^{a}$ the advancing contact angle of the drop on the top surface (force probe, see fig. 3.1b). Notice that in this expression we have assumed the contact angles on the top and bottom surfaces to be equal, $\theta_{f p}^{a}=\theta_{p}^{a}$. This assumption is reasonable as both surfaces are superhydrophobic and the drop is under symmetric compression from both sides. Therefore, the local advancing contact angle of both surfaces is expected to be close to $180^{\circ}$.

We test eq. 3.1 by extracting the information of $l$ and $r$ from the top-view images and computing the force using eq. 3.1. This is presented in fig. 3.5a, where we show the experimental values together with the prediction assuming $\theta=180^{\circ}$ as advancing contact angle for superhydrophobic surfaces [108]. We notice that for this force curve, the calculated values are slightly higher than the measured ones. However, we see that the calculated force values (using the information from the top-view images) are reasonably close to the experimental ones. The force values just before impalement for the experimental and calculated force curves are shown in red and green, respectively.

The comparison of the critical force, measured just before impalement $\left(F_{C}\right)$, and the calculated values $\left(F_{T}\right)$ using top-view measured values and eq. 3.1 is shown in fig. 3.5b for all our experiments. Here, the dashed line represents a slope of 1 , indicating a perfect agreement between the calculations and the values measured by the force sensor. From figure $3.5 \mathrm{~b}$, we see that the experimental values are consistently below the calculated ones. 

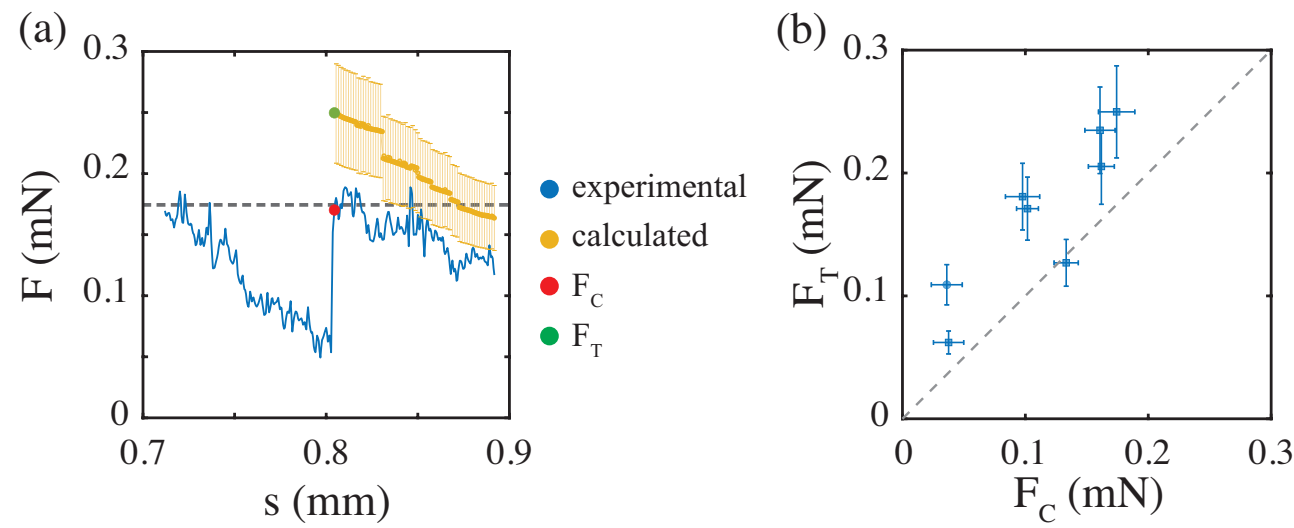

Figure 3.5: (a) Force-separation curve of a squeezed drop near the Cassie-to-Wenzel transition. The experimental and calculated values are, respectively, the blue and yellow markers. The dashed line indicates the critical force, $F_{C}$, before the transition (red marker). The calculated critical force, $F_{T}$, is indicated by the green marker. In (b), we show the calculated impalement force vs the experimental value recorded by the force sensor. The dashed line has a slope of 1 .

This discrepancy may be due to the overestimation of the contact area of the drop and the micropillared surface. We remark that both radii of curvature of the drop were used to calculate the capillary pressure, as experimentally, we found $r \sim h$. Additionally, we note that considering $\theta<180^{\circ}$ in eq. 3.1, yields lower force values. However, considering the offset due to the overestimation of the area and the microscopic evidence presented in [108], we believe $\theta=180^{\circ}$ is a good estimation of the advancing contact angle on the superhydrophobic surfaces. By assuming $\theta=180^{\circ}$, the critical capillary pressure of the drop can be calculated as the force divided by the drop contact area $\pi l^{2}$ from the videos. Therefore, we can directly correlate the critical force $F_{C}$ (just before the transition) with the critical impalement pressure $P_{C}$.

\subsubsection{Impalement pressure}

Up to now, we have examined the force curves and the impalement force as a function of the separation between the surfaces. From the sharp fall in force at the Cassie-to-Wenzel transition, we can extract the critical impalement force, and from the top-view images, we can obtain the capillary pressure in the drop at impalement which is equal to the critical impalement pressure $P_{C}$.

Several previous studies have estimated and classified the impalement pressure through depinning, sagging, and curvature arguments $[37,45,102,105]$. In this section, we compare 
(a)

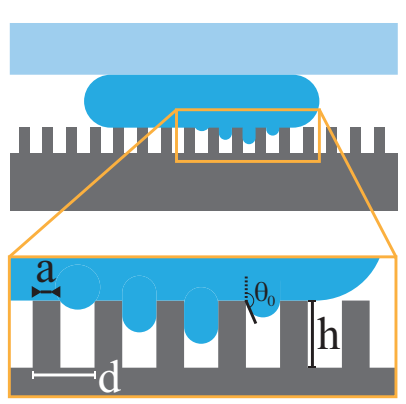

(b)

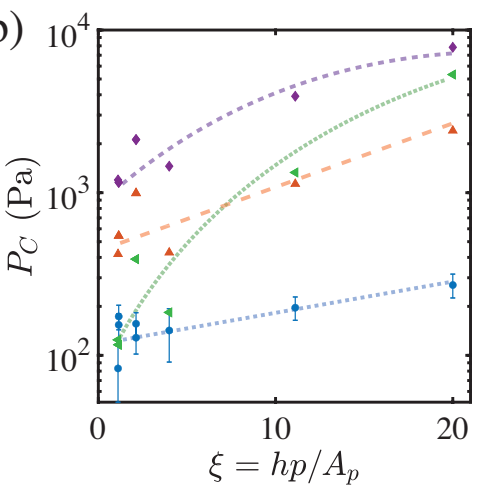

experiments

$\Delta$ Zheng et al. [105] $P_{C}=-\frac{4 \gamma \phi \cos \theta_{0}}{(1-\phi) a}$

4 Reyssat et al. [45] $P_{C}=\frac{\gamma h}{2(d-a)^{2}}$

Butt et al. [37] $P_{C}=-2 \sqrt{2} \frac{\gamma}{(d-a)} \cos \theta_{0}$

Figure 3.6: (a) Sketch of an impaling drop. The pillar dimensions $a$ and $d$ are shown along with the microscopic angle of the drop on a single pillar, $\theta_{0}$. $\phi$ represents the packing fraction of the micropillared structure. Thus, the area ratio of the cross-section of a pillar with the area of one periodic cell of the structure. For square pillars $\phi=(a / d)^{2}$. (b) Impalement pressure as a function of the pillar slenderness ratio $(\xi)$. The dashed lines are intended as a guide to the eye.

the impalement pressure calculated from the experimental measurements,

$$
P_{C}=\frac{F_{C}}{\pi l^{2}}
$$

with these theoretical predictions. We do this by examining the impalement pressure as a function of the pillar slenderness ratio $\xi$ proposed in [105]. We remark that $\xi$ relates the pillar's height, perimeter, and cross-section area. For pillars of square and round crosssections $\xi=4 h / a$. These dimensions, along with the microscopic contact angle of the drop and a single pillar $\theta_{0}$, are shown in the sketch of an impaling drop in fig. 3.6a.

In fig. 3.6b, we show the impalement pressure as a function of the pillar slenderness ratio. Comparing our data to the predictions in [105], [45], and [37], we find that our experimental values are noticeably smaller than the predictions. The first prediction, given in Ref. [105], is calculated equating the force due to the capillary pressure in the drop with the contact line force in one periodic cell of the structure. Thus, $\theta_{0}$ is not the contact angle of the drop on the micropillar array but the microscopic contact angle of the contact line and one individual pillar (as sketched in fig. 3.6a). The basis behind this argument is that the force due to the pressure inside the drop cannot exceed the surface tensional force at the contact line. Otherwise the contact line starts to move, and impalement occurs. In this scenario, when $\theta_{0}$ reaches the advancing contact angle for that material $\left(\theta_{0}=110^{\circ}\right.$ for silanized SU-8 in our case), the contact line will advance on the pillar surface and will slide down to the bottom surface. In case of strong pinning of the contact line at the pillar tops, one might have also had a situation where $\theta_{0}$ exceeds the advancing contact angle before depinning and sliding occurs. Therefore we refer to this type of impalement as 'depinning'. 
Another way to define a criterion for impalement is to equate the capillary pressure in the drop with the pressure due to curvature of the menisci forming in between the pillars. Thus, we compare our experimental data with two predictions that focus on the curved contact line in between pairs of pillars [45], and Ref. [37]. The prediction of Ref. [45] is derived by equating the pressure inside the drop with the maximum pressure a meniscus with curvature $\sim h /(d-a)^{2}$ could resist. This estimation is closer to our data for $\xi<5$. However, it rapidly deviates for higher $\xi$-values. This result is expected as the slenderness ratio depends explicitly on the width of the pillars, while the curvature-and therefore pressure-does not. Finally, we compare the experimental data to the prediction in Ref. [37] where they propose a more accurate estimation of the curvature of the meniscus, such that the exact curvature between the pillars is derived geometrically. However, we see that also for this model, our experimental data are smaller by almost one order of magnitude.

\subsection{Summary and conclusions}

In summary, we have revisited the Cassie-to-Wenzel transition by squeezing a drop between two parallel superhydrophobic surfaces. Our experimental set-up records both force and top-view videos which allow us to monitor the squeezing process closely. We find that the capillary pressure acting over the drop's contact area (as derived from the squeezed drop shape) is higher than the force values measured in experiments. This deviation can be attributed to the overestimation of the contact area of the drop and the micropillared surface. However, we find that overall the calculations follow the same trend as the measured values.

When comparing the experimental pressure at the Cassie-to-Wenzel transition $P_{C}$ with existing models, we find much lower absolute values of $P_{C}$. Overall, our measurements show the difficulty in predicting the impalement pressure even of simple model superhydrophobic surfaces. Possible causes could be a mixed mode of impalement where depinning and sagging both play a role. The observed lower critical impalement pressures might also be related to the presence of micro-drops nucleating on the bottom surface. The presence of these micro-drops might facilitate impalement by coalescence with the approaching airwater interface of the drop. In conclusion, subtle details of the impalement process that are not captured by the existing theories may be responsible for the lower than predicted impalement pressures, and further studies will be necessary to pinpoint such additional dependencies. 


\section{Drawing liquid bridges from a thin viscous film ${ }^{\S}$}

When a particle, such as dust, contacts a surface covered by a thin liquid film, it is trapped by the liquid. This effect is caused by the formation of a meniscus, resulting in a capillary force that makes the particle adhere to the surface. While capillary adhesion is well-characterised in static situations, the dynamic formation of the liquid bridge after the initial contact is highly intricate. Here, we experimentally study the evolution of a liquid bridge after a glass sphere is gently brought into contact with a thin viscous film. It is found that the contact creates a ripple on the thin film, which influences the growth of the meniscus. Initially, the ripple and the meniscus are coupled and exhibit similar dynamics. This initial regime is well accounted for by a scaling law derived from lubrication theory. At a later stage, the ripple is "detached" from the liquid bridge, leading to a second regime of bridge dynamics. Our findings highlight the importance of dynamics in adhesion, which leads to capillary forces that are strongly time-dependent.

\footnotetext{
${ }^{\S}$ Submitted as: Garcia-Gonzalez, D., Hack, M.A, Kappl, M., Butt, H. J. , and Snoeijer, J.H. , Drawing liquid bridges from a thin viscous film.
} 


\subsection{Introduction}

Anyone who has been at the beach has noticed the effect of liquid bridges, from sandcastles [58] to the sand that attaches to your skin when wet. It is the same phenomenon that we experience when our skin contacts glitter. The small liquid menisci created between the particles and the surface are strong enough to keep the particles in place. In fact, most powders and small particles attach spontaneously to liquid interfaces; even to thin films, like sweat on your skin in the case of glitter. In industrial settings, the study of liquid bridges is relevant for powders $[6,109]$, soils $[7,62,110]$, and granular materials $[63,111]$ as storage and applications may involve humid environments.

The simplest scenarios of capillary adhesion consist of a (spherical) particle adsorbed on a liquid interface $[2,112,113]$, or held in contact with a flat solid by a liquid bridge of finite volume [64,114-116]. This is closely related to the work of adhesion when detaching microparticles from liquid films and soft gels [56, 64-67, 115-117]. However, most of the understanding of capillary adhesion has centred on quasistatic scenarios [118-120]. At equilibrium, the shapes of the liquid menisci, or liquid bridges, can be computed by minimising the surface free energy subjected to wetting conditions imposed by the solids. Once the shapes of the liquid menisci are known, one can directly infer the capillary adhesive force exerted on the particle. However, liquid interfaces are known to exhibit intricate dynamics, especially at early times immediately after a contact is initiated. Consider, for example, the menisci observed at a solid wall or around a partially immersed fibre. Before reaching their well-known equilibrium states, the dynamical onset of these menisci is highly complex [121]. A similarly rapid dynamics is observed in the first stages after a liquid drop is gently deposited on a substrate [122-124]. The temporal evolution of these menisci and liquid bridges will naturally lead to capillary adhesion that is far from quasistatic, but which exhibits strongly time-dependent adhesive forces.

The aim of the present work is to highlight the dynamics of liquid bridges that form after a spherical particle is brought into contact with a thin viscous film. This situation is illustrated in fig. 4.1, where we show snapshots of a liquid bridge formed by a millimetric glass sphere and a micrometric oil film such that the sphere's radius is much larger than the thickness of the film. The liquid and the sphere are gently brought into contact, creating a liquid meniscus suspended from the surface of the sphere. In the first image of fig. 4.1, taken at $t=0.1 \mathrm{~s}$ after the initial contact, the contact does not visibly affect the micrometric film, and we are not yet able to properly resolve the contact line between the film and the sphere. However, at $t=1 \mathrm{~s}$, we observe a small meniscus formed between the sphere and the film, which continues to grow over time. At $t=10 \mathrm{~s}$, we also observe a clear deformation of the previously flat oil surface: an oil ripple is formed. The ripple moves and widens over the surface of the oil film in a way that resembles visco-capillary ripples in previous studies $[57,69,70,72,121]$. At the same time, the contact line continues to move slowly over the surface of the sphere $(t=60 \mathrm{~s})$. Since the contact radius of the liquid bridge grows over time, the adhesion force exerted on the sphere is expected to grow in a similar fashion $[114,118]$. 

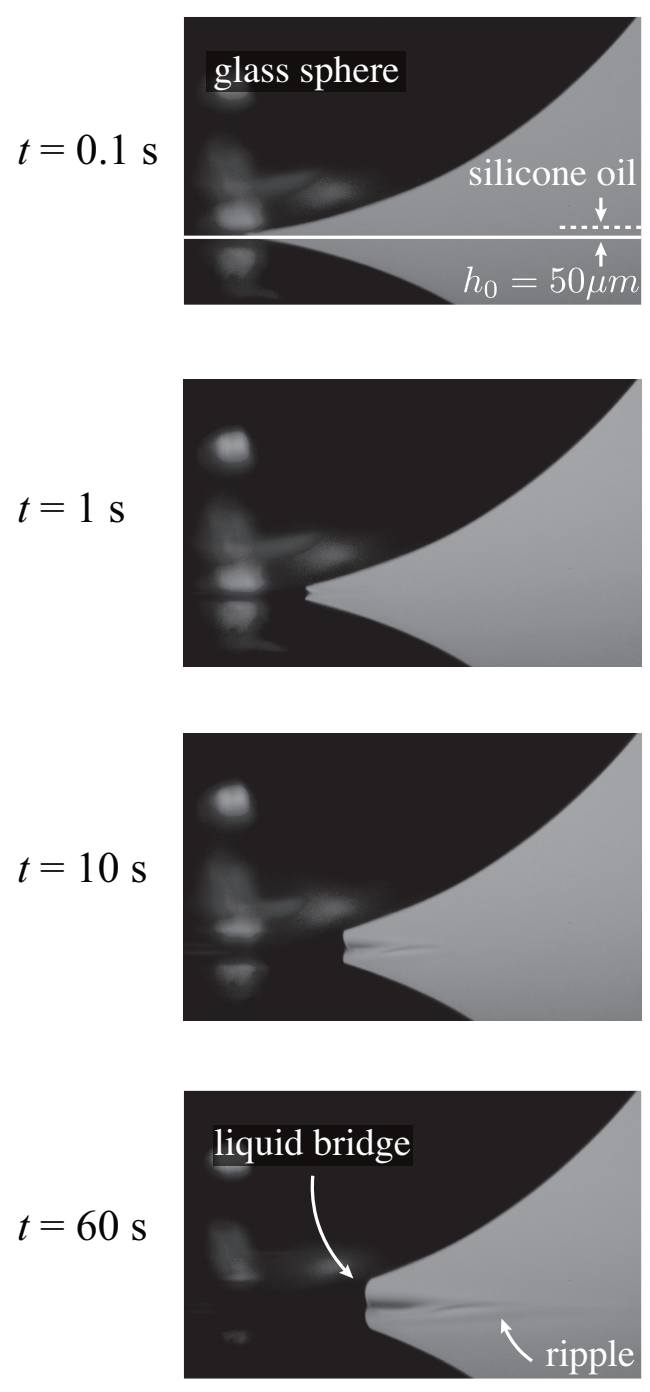

Figure 4.1: Snapshots of the contact between a glass sphere, $R=1.5 \mathrm{~mm}$, and a $50 \mu \mathrm{m}$ thin oil film of viscosity $100 \mathrm{~Pa} \cdot \mathrm{s}$. At early times, both the meniscus and the deformation on the oil film are barely visible. At later times, the contact line advances on the surface of the sphere as the ripple moves away from the contact point. 
In this chapter, we experimentally study the dynamical evolution of the liquid bridge after a sphere is brought into contact with a viscous film. The various aspects of the process are captured by bottom- and side-view images of the liquid bridge, while we also quantify the dynamics of the ripple as it propagates over the oil film. Our key finding is that the process as exemplified in fig. 4.1 consists of two stages. Initially, the meniscus growth is coupled to the dynamics of the ripple. This regime can be described in terms of a scaling analysis of the lubrication equation. At later stages, the ripple detaches from the meniscus (see, e.g. the last image of fig. 4.1), thereby changing the dynamics of the liquid bridge. We discuss how this evolution results in a time-dependent capillary adhesion.

\subsection{Experimental methods}

Figure 4.2 provides a schematic overview of the geometry of the problem and the experimental methods used to characterise meniscus and film. The experiments are performed as follows. A glass sphere is glued to the lower side of a glass slide mounted on a linear translation stage (Zaber X-DMQ12P-DE52). The stage moves downwards in the $z$-direction with a velocity of $5.21 \pm 0.03 \mathrm{~mm} / \mathrm{s}$, until the sphere gently touches a glass slide that is covered with a previously spin-coated oil film. Once the sphere touches the glass slide, the sphere is kept in place by the stage throughout the measurement, as sketched in fig. 4.2a. This procedure ensures the reproducibility of the measurements. It was found that simply dropping the sphere from a very small height led to variability of the results, partly owing to a lateral sliding of the sphere over the film.

Throughout our experiments, we vary three parameters; the size of the sphere, viscosity, and thickness of the film. The glass spheres used were precision polished soda-lime glass spheres with radii of $R=0.50,1.49,3.00$, and $4.50 \mathrm{~mm}$ with a radial tolerance of $\pm 10 \mu \mathrm{m}$ (Cospheric). For the thin films, we used silicone oils with viscosity $\eta=0.1,1$, and $100 \mathrm{~Pa} \cdot \mathrm{s}$ (Sigma Aldrich). We use silicone oil as its surface tension is low, $\gamma=21.2 \mathrm{mN} / \mathrm{m}$, and it does not evaporate within the timeframe of our experiments $(\sim 1 \mathrm{~h})$. Silicone oils are also convenient for controlling the thickness of the film $\left(h_{0}\right)$, varied in the range of 7 to $35 \mu \mathrm{m}$. The films were deposited by spin-coating at different rotational speeds and spinning times [57,72]. The thickness of all films was measured at multiple locations on the same film to ensure its flatness. These measurements were taken using a spectrometer (HR2000+), with a HL-2000-FHSA halogen light source from Ocean Optics.

We visualise the evolution of the liquid bridge and the ripple that forms on the viscous film with two distinct visualisation systems; one for side and bottom images and one for the visualisation of the surface of the oil film. To perform the experiments shown in fig. 4.1 \& $4.2 \mathrm{c}$ we use backlight illumination and a full-frame digital camera (Nikon D850) equipped with a microscopic lens (Navitar $12 \times$ zoom lens). Given the broad range of timescales of the process, we used either $120 \mathrm{fps}$ for one minute or $1 / 60 \mathrm{fps}$ for one hour. Our optical system allows for resolutions in the range of $0.32-1.11 \mu \mathrm{m} /$ pixel. The prime quantity of interest is the contact radius $l(t)$, as defined in fig. 4.2c. The dark circle appearing in the figure 


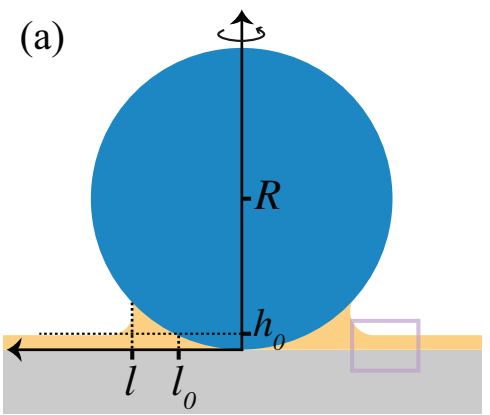

(b)
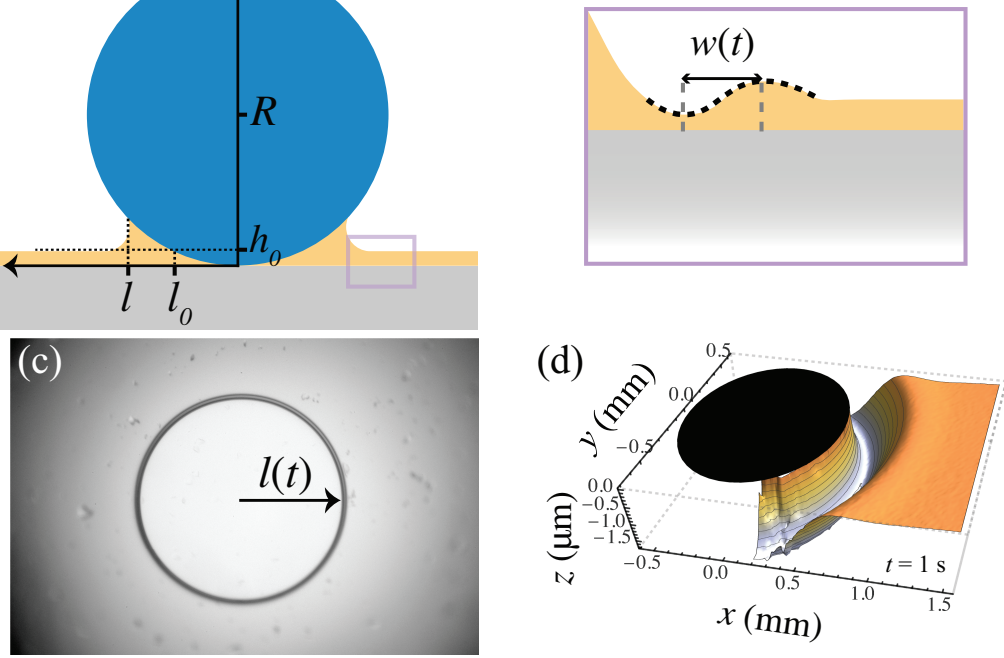

Figure 4.2: (a) Schematic view of the sphere, radius $R$, in contact with the oil film. The contact radius, $l$ is much larger than the film thickness, $h_{0}$. The rectangle is zoomed-in in (b), where we show the ripple created upon contact. The width of this ripple is denoted by $w(t)$, measuring the horizontal distance between the minimum and the maximum of the ripple. In figures (c) and (d), we show typical measurements of $l(t)$, and the surface deformation of the oil film. The dark circle appearing (d) corresponds to the region where the meniscus is strongly curved, and cannot be resolved by the experimental method (DHM, see text).

corresponds to the region where the meniscus is strongly curved. We take as a measurement for $l(t)$ the interior of the dark circle, which is the minimum inner radius of the liquid bridge. We remark that this is, in practice, very close to the actual contact line position. Additionally, we note that the dark ring takes the form of a perfect circle; this is a strong indication that contact line pinning plays no significant role in these experiments, owing to the smoothness of the sphere. Furthermore, the contact angle measurements presented in Section 4.4 indicate that we work approximately under ideal complete wetting conditions.

To measure the ripple dynamics shown in fig. $4.2 \mathrm{~b}$,d, we use a reflection Digital Holographic Microscope (DHM-R1000 by Lynceé Tec) in its inverted configuration (bottomview), coupled with a $5 \times$ objective (Leica) with a lateral resolution of $1.47 \mu \mathrm{m} /$ pixel. The DHM is a commercially available instrument that records the hologram created by laser interference between an object, and the reference beam [125] $(\lambda=666 \mathrm{~nm})$. Recording the hologram allows for real-time measurements of the oil's surface. This is done by reconstructing the interface from the intensity and phase information encoded in the hologram $[57,72]$. Note that with this set-up, the maximum deformation slope on the surface is 
up to $3.4^{\circ}$. Higher slopes on the surface profile cannot be resolved accurately with this objective. However, we can characterise the oil ripple accurately with this method. From the deformation profiles, we extract the characteristic width $w(t)$ of the ripple, which is defined as the horizontal distance between the minimum and the maximum of the wave (fig. $4.2 \mathrm{~b}$ ).

\subsection{Results}

\subsubsection{The contact radius}

We first examine the motion of the oil onto the surface of the sphere by measuring the contact radius $l(t)$. The measurement is taken from bottom view images as in fig. 4.2c. All the data reported below are averages over 3 to 5 different experimental realisations. The good reproducibility of experiments can be inferred from the error bars, which indicate the standard deviations obtained during the averaging. 


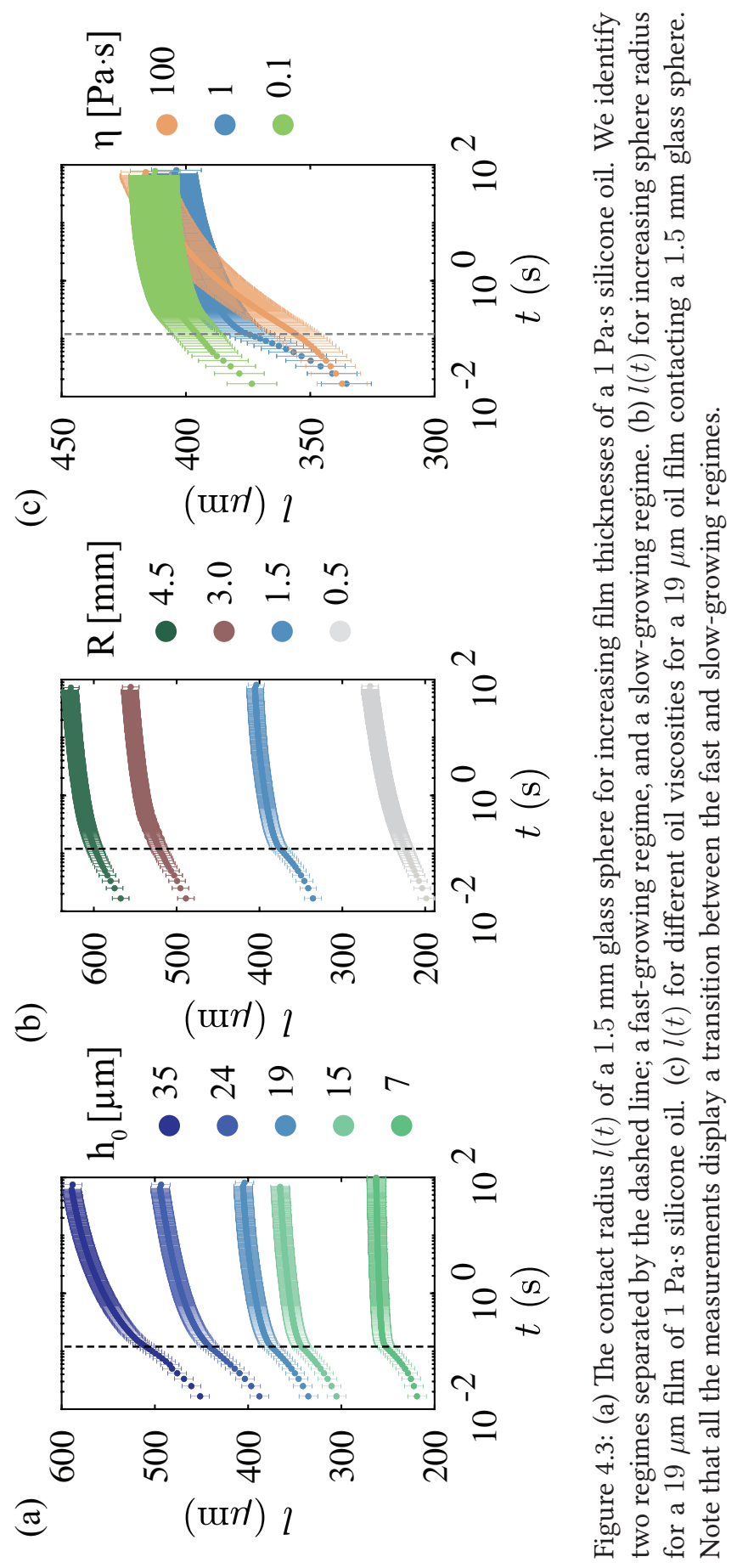


Effect of film thickness. In fig. 4.3a, we show the contact radius $l(t)$ for a glass sphere with $R=1.5 \mathrm{~mm}$ in contact with oil films of increasing thickness $h_{0}$ of viscosity $1 \mathrm{~Pa} \cdot \mathrm{s}$. We observe that $l(t)$ grows considerably faster during the early stages of contact, as compared to the later stages. Note that the horizontal axis indicates a logarithmic scale, enabling to clearly visualise the entire range of timescales. Each of the datasets exhibits a "kink", or at least an inflection point, which is approximately located around $t \sim 0.1 \mathrm{~s}$. This is indicated by the vertical dashed line. An important experimental detail is that the glass sphere is mounted on a linear motor, which takes some time to "traverse" the viscous film. This time is typically about $0.01 \mathrm{~s}$, as confirmed in additional tests recorded at higher frame rates (not shown). The first datapoints in fig. 4.3 are recorded after this immersion time. This immersion time is at least one order of magnitude shorter than the time at which we see the appearance of the kink, which is therefore, an intrinsic feature of the dynamics after immersion. After the rapid early stage, we observe a very slow dynamics; the evolution of which is most prominent for the experiments on large thickness $h_{0}$. Only for the smallest thickness $(7 \mu \mathrm{m})$ do we seem to observe a saturation of the contact radius within our experimental resolution. In all experiments, the dark ring remained circular, suggesting that contact line pinning at defects plays no significant role in our experiments.

We remind that the sphere in the experiments of fig. 4.3a had a radius $R=1.5 \mathrm{~mm}$. This implies that for all datasets, the system is still far from a complete sphere engulfment by the liquid film. Moreover, the maximum contact radius $l(t)$ remains well below the capillary length (1.5 mm for our system); The typical height of the liquid bridge is even much smaller than this capillary length so that gravity is expected to have a negligible effect on the bridge shape.

Thus, we observe two distinct regimes that are separated by the kink (dashed line). The early, or fast-growing regime, and the late, or slow-growing regime. We also conclude that thicker films give rise to larger contact radii. This can be understood from the fact that a larger volume is available to fill the liquid bridge and that thick films exhibit a weaker resistance to flow. Remarkably, the transition between the slow- and fast-growing regimes occurs approximately at the same time, independent of film thickness.

Effect of the sphere radius. To explore the effect of the size of the particle, we vary the sphere radius from $R=0.5$ to $4.5 \mathrm{~mm}$ while keeping the thickness and viscosity of the film constant; $h_{0}=19 \mu \mathrm{m}$ and $1 \mathrm{~Pa} \cdot \mathrm{s}$, respectively. In all cases $R \gg h_{0}$, and the evolution of $l(t)$ is qualitatively similar for all sphere radii (fig. 4.3b). We again observe two stages, which once again can be distinguished around approximately the same time (dashed line) for the different sphere radii. Spheres of a larger radius $R$ lead to larger contact zones $l(t)$. However, even at late times, none of the data exhibits a saturation within our observation time of $1 \mathrm{~h}$, which implies that liquid is still continuously drawn into the growing liquid bridge.

Effect of the oil viscosity. In fig. 4.3c, we explore the effect of viscosity in our experiments by using three different silicone oils; $\eta=0.1,1$, and $100 \mathrm{~Pa} \cdot \mathrm{s}$. The experiments were performed with the $R=1.5 \mathrm{~mm}$ glass sphere and films of thickness $h_{0}=19 \mu \mathrm{m}$. We thus vary the viscosity by 3 orders of magnitude. In the initial stage, we observed that the dynamics is fastest for the lowest viscosity, as expected. The time of the transition between 
the two regimes is comparable for the two lowest viscosities $(\eta=0.1,1 \mathrm{~Pa} \cdot \mathrm{s})$, while it occurs later for the largest viscosity $(\eta=100 \mathrm{~Pa} \cdot \mathrm{s})$. Remarkably, towards the end of the experiment, the contact radius $l(t)$ approaches similar values-this corresponds to the regime that exhibits a very slow dynamics, where the contact radius nearly reaches a saturation on the timescale of our experiments.

\subsubsection{The ripple dynamics}

Up to now, we have considered only the optical bottom views of the contact. To gain further insight into how the liquid bridge grows, we need to understand the dynamics of the oil film. Specifically, we quantify the "ripple" from the height deformation maps obtained from the Digital Holographic Microscopy (DHM) experiments. In fig. 4.2d, we show the height profile of a $19 \mu \mathrm{m}$ oil film $1 \mathrm{~s}$ after a $1.5 \mathrm{~mm}$ glass sphere has touched the film. The black region represents the area where the DHM is no longer able to resolve the topography owing to the steep slopes of the free surface near the meniscus. However, the ripple itself is sufficiently shallow to be imaged in detail. In what follows, we exploit the axisymmetric geometry and present the ripple profiles after taking an azimuthal average. 


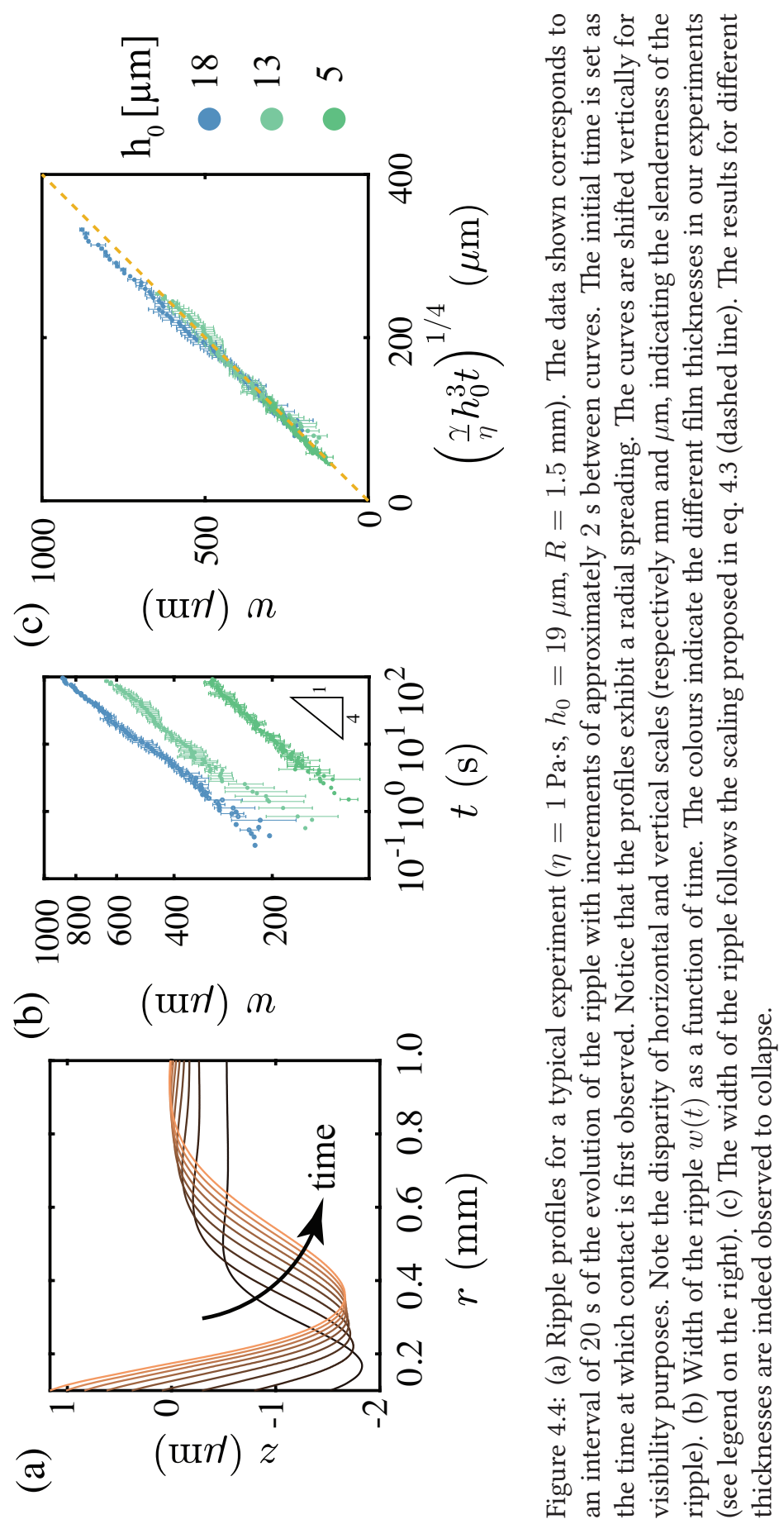


Figure 4.4a shows a typical spatio-temporal evolution of the ripple on the oil surface. The arrow indicates the direction of time, such that darker colours represent earlier stages of the experiment. First, we observe that the ripple moves radially outward from the contact zone. This feature was already visible in fig. 4.1, but now is resolved in full detail. Second, the profile exhibits a wave-like shape, with a minimum and a maximum. Though we can only distinguish a single maximum, we expect that the ripple consists of a series of oscillations that decay exponentially towards the undeformed outer region of the thin film [72]. A third prominent feature is that the radial translation is accompanied by a widening of the ripple profile. To quantify this in more detail, we define the ripple's width $w(t)$ as distance between the radial locations of the maximum and the minimum, defined in fig. $4.2 \mathrm{c}$ as $w=$ $r\left(z_{\max }\right)-r\left(z_{\min }\right)$. Figure $4.4 \mathrm{~b}$ reports the growth of the ripple's width $w(t)$ for films of varying thickness with $R=1.5 \mathrm{~mm}$ and $\eta=1 \mathrm{~Pa} \cdot \mathrm{s}$. Indeed, we identify a widening of the ripple over time, and thicker films yield wider ripples.

The observed properties of the ripple on the viscous film resemble those in $[57,70,73]$, and can be understood from the thin film (lubrication) equation. Denoting the film thickness as $h(x, y, t)$, the thin film equation takes the form

$$
\frac{\partial h}{\partial t}=-\frac{\gamma}{3 \eta} \nabla \cdot\left(h^{3} \nabla \nabla^{2} h\right)
$$

where $\nabla$ is the nabla-operator in the $(x, y)$ plane, parallel to the glass substrate. The lubrication equation should indeed be applicable here, owing to the disparity in horizontal and vertical length scales (millimetres and microns, respectively), while gravity is can be neglected for very thin films. We analyse eq. 4.1 using a scaling argument for the width $w(t)$ of the ripple. For this, we write the perturbation of the film height as $h=h_{0}+\delta(x, y, t)$. Subsequently, we use that the gradient operator acts on the lateral direction, and thus is expected to scale as $\nabla \sim \frac{1}{w}$. Assuming that the perturbation $\delta$ is small to the original height $h_{0}$, the lubrication equation gives the scaling:

$$
\frac{\delta}{t} \sim\left(\frac{\gamma}{\eta} h_{0}^{3}\right) \frac{\delta}{w^{4}}
$$

So that

$$
w \sim\left(\frac{\gamma}{\eta} h_{0}^{3} t\right)^{1 / 4} .
$$

This scaling equally applies in two-dimensions and three-dimensions; a detailed similarity analysis is, in fact, feasible for the two-dimensional case [70,73].

To test the prediction (eq. 4.3), we scale the experimentally obtained $w(t)$ as shown in fig. 4.4c. The datasets of different $h_{0}$ indeed collapse onto one another and closely follow the predicted $w \sim t^{1 / 4}$ scaling. The dashed line corresponds to eq. 4.3 with a prefactor 2.5 . The fact that this empirical prefactor is of order unity confirms the validity of the approach. While we here report only the lateral distance between the minimum and the maximum (owing to limitations of the DHM), the scaling is expected to be characteristic for the entire ripple profile. 


\subsection{Discussion}

\subsubsection{Relating the liquid bridge and the ripple}

We now compare directly the observed contact radius $l(t)$ and the ripple width $w(t)$. For the latter, we have identified a scaling law (eq. 4.3) that captures the dependence on the film thickness, $h_{0}$. For the former, we propose that the main effect of $h_{0}$ is geometric in nature. Namely, the combined effect of $h_{0}$ and $R$ is sketched in fig. 4.2a: once the sphere has traversed the film, it effectively yields an initial contact radius $l_{0}$. This quantity is defined geometrically from the intersection of a sphere by the plane at the height $h_{0}$, which gives:

$$
l_{0}=\sqrt{2 h_{0} R-h_{0}^{2}} \simeq \sqrt{2 h_{0} R},
$$

where the latter expression holds when $h_{0} \ll R$. This radius $l_{0}$ is much larger than the film thickness $h_{0}$, but smaller than the sphere radius $R$. Physically, the quantity $l_{0}$ represents the contact radius upon touching the film if no meniscus were developed, reflected by the vertical offsets of the starting points of the curves in fig $3 \mathrm{a}$.

To account for this geometrically imposed "initial condition", we thus propose to subtract $l_{0}$ from $l(t)$ in order to describe the growth of the contact radius. The result is shown in fig. 4.5, where we plot $l(t)-l_{0}$ as a function of the rescaled time for different film thicknesses (a), different sphere sizes (b), and different oil viscosities (c). In the same plot, we superimpose the scaled experimental data of the width of the ripple (averaged from the collapsed data in fig. 4.4c), and the prediction (eq. 4.3) as the yellow dashed line. 


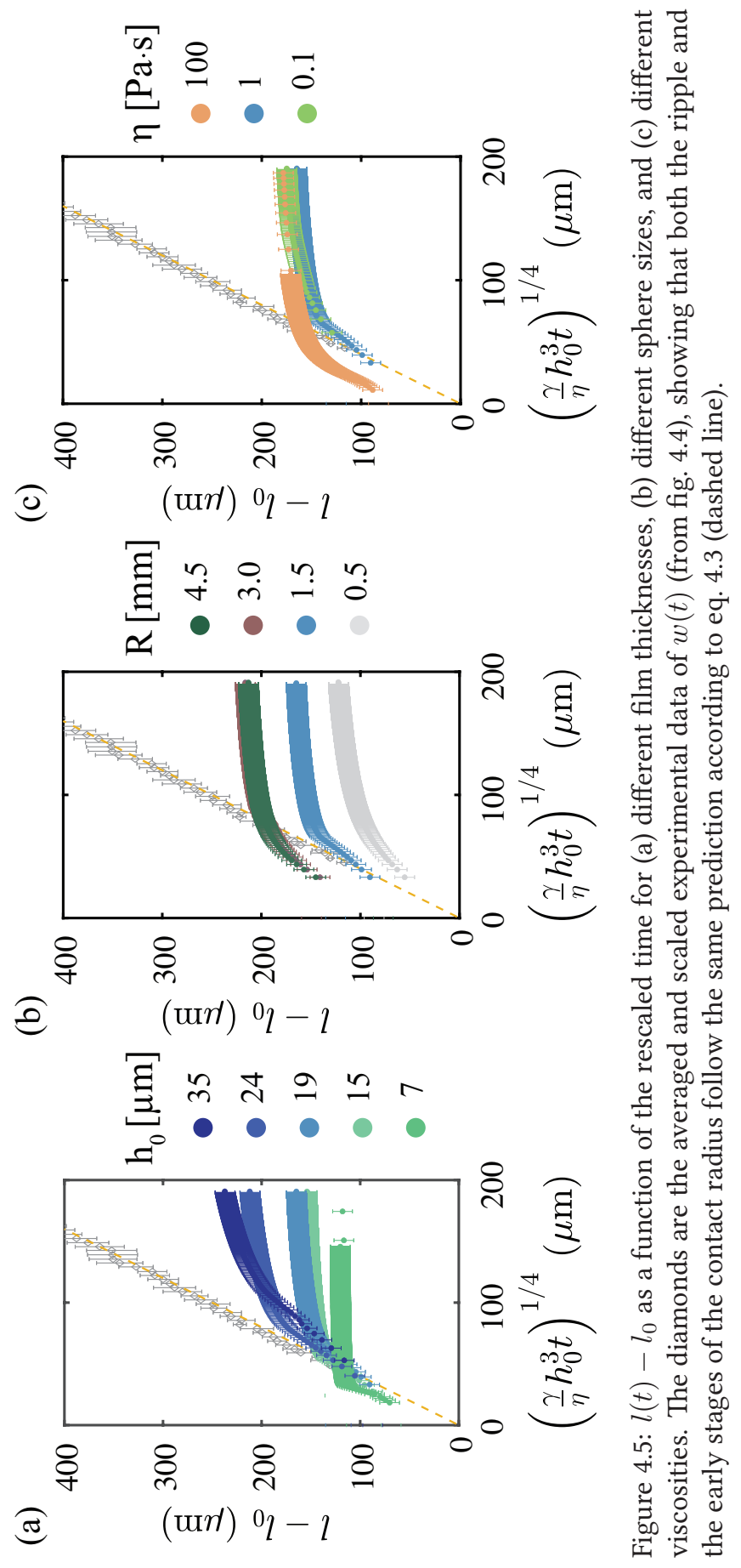


In fig. 4.5a, we see that the subtraction of $l_{0}$ accounts for the thickness dependence, as it leads to a collapse of the data during the early regime of growth of the contact radius. In addition, this fast growth dynamics coincides nearly perfectly with the ripple dynamics. Then, in the later stages, the ripple propagates more rapidly than the liquid bridge. This behaviour can be understood with the help of the side-view images in fig. 4.1. During the early stages, the dynamics of the liquid bridge is coupled to that of the ripple. This suggests that in this regime, the growth of the liquid bridge is limited by the transport by the flow inside the thin-film. At later times, the ripple moves freely over the oil surface, detached from the meniscus, still obeying the same scaling law (eq. 4.3). In contrast, we observe that the growth of the contact radius is slowed down. This suggests that in this second regime, the growth of the liquid bridge is no longer limited by the fluid transport in the thin filmwe hypothesise that in this regime, the bridge radius is dictated by the speed of the contact line moving up the sphere. Qualitatively, the same dynamics is observed in figs. $4.5 \mathrm{~b}$ and c, which highlight the effect of sphere radius and viscosity. While the collapse at early times is less compelling than in fig. $4.5 \mathrm{a}$, the data are much more tightly grouped as compared to their unscaled form (cf. fig. $4.3 \mathrm{~b}, \mathrm{c}$ ).

In summary, we conclude that at early stages, the growth in contact radius $l(t)-l_{0}$ follows the motion of the ripple, suggesting that the bridge growth is limited by the thin film flow. Subsequently, the ripple detaches from the meniscus; this marks the second regime where the bridge growth slows down.

\subsubsection{Contact angles and capillary forces}

We now turn our attention to the contact angle that the spreading bridge attains with respect to the sphere. This serves two purposes; first, we would like to investigate whether the slow second regime can be correlated to the "usual" slow dynamics associated with the motion of contact lines. Second, we are interested in estimating the force of capillary adhesion, for which the contact angle is an essential parameter.

Figure 4.6a illustrates how the contact angle has been determined experimentally. We apply a fit to the meniscus using the catenary shape [27], shown as the yellow dashed line, which offers an accurate description of the profile in the vicinity of the contact line. The contact line position follows from the intersection of this fit with the contour of the sphere (indicated by the red marker). Finally, we determine the angle $\theta$ from these intersections. We remark that these optical measurements of the contact angle are only possible for relatively thick oil films $\left(h_{0}>40 \mu \mathrm{m}\right)$ and at late times $(t>0.1 \mathrm{~s})$. This limitation arises from the spatial resolution, as we require sufficient contrast to accurately resolve the meniscus.

Figure 4.6b shows the resulting contact angle as a function of time. It is clear that the contact angle of the oil is initially not negligible. The angle is as large as $\theta \approx 0.6 \mathrm{rad}$ $\left(34^{\circ}\right)$. The contact angle decreases as time passes, and at late times seems to approach $\theta \rightarrow 0$, though we remark an increasing difficulty to accurately resolve the angle. To obtain further insight, we report the same data by plotting $\theta^{3}$ versus the velocity at which the contact line moves with respect to the sphere (inset of fig. 4.6b). The data now exhibits a 
linear dependence, which is in line with the classical Tanner's law for the dynamic contact angle [126]. In addition, the data extrapolates to $\theta \approx 0$ in the limit of small velocity, i.e. at late times where equilibrium is approached. This vanishing of the contact angle implies that the contact line is subjected to complete wetting conditions, as is expected for oil on polished glass. Hence, the contact line motion during the slow phase is observed to follow the classical laws of wetting dynamics.

With this information in hand, we are now in a position to determine the capillary force exerted by the liquid bridge onto the sphere. For a static liquid bridge with $l \ll R$, the capillary force is given by [114]

$$
F \simeq 2 \pi \gamma l \sin (\theta+\beta),
$$

which represents the vertical projection of the pulling force of the contact line on the sphere. In this expression, $\beta=\arcsin (l / R)$ is the polar angle that indicates the contact line position on the sphere. This expression assumes that the contributions due to the pressure (Laplace pressure complemented with viscous stress) is negligible compared to the contact line force. In a purely static situation, this is naturally justified for $l \ll R$, while in the present dynamical case, we assume, in line with Tanner's law, that viscous effects are effectively accounted for by the dynamic contact angle. 

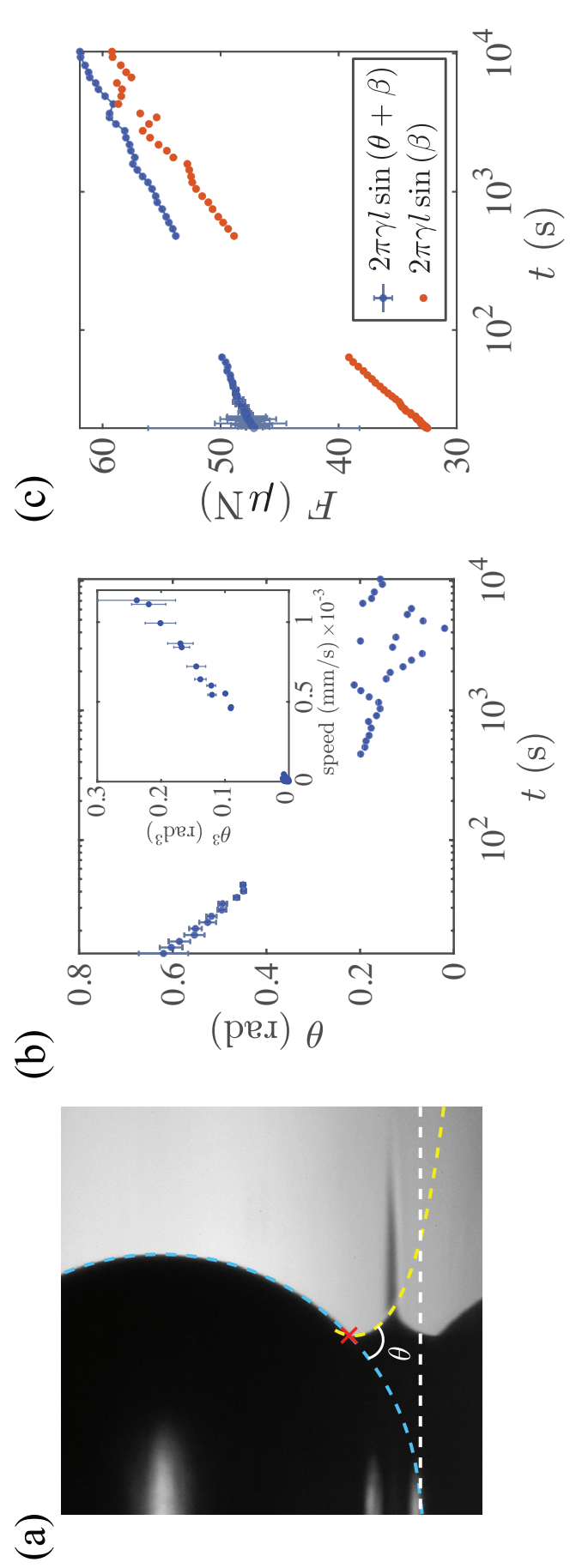

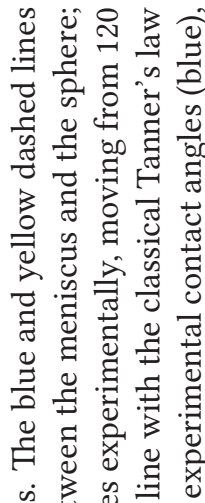

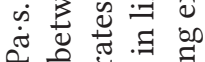

8 की पुछ

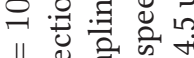

- क्षे छ छ

है

클.

न

घี తี ญे

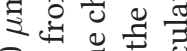

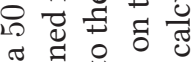

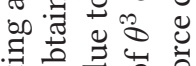

U. 0 \%

苛司至

०

ฮี สี ป ช

के प्र के प्च

घี 节艺芯

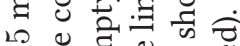

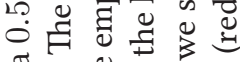

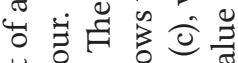

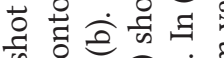

นิ

कै

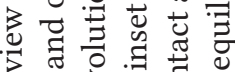

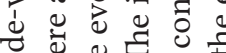

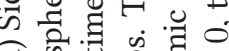

त्र की

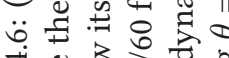

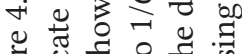

덩

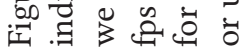


Using eq. 4.5, we combine the measurements of $l(t)$ and $\theta(t)$ to compute the capillary adhesion force as a function of time. The result is shown in fig. 4.6c, as the blue data points. Indeed, one observes an adhesion force that is far from static but which exhibits a slow time dependence, which is followed over nearly three decades in time. This slow evolution mimics the slow dynamics of the liquid bridge in the second regime; we remind that contact angles could only be measured when the meniscus is sufficiently large, which in practice coincides with the second (slow) regime of bridge growth. In the early regime, it is still possible to measure $l(t)$; one could therefore be tempted to approximate the capillary force by assuming a nearly vanishing contact angle, i.e. by using eq. 4.5 with $\theta=0$. The approximation $\theta=0$ is also given in fig. 4.6c, plotted as the red data. While it gives an estimate for the order of magnitude of the force and its time-dependence, it is clear that this approximation significantly underestimates the actual capillary force. The reason for this is that the finite $\theta$ due to the moving contact line reorients the liquid-air interface-thereby significantly increasing its vertical projection-which leads to an increase of the capillary force. These findings underline the importance of the dynamic contact angle in the dynamical formation of the liquid bridge and the resulting capillary adhesion.

\subsection{Summary and Conclusions}

When bringing spherical particles into contact with a thin viscous film, a liquid meniscus is formed. Following the growth of the contact radius, we find two dynamic regimes (even while being far from total engulfment by the oil film); first, a fast-growing regime, and then, a slow-growing one. We find these two regimes consistently for different combinations of film thickness, viscosity, and sphere's radius. Following the deformation on the oil's surface, we find a wave-like structure (ripple) that precedes the liquid bridge and widens over time $t$. The widening of this ripple exhibits a $t^{1 / 4}$ dependence. This scaling can also be derived by scaling arguments based on thin-film (lubrication) theory. The temporal scaling of the fast dynamics of the meniscus growth agrees with that of the ripple's width. This correlation leads us to propose that the early stage of the liquid bridge growth is limited by the ripple dynamics, i.e. the flow in the thin film. The transition between the two dynamic regimes is related to the detachment of the oil ripple from the liquid bridge. The second, slower bridge growth regime, is dominated by the wetting dynamics on the surface of the glass, related to the dynamic contact angle of the moving contact line.

A consequence of the meniscus dynamics is that the adhesion force is highly timedependent, as both the contact angle and the contact radius evolve in time. During the early stages of the contact, a simple estimation of the adhesion force is challenging due to the dynamic contact angle. At later stages, the contact angle is close to its equilibrium value, but care must be taken that the adhesion force continues to evolve gradually due to the prolonged evolution of the contact radius. 


\section{Bibliography}

[1] O. E. Butler, Parable of the Sower (Headline Publishing Group) (1993).

[2] D. Vella, "Floating versus sinking”, Annu. Rev. Fluid Mech. 47, 115-135 (2015).

[3] J. Bico, B. Roman, L. Moulin, and A. Boudaoud, "Elastocapillary coalescence in wet hair”, Nature 432, 690-690 (2004).

[4] B. Pokroy, S. H. Kang, L. Mahadevan, and J. Aizenberg, "Self-organization of a mesoscale bristle into ordered, hierarchical helical assemblies”, Science 323, 237-240 (2009).

[5] T. Tanaka, M. Morigami, and N. Atoda, "Mechanism of resist pattern collapse during development process”, Jpn. J. Appl. Phys. 32, 6059-6064 (1993).

[6] J. Feeney and J. Fitzpatrick, "Visualization of the caking behavior between two powder particles”, Part. Sci. Technol. 29, 397-406 (2011).

[7] P. Tegzes, R. Albert, M. Paskvan, A.-L. Barabási, T. Vicsek, and P. Schiffer, "Liquidinduced transitions in granular media”, Phys. Rev. E 60, 5823 (1999).

[8] L. Böttcher, "Glass of water", URL https://pixabay.com/photos/ cup-water-glass-poloplny-thirst-4591710/.

[9] S. Molnar, "Wet fur", URL https://pixabay.com/photos/ fur-wet-dog-furry-hair-animal-6159866/.

[10] A. Malec, "Droplets on hydrophobic texture", URL https : / /pixabay . com/ photos/droplets-hydrophobic-water-texture-2262304/.

[11] A. Marchand, J. H. Weijs, J. H. Snoeijer, and B. Andreotti, "Why is surface tension a force parallel to the interface?”, Am. J. Phys. 79, 999-1008 (2011).

[12] T. Young, "III. an essay on the cohesion of fluids", Philos. Trans. R. Soc. Lond. 65-87 (1805).

[13] J. Bico, E. Reyssat, and B. Roman, "Elastocapillarity: When surface tension deforms elastic solids”, Annu. Rev. Fluid Mech. 50, 629-659 (2018).

[14] B. Roman and J. Bico, "Elasto-capillarity: deforming an elastic structure with a liquid droplet”, J. Phys. Condens. Matter 22, 493101 (2010). 
[15] B. Andreotti and J. H. Snoeijer, "Statics and dynamics of soft wetting", Annu. Rev. Fluid Mech. 52, 285-308 (2020).

[16] R. W. Style, A. Jagota, C.-Y. Hui, and E. R. Dufresne, "Elastocapillarity: Surface tension and the mechanics of soft solids”, Annu. Rev. Condens. Matter Phys. 8, 99-118 (2017).

[17] S. B. Sameh H. Tawfick, José Bico, "Three-dimensional lithography by elasto-capillary engineering of filamentary materials", MRS Bull. 41, 108-114 (2016).

[18] A. Nasto, M. Regli, P.-T. Brun, J. Alvarado, C. Clanet, and A. Hosoi, “Air entrainment in hairy surfaces", Phys. Rev. Fluid 1, 033905 (2016).

[19] C. Duprat, S. Protiere, A. Beebe, and H. A. Stone, "Wetting of flexible fibre arrays", Nature 482, 510 (2012).

[20] A. E. Cohen and L. Mahadevan, "Kinks, rings, and rackets in filamentous structures", Proc. Natl. Acad. Sci. U.S.A. 100, 12141-12146 (2003).

[21] C. Duprat, J. M. Aristoff, and H. A. Stone, "Dynamics of elastocapillary rise”, J. Fluid Mech. 679, 641-654 (2011).

[22] C. Py, R. Bastien, J. Bico, B. Roman, and A. Boudaoud, “3D aggregation of wet fibers”, EPL 77, 44005 (2007).

[23] H.-Y. Kim and L. Mahadevan, "Capillary rise between elastic sheets", J. Fluid Mech. 548, 141-150 (2006).

[24] M. Taroni and D. Vella, "Multiple equilibria in a simple elastocapillary system”, J. Fluid Mech. 712, 273-294 (2012).

[25] C. Neinhuis and W. Barthlott, "Characterization and distribution of water-repellent, self-cleaning plant surfaces”, Ann. Bot. 79, 667-677 (1997).

[26] W. Barthlott and C. Neinhuis, "Purity of the sacred lotus, or escape from contamination in biological surfaces”, Planta 202, 1-8 (1997).

[27] P.-G. De Gennes, F. Brochard-Wyart, and D. Quéré, Capillarity and wetting phenomena: drops, bubbles, pearls, waves, volume 336 (Springer) (2004).

[28] J. Bico, C. Tordeux, and D. Quéré, “Rough wetting”, EPL 55, 214 (2001).

[29] J. Bico, U. Thiele, and D. Quéré, "Wetting of textured surfaces", Colloids Surf. A Physicochem. Eng. Asp. 206, 41-46 (2002).

[30] D. Quéré, "Wetting and roughness”, Annu. Rev. Mater. Res. 38, 71-99 (2008).

[31] S. Herminghaus, "Roughness-induced non-wetting”, EPL 52, 165 (2000).

[32] J. Bico, C. Marzolin, and D. Quéré, “Pearl drops”, EPL 47, 220 (1999).

[33] S. J. Kim, M.-W. Moon, K.-R. Lee, D.-Y. Lee, Y. S. Chang, and H.-Y. Kim, "Liquid spreading on superhydrophilic micropillar arrays”, J. Fluid Mech. 680, 477-487 (2011). 
[34] P. Papadopoulos, L. Mammen, X. Deng, D. Vollmer, and H.-J. Butt, "How superhydrophobicity breaks down”, Proc. Natl. Acad. Sci. U.S.A. 110, 3254-3258 (2013).

[35] X.-M. Li, D. Reinhoudt, and M. Crego-Calama, "What do we need for a superhydrophobic surface? a review on the recent progress in the preparation of superhydrophobic surfaces", Chem. Soc. Rev. 36, 1350-1368 (2007).

[36] H.-J. Butt, D. Vollmer, and P. Papadopoulos, "Super liquid-repellent layers: The smaller the better”, Adv. Colloid Interface Sci. 222, 104-109 (2015).

[37] H.-J. Butt, I. V. Roisman, M. Brinkmann, P. Papadopoulos, D. Vollmer, and C. Semprebon, "Characterization of super liquid-repellent surfaces", Curr. Opin. Colloid Interface Sci. 19, 343-354 (2014).

[38] L. Mammen, X. Deng, M. Untch, D. Vijayshankar, P. Papadopoulos, R. Berger, E. Riccardi, F. Leroy, and D. Vollmer, "Effect of nanoroughness on highly hydrophobic and superhydrophobic coatings", Langmuir 28, 15005-15014 (2012).

[39] E. Bormashenko, "Progress in understanding wetting transitions on rough surfaces", Adv. Colloid Interface Sci. 222, 92-103 (2015).

[40] Y. Xue, P. Lv, H. Lin, and H. Duan, "Underwater superhydrophobicity: Stability, design and regulation, and applications”, Appl. Mech. Rev. 68, 030803 (2016).

[41] D. Wang, Q. Sun, M. J. Hokkanen, C. Zhang, F.-Y. Lin, Q. Liu, S.-P. Zhu, T. Zhou, Q. Chang, B. He, et al., "Design of robust superhydrophobic surfaces", Nature 582, 55-59 (2020).

[42] J. Song, D. Zhao, Z. Han, W. Xu, Y. Lu, X. Liu, B. Liu, C. J. Carmalt, X. Deng, and I. P. Parkin, "Super-robust superhydrophobic concrete", J. Mater. Chem. A 5, 14542-14550 (2017).

[43] P. Lv, Y. Xue, H. Liu, Y. Shi, P. Xi, H. Lin, and H. Duan, "Symmetric and asymmetric meniscus collapse in wetting transition on submerged structured surfaces", Langmuir 31, 1248-1254 (2015).

[44] A. M. Mohamed, A. M. Abdullah, and N. A. Younan, "Corrosion behavior of superhydrophobic surfaces: A review”, Arab. J. Chem. 8, 749-765 (2015).

[45] M. Reyssat, J. M. Yeomans, and D. Quéré, "Impalement of fakir drops", EPL 81, 26006 (2007).

[46] P. Tsai, R. G. Lammertink, M. Wessling, and D. Lohse, "Evaporation-triggered wetting transition for water droplets upon hydrophobic microstructures”, Phys. Rev. Lett. 104, $116102(2010)$.

[47] A. Lafuma and D. Quéré, "Superhydrophobic states”, Nat. Mater. 2, 457 (2003).

[48] P. Papadopoulos, B.-E. Pinchasik, M. Tress, D. Vollmer, M. Kappl, and H.-J. Butt, "Wetting of soft superhydrophobic micropillar arrays", Soft Matter 14, 7429-7434 (2018). 
[49] M. De Volder, S. H. Tawfick, S. J. Park, D. Copic, Z. Zhao, W. Lu, and A. J. Hart, "Diverse $3 \mathrm{~d}$ microarchitectures made by capillary forming of carbon nanotubes", Adv. Mater. 22, 4384-4389 (2010).

[50] M. F. L. D. Volder, S. J. Park, S. H. Tawfick, D. O. Vidaud, and A. J. Hart, "Fabrication and electrical integration of robust carbon nanotube micropillars by self-directed elastocapillary densification”, J. Micromech. Microeng. 21, 045033 (2011).

[51] T. Tanaka, M. Morigami, H. Oizumi, T. Soga, T. Ogawa, and F. Murai, "Prevention of resist pattern collapse by resist heating during rinsing", J. Electrochem. Soc. 141, L169-L171 (1994).

[52] S. H. Kang, B. Pokroy, L. Mahadevan, and J. Aizenberg, "Control of shape and size of nanopillar assembly by adhesion-mediated elastocapillary interaction", ACS Nano 4, 6323-6331 (2010), pMID: 21038896.

[53] M. De Volder and A. J. Hart, "Engineering hierarchical nanostructures by elastocapillary self-assembly”, Angew. Chem. 52, 2412-2425 (2013).

[54] Maryamassimi, "Glitter in hand", URL https://pixabay.com/photos/ glitter-pink-water-shiny-bright-2500318/.

[55] J. Cigánek, "Powder, holi", URL https://pixabay.com/photos/ colors-powder-color-holi-portrait-3185020/.

[56] J. T. Pham, F. Schellenberger, M. Kappl, and H.-J. Butt, "From elasticity to capillarity in soft materials indentation”, Phys. Rev. Mater. 1, 015602 (2017).

[57] M. A. Hack, M. Costalonga, T. Segers, S. Karpitschka, H. Wijshoff, and J. H. Snoeijer, "Printing wet-on-wet: Attraction and repulsion of drops on a viscous film", Appl. Phys. Lett. 113, 183701 (2018).

[58] D. Hornbaker, R. Albert, I. Albert, A.-L. Barabási, and P. Schiffer, "What keeps sandcastles standing?", Nature 387, 765-765 (1997).

[59] M. Schenk, M. Füting, and R. Reichelt, "Direct visualization of the dynamic behavior of a water meniscus by scanning electron microscopy”, J. Appl. Phys. 84, 4880-4884 (1998).

[60] L.-Y. Zhu, "Strength and stability of a meniscus in a slider-disk interface", IEEE Trans. Magn 35, 2415-2417 (1999).

[61] Y. Li and F. E. Talke, "A model for the effect of humidity on stiction of the head/disk interface”, Tribol. Trans. 35, 429-434 (1992).

[62] P. Tegzes, T. Vicsek, and P. Schiffer, "Avalanche dynamics in wet granular materials", Phys. Rev. Lett. 89, 094301 (2002).

[63] S. Herminghaus, "Dynamics of wet granular matter", Adv. Phys. 54, 221-261 (2005). 
[64] F. Schellenberger, P. Papadopoulos, M. Kappl, S. A. L. Weber, D. Vollmer, and H.-J. Butt, "Detaching microparticles from a liquid surface", Phys. Rev. Lett. 121, 048002 (2018).

[65] O. Pitois and X. Chateau, "Small particle at a fluid interface: Effect of contact angle hysteresis on force and work of detachment”, Langmuir 18, 9751-9756 (2002).

[66] C.-Y. Hui, T. Liu, T. Salez, E. Raphael, and A. Jagota, "Indentation of a rigid sphere into an elastic substrate with surface tension and adhesion”, Proc. R. Soc. A. 471, 20140727 (2015).

[67] S. Karpitschka, L. van Wijngaarden, and J. H. Snoeijer, "Surface tension regularizes the crack singularity of adhesion", Soft Matter 12, 4463-4471 (2016).

[68] J. D. Glover and J. T. Pham, "Capillary-driven indentation of a microparticle into a soft, oil-coated substrate", Soft Matter 16, 5812-5818 (2020).

[69] T. Salez, J. D. McGraw, O. Bäumchen, K. Dalnoki-Veress, and E. Raphaël, "Capillarydriven flow induced by a stepped perturbation atop a viscous film”, Phys. Fluids 24, 102111 (2012).

[70] J. D. McGraw, T. Salez, O. Bäumchen, E. Raphaël, and K. Dalnoki-Veress, "Selfsimilarity and energy dissipation in stepped polymer films”, Phys. Rev. Lett. 109, 128303 (2012).

[71] L. E. Stillwagon and R. G. Larson, "Fundamentals of topographic substrate leveling", J. Appl. Phys. 63, 5251-5258 (1988).

[72] M. Jalaal, C. Seyfert, and J. H. Snoeijer, "Capillary ripples in thin viscous films", J. Fluid Mech. 880, 430-440 (2019).

[73] S. Lakshman, W. Tewes, K. Harth, J. H. Snoeijer, and D. Lohse, "Deformation and relaxation of viscous thin films under bouncing drops”, J. Fluid Mech. 920, A3 (2021).

[74] D. Chandra and S. Yang, "Capillary-force-induced clustering of micropillar arrays: Is it caused by isolated capillary bridges or by the lateral capillary meniscus interaction force?”, Langmuir 25, 10430-10434 (2009), pMID: 19735125.

[75] A. Cassie and S. Baxter, "Wettability of porous surfaces", Trans. Faraday Soc. 40, 546551 (1944).

[76] S. Neukirch, B. Roman, Benoît, and J. Bico, "Piercing a liquid surface with an elastic rod: Buckling under capillary forces”, J. Mech. Phys. Solids 55, 1212-1235 (2007).

[77] A. Hadjittofis, J. R. Lister, K. Singh, and D. Vella, "Evaporation effects in elastocapillary aggregation”, J. Fluid Mech. 792, 168-185 (2016).

[78] D. Chandra and S. Yang, "Stability of high-aspect-ratio micropillar arrays against adhesive and capillary forces”, Acc. Chem. Res. 43, 1080-1091 (2010), pMID: 20552977.

[79] H. Duan and K. K. Berggren, "Directed self-assembly at the $10 \mathrm{~nm}$ scale by using capillary force-induced nanocohesion”, Nano Lett. 10, 3710-3716 (2010), pMID: 20704183. 
[80] D. Chandra, S. Yang, A. A. Soshinsky, and R. J. Gambogi, "Biomimetic ultrathin whitening by capillary-force-induced random clustering of hydrogel micropillar arrays”, ACS Appl. Mater. Interfaces 1, 1698-1704 (2009), pMID: 20355785.

[81] F. Chiodi, B. Roman, and J. Bico, "Piercing an interface with a brush: Collaborative stiffening”, EPL 90, 44006 (2010).

[82] K. Singh, J. R. Lister, and D. Vella, "A fluid-mechanical model of elastocapillary coalescence”, J. Fluid Mech. 745, 621-646 (2014).

[83] D. Qin, Y. Xia, and G. M. Whitesides, "Soft lithography for micro- and nanoscale patterning”, Nat. Protoc. 5, 491-502 (2010).

[84] B. Goodno and J. Gere, Mechanics of Materials, SI Edition (Cengage Learning) (2017).

[85] K. L. Johnson, K. Kendall, and A. Roberts, "Surface energy and the contact of elastic solids”, Proc. R. Soc. Lond.A. 324, 301-313 (1971).

[86] K. L. Johnson, Contact Mechanics (Cambridge University Press) (1985).

[87] F. Schneider, J. Draheim, R. Kamberger, and U. Wallrabe, "Process and material properties of polydimethylsiloxane (pdms) for optical mems”, Sens. Actuator A-Phys. 151, 95-99 (2009).

[88] X. Zhang, F. Shi, J. Niu, Y. Jiang, and Z. Wang, "Superhydrophobic surfaces: from structural control to functional application”, J. Mater. Chem. 18, 621-633 (2008).

[89] K. Liu and L. Jiang, "Bio-inspired self-cleaning surfaces”, Annu. Rev. Mater. Sci. 42, 231-263 (2012).

[90] J. Genzer and K. Efimenko, "Recent developments in superhydrophobic surfaces and their relevance to marine fouling: a review", Biofouling 22, 339-360 (2006).

[91] M. Azad, D. Ellerbrok, W. Barthlott, and K. Koch, "Fog collecting biomimetic surfaces: Influence of microstructure and wettability”, Bioinspir. Biomim. 10, 016004 (2015).

[92] X. Gao, X. Yan, X. Yao, L. Xu, K. Zhang, J. Zhang, B. Yang, and L. Jiang, “The dry-style antifogging properties of mosquito compound eyes and artificial analogues prepared by soft lithography”, Adv. Mater. 19, 2213-2217 (2007).

[93] M. J. Kreder, J. Alvarenga, P. Kim, and J. Aizenberg, "Design of anti-icing surfaces: smooth, textured or slippery?”, Nat. Rev. Mater. 1, 1-15 (2016).

[94] R. J. Daniello, N. E. Waterhouse, and J. P. Rothstein, "Drag reduction in turbulent flows over superhydrophobic surfaces”, Phys. Fluids 21, 085103 (2009).

[95] F. Geyer, C. Schönecker, H.-J. Butt, and D. Vollmer, "Enhancing CO2 capture using robust superomniphobic membranes", Adv. Mater. 29, 1603524 (2017).

[96] B. Bhushan and Y. C. Jung, "Natural and biomimetic artificial surfaces for superhydrophobicity, self-cleaning, low adhesion, and drag reduction”, Prog. Mater. Sci. 56, 1-108 (2011). 
[97] K. K. Lau, J. Bico, K. B. Teo, M. Chhowalla, G. A. Amaratunga, W. I. Milne, G. H. McKinley, and K. K. Gleason, "Superhydrophobic carbon nanotube forests", Nano Lett. 3, 1701-1705 (2003).

[98] N. A. Patankar, "Mimicking the lotus effect: influence of double roughness structures and slender pillars”, Langmuir 20, 8209-8213 (2004).

[99] L. Gao and T. J. McCarthy, "A commercially available perfectly hydrophobic material $(\theta \mathrm{a} / \theta \mathrm{r}=180 / 180)$ ”, Langmuir 23, 9125-9127 (2007).

[100] X. Deng, L. Mammen, H.-J. Butt, and D. Vollmer, "Candle soot as a template for a transparent robust superamphiphobic coating”, Science 335, 67-70 (2012).

[101] X. Yao, Q. Chen, L. Xu, Q. Li, Y. Song, X. Gao, D. Quéré, and L. Jiang, "Bioinspired ribbed nanoneedles with robust superhydrophobicity", Adv. Funct. Mater. 20, 656$662(2010)$.

[102] W. Fang, H.-Y. Guo, B. Li, Q. Li, and X.-Q. Feng, "Revisiting the critical condition for the cassie-wenzel transition on micropillar-structured surfaces”, Langmuir 34, 38383844 (2018).

[103] J. Li, "Characterization for cassie-wenzel wetting transition based on the force response in the process of squeezing liquid drops by two parallel superhydrophobic surfaces”, Rev. Sci. Instrum. 87, 065108 (2016).

[104] L. Zhang, M. D’Acunzi, M. Kappl, A. Imhof, A. van Blaaderen, H.-J. Butt, R. Graf, and D. Vollmer, "Tuning the mechanical properties of silica microcapsules", Phys. Chem. Chem. Phys 12, 15392-15398 (2010).

[105] Q.-S. Zheng, Y. Yu, and Z.-H. Zhao, "Effects of hydraulic pressure on the stability and transition of wetting modes of superhydrophobic surfaces", Langmuir 21, 1220712212 (2005).

[106] M. Sbragaglia, A. M. Peters, C. Pirat, B. M. Borkent, R. G. Lammertink, M. Wessling, and D. Lohse, "Spontaneous breakdown of superhydrophobicity", Phys. Rev. Lett. 99, 156001 (2007).

[107] C. Pirat, M. Sbragaglia, A. Peters, B. Borkent, R. G. Lammertink, M. Wessling, and D. Lohse, "Multiple time scale dynamics in the breakdown of superhydrophobicity", EPL 81, 66002 (2008).

[108] F. Schellenberger, N. Encinas, D. Vollmer, and H.-J. Butt, "How water advances on superhydrophobic surfaces”, Phys. Rev. Lett. 116, 096101 (2016).

[109] K. P. Hapgood and B. Khanmohammadi, "Granulation of hydrophobic powders", Powder Technol. 189, 253-262 (2009).

[110] R. Fisher, "On the capillary forces in an ideal soil; correction of formulae given by wb haines”, J Agric Sci. 16, 492-505 (1926). 
[111] H. Li and J. McCarthy, "Cohesive particle mixing and segregation under shear", Powder Technol. 164, 58-64 (2006).

[112] S. Hartland, "The approach of a rigid sphere to a deformable liquid/liquid interface", J. Colloid Interface Sci. 26, 383-394 (1968).

[113] D.-G. Lee and H.-Y. Kim, "The role of superhydrophobicity in the adhesion of a floating cylinder”, J. Fluid Mech. 624, 23-32 (2009).

[114] H.-J. Butt and M. Kappl, "Normal capillary forces", Adv. Colloid Interface Sci. 146, 48-60 (2009).

[115] J. Ally, E. Vittorias, A. Amirfazli, M. Kappl, E. Bonaccurso, C. E. McNamee, and H.-J. Butt, "Interaction of a microsphere with a solid-supported liquid film", Langmuir 26, 11797-11803 (2010).

[116] A. P. Bowles, Y.-T. Hsia, P. M. Jones, L. R. White, and J. W. Schneider, "Quasiequilibrium afm measurement of disjoining pressure in lubricant nanofilms ii: effect of substrate materials", Langmuir 25, 2101-2106 (2009).

[117] R. W. Style, C. Hyland, R. Boltyanskiy, J. S. Wettlaufer, and E. R. Dufresne, "Surface tension and contact with soft elastic solids", Nat. Commun. 4, 1-6 (2013).

[118] K. Hotta, K. Takeda, and K. Iinoya, "The capillary binding force of a liquid bridge", Powder Technol. 10, 231-242 (1974).

[119] W. Clark, J. Haynes, and G. Mason, "Liquid bridges between a sphere and a plane", Chem. Eng. Sci. 23, 810-812 (1968).

[120] H. N. G. Nguyen, O. Millet, and G. Gagneux, "Liquid bridges between a sphere and a plane-classification of meniscus profiles for unknown capillary pressure", Math. Mech. Solids 24, 3042-3060 (2019).

[121] C. Clanet and D. Quéré, “Onset of menisci”, J. Fluid Mech. 460, 131-149 (2002).

[122] A.-L. Biance, C. Clanet, and D. Quéré, "First steps in the spreading of a liquid droplet", Phys. Rev. E 69, 016301 (2004).

[123] K. G. Winkels, J. H. Weijs, A. Eddi, and J. H. Snoeijer, "Initial spreading of lowviscosity drops on partially wetting surfaces”, Phys. Rev. E 85, 055301 (2012).

[124] J. C. Bird, S. Mandre, and H. A. Stone, "Short-time dynamics of partial wetting”, Phys. Rev. Lett. 100, 234501 (2008).

[125] M. K. Kim, "Principles and techniques of digital holographic microscopy", SPIE reviews 1, 018005 (2010).

[126] D. Bonn, J. Eggers, J. Indekeu, J. Meunier, and E. Rolley, "Wetting and spreading”, Rev. Mod. Phys. 81, 739 (2009). 


\section{Summary}

Capillary interactions are crucial for many aspects of our lives, from the shapes acquired by water drops on grass and leaves to scientific applications such as lithography and liquidmediated adhesion. In this thesis, we explore three systems where capillary interactions play a key role: Firstly, an evaporating drop on a soft micropillared substrate. Secondly, a drop being squeezed between two superhydrophobic surfaces, and thirdly, a glass sphere in contact with a thin viscous oil film.

In chapters 2 and 3 of this thesis, we deal with structured solids that display waterrepellent properties. In chapter 2, we start by investigating a soft microstructured surface: a polydimethylsiloxane (PDMS) micropillar array. Our experiments show how capillary forces can cause slender pillars on the array to deform and collapse onto one another. This had previously been studied. However, the kinematics of the process had remained unexplored due to the difficulty in imaging the individual menisci between the pillars at the time of the collapse. We visualized this process through confocal microscopy and found that a key ingredient in capillary self-assembly and collapse is the local contact angle of the meniscus between the pillars. We do this by imaging the impalement process of a water drop on the PDMS micropillar array in two scenarios: a classic superhydrophobic state (with air between the pillars) and an infused case (with FC-40 between the pillars). Our observations lead us to develop a simple model, with three consecutive 2D pillars, that includes the local contact angle, stiffness of the pillars, and interfacial tension to predict the onset of the structural collapse. The model accurately reproduces the onset of bundling seen in our experiments.

Chapter 3 moves on to rigid superhydrophobic micropillared surfaces. In that chapter, we focus on compression tests of a drop between two superhydrophobic surfaces. We image the compression of a water drop from the top while simultaneously measuring the compression force on one of the surfaces. The Cassie-to-Wenzel transition is evident in our experiments from both types of measurements, and with this, we calculate the experimental impalement pressure of our superhydrophobic surfaces. We then discuss our experimental results with the current impalement pressure estimations, which show that our experimental values lie below the current predictions. This emphasizes the difficulty in accurately assessing the pressure threshold for the Cassie-to-Wenzel transition with the current models.

In Chapter 4, we move on to smooth solids and study the formation and evolution of a liquid bridge between a sphere and a flat solid covered by a thin viscous film. In this 
chapter, we investigate the radial growth of the liquid bridge and its correlation with the dynamics present in the thin viscous film. Our experiments use a combination of imaging techniques; bright-field and digital holographic microscopy. This allows us to describe in detail the rich dynamics at play when a liquid bridge is forming from a thin viscous layer. We reveal that the liquid bridge growth displays two distinct dynamic regimes: an early fast-growing regime, and a late slow-growing regime. This is of particular importance as a dynamic liquid bridge gives rise to time-dependent capillary adhesion forces. 


\section{Síntesis}

Las interacciones capilares son cruciales para muchos aspectos de nuestra vida, desde las formas que adquieren las gotas de agua en hojas y plantas hasta aplicaciones científicas como litografía y procesos que incorporen adhesión mediada por líquidos. En esta tesis, exploramos tres sistemas en los que las interacciones capilares desempeñan un papel fundamental: En primer lugar, una gota que se evapora sobre un sustrato cuya superficie esta llena de micropilares delgados y blandos. En segundo lugar, una gota que se comprime entre dos superficies superhidrofóbicas rígidas, y en tercer lugar, una esfera de vidrio en contacto con una película fina de aceite viscoso.

En los capítulos 2 y 3 de esta tesis, estudiamos sólidos estructurados que muestran propiedades que repelen al agua; superhidrofóbicos. En el capítulo 2, comenzamos investigando una superficie microestructurada y blanda: un conjunto de micropilares de polidimetilsiloxano (PDMS). Nuestros experimentos muestran cómo las fuerzas capilares pueden hacer que los pilares de la matriz se deformen y colapsen unos sobre otros creando diferentes patrones geométricos a través de este proceso de autoasemblaje. Esto se había estudiado anteriormente. Sin embargo, la cinemática del proceso había permanecido inexplorada debido a la dificultad de obtener imágenes de los meniscos individuales entre los pilares al momento del colapso. Nosotros visualizamos precisamente este proceso mediante microscopía confocal y descubrimos que un ingrediente clave en el colapso y subsecuente autoensamblaje de las estructuras es el ángulo de contacto local del menisco entre los pilares. Para ello, visualizamos el proceso por el cual una gota de agua pasa de estar suspendida sobre el conjunto de micropilares de PDMS a mojar toda la superficie entre los pilares. Visualizamos esto en dos escenarios: un estado superhidrófobico clásico (con aire entre los pilares) y un caso en el cual introducimos otro líquido (FC-40) entre los pilares. Nuestras observaciones nos llevan a desarrollar un modelo sencillo, con tres pilares bidimensionales consecutivos, que incluye el ángulo de contacto local, la rigidez de los pilares y la tensión interfacial para predecir el inicio del colapso estructural. El modelo reproduce con exactitud el inicio del colapso y autoasemblaje observado en nuestros experimentos.

El capítulo 3 se centra en superficies superhidrófobicas con micropilares rígidos. En ese capítulo, nos centramos en pruebas de compresión de una gota entre dos superficies superhidrofóbicas. Visualizamos la compresión de una gota de agua desde arriba mientras medimos simultáneamente la fuerza de compresión en una de las superficies. La transición del estado Cassie (superhidrófobico) al estado Wenzel (completamente mojado) es evidente a partir de ambos tipos de mediciones, y con ello calculamos la presión experimental nece- 
saria para obtener esta transición de estado en nuestras superficies superhidrofóbicas. A continuación, discutimos nuestros resultados con las estimaciones actuales de dicha presión. La comparación muestra que los valores experimentales se sitúan por debajo de las predicciones, lo cual recalca la dificultad de evaluar con precisión el umbral de presión para la transición de Cassie a Wenzel con los modelos actuales.

En el capítulo 4, pasamos de solidos microestructurados a sólidos lisos. Ahí estudiamos la formación y evolución de un puente líquido formado entre una esfera y un plano cubierto por una película delgada y viscosa de aceite. En este capítulo, investigamos el crecimiento radial del puente líquido y su correlación con la dinámica presente en la superficie de la película viscosa delgada conectada a él. Nuestros experimentos combinan diferentes técnicas de experimentales: microscopía de campo claro y microscopía holográfica digital. Esto nos permite describir con mucho detalle la creación y evolución del puente líquido formado a partir de la película viscosa delgada. Con nuestros experimentos mostramos que el crecimiento del puente líquido tiene dos regímenes dinámicos distintos; uno rápido al inicio del proceso y uno lento al final. Este resultado es clave ya que la evolución dinámica del puente líquido implica que las fuerzas de adhesión capilar dependen también del tiempo. 


\section{Samenvatting}

Capillaire interacties zijn cruciaal voor vele aspecten van ons leven, van de vormen die waterdruppels aannemen op gras en bladeren tot wetenschappelijke toepassingen zoals lithografie en vloeistof-gemedieerde adhesie. In dit proefschrift onderzoeken we drie systemen waarin capillaire interacties een sleutelrol spelen: Ten eerste, een verdampende druppel op een zacht substraat met micropilaren. Ten tweede, een druppel die samengeperst wordt tussen twee superhydrofobe oppervlakken, en ten derde, een glazen bol in contact met een dunne viskeuze olielaag.

In de hoofdstukken 2 en 3 van dit proefschrift behandelen we gestructureerde oppervlakken die waterafstotende eigenschappen vertonen. In hoofdstuk 2 beginnen we met het onderzoeken van een zacht microgestructureerd oppervlak: een rooster van polydimethylsiloxaan (PDMS) micropilaren. Onze experimenten laten zien hoe capillaire krachten kunnen leiden tot vervorming en ineenstorting van slanke pilaartjes. Dit was al eerder bestudeerd, echter de kinematica van het proces was nog niet goed begrepen omdat het moeilijk is om de individuele menisci tussen de pilaren in beeld te brengen op het moment van de ineenstorting. We visualiseerden dit proces door middel van confocale microscopie en vonden dat de lokale contacthoek van de meniscus tussen de pilaren een belangrijke rol speelt in de capillaire zelfassemblage en ineenstorting. We doen dit door het in beeld te brengen van een waterdruppel die spietst op een rooster van PDMS micropilaren voor twee gevallen: een klassieke superhydrofobe staat (met lucht tussen de pijlers) en een doordrenkte staat (met FC-40 tussen de pijlers). Onze waarnemingen leidden tot de ontwikkeling van een eenvoudig model met drie opeenvolgende 2D pilaren, dat de lokale contacthoek, de stijfheid van de pilaren en de oppervlaktespanning omvat om het begin van de structurele ineenstorting te voorspellen. Het model reproduceert nauwkeurig het begin van de bundeling zoals waargenomen in onze experimenten.

Hoofdstuk 3 gaat verder met starre superhydrofobische oppervlakken met micropilaren. In dat hoofdstuk richten we ons op compressietesten van een druppel tussen twee superhydrofobe oppervlakken. We brengen de compressie van een waterdruppel van bovenaf in beeld en meten tegelijkertijd de compressiekracht op een van de oppervlakken. De Cassienaar-Wenzel-overgang is duidelijk aanwezig in onze experimenten voor beide typen metingen, en hiermee berekenen we de experimentele druk van onze superhydrofobe oppervlakken die nodig is om de druppel te spietsen. Vervolgens bespreken we onze experimentele resultaten met de huidige spietsdrukschattingen, waaruit blijkt dat onze experimentele waarden onder de huidige voorspellingen liggen. Dit onderstreept de moeilijkheid 
om de drempelwaarde van de druk voor de Cassie-naar-Wenzel-overgang nauwkeurig te bepalen met de huidige modellen.

In hoofdstuk 4 gaan we over op gladde oppervlakken en bestuderen we de vorming en evolutie van een vloeistofbrug tussen een bol en een oppervlak bedekt met een dunne viskeuze vloeistoflaag. In dit hoofdstuk onderzoeken we de radiale groei van de vloeistofbrug en de correlatie die deze heeft met de dynamica in de dunne viskeuze vloeistoflaag. Onze experimenten maken gebruik van een combinatie van beeldvormingstechnieken; helderveld en digitale holografische microscopie. Dit stelt ons in staat om in detail de rijke dynamica te beschrijven die een rol speelt bij de vorming van een vloeistofbrug uit een dunne viskeuze vloeistoflaag. Wij tonen aan dat de groei van de vloeistofbrug twee verschillende dynamische regimes vertoont: een vroeg snel-groeiend regime, en een laat traag-groeiend regime. Dit is van bijzonder belang omdat een dynamische vloeistofbrug tijdsafhankelijke capillaire adhesiekrachten veroorzaakt. 


\section{Acknowledgements}

I have a notebook in which I write about the important things and changes in my life. In 2015 I was on my way to Enschede for my master's when I wrote: "Yes, I do not know anything. But I will learn”. We are now close to 2022, and I am certain now, there is still much I do not know. However, I have learnt a few things, and I have learned them thanks to many people who have crossed my path over these years. I would like to dedicate a few words to all of these people who have helped me learn and those who have been there for me throughout the process.

First off, let me thank the people who kindly guided me through the last four years, my supervisors. Hans-Fürgen, our discussions were always insightful and your questions always helped me get a clear picture of the path to follow. I am happy that after my master's internship, you agreed to this half-and-half $\mathrm{PhD}$ project. I am very thankful to have joined and learned at the AK-Butt. Michael, thank you for your patience when explaining to me all kinds of experimental details and even going to the lab with me whenever I needed another point of view. Thank you for your trust and your appreciation during this time, it has been very valuable and it has helped me grow as a scientist and as a person. Facco, we met during the AFM lectures of the master, and already then, I thought that you were a great scientist. I remember going to ask you questions during the break and the advice you gave me during the master's thesis process. The last few years showed me that you are indeed a great scientist with a keen eye for questions, but also a great person. Thank you for your support and advice throughout this time. It has been fundamental in this process. HansFürgen, Michael, facco, thank you. My PhD would not have been possible without you and would have been certainly very different if any of you would not have been there. Thank you for your time, questions, feedback, for pushing me when I needed to be pushed, and for all the different discussions we had.

Besides my supervisors, there have been others who have contributed immensely to this thesis, and in general, to me being able to complete this $\mathrm{PhD}$. Devaraj, I would probably not be writing this document if it had not been for you. During my master's, you were there to guide me throughout the capita selecta, the thesis, and in general when I was adjusting to life at the UT. Thank you for your patience and your trust, for letting me TA vloeistoffysica, and also, thank you so much for agreeing to chair my defence! I am very happy it is you. Detlef, thank you for PoF, for the Max Planck Centre, and for all your efforts to push the boundaries of science and knowledge. I would most definitely not be writing this document if it was not for you. Doris, while I wish we had collaborated a bit more, I am very thankful 
that I got to work with you. I got to see your approach to research, and teamwork and I found it inspiring. Thank you for the time you took to teach me and to discuss with me. Tomas $C$., I know I drove you crazy with all the questions and the emails, but I am very happy we got to collaborate. I learned a lot from you and our collaboration. I hope we get to meet again at some point.

My paranymphs: Minkush, we met at PoF around my second year and the first thing you said to me was "Who are you and what are you doing here?". Well, I hope the past two years of friendship have helped a bit to answer the who-am-I part. The what-am-I-doing part we have discussed at times during our walk-and-talk meetings, tea breaks, and also while going back to the city centre. However, if you would like more details, they are all within this document and we can discuss them later if you would like. Thank you for all the jokes, your constant support, and your help. Above all, thank you for your kindness and friendship. It means a lot to me. Michiel, indeed! it took us almost four years to start talking. However, I am really happy we started to! I must say, I am very glad we got to go to Münster together. Thank you for showing me the ways around the DHM, for helping me out with the samenvatting, and also for so many science and not science-related discussions. I enjoyed them a lot. By the way, I know that secretly you laugh at the silly jokes and the bad music choices I keep sending you. I just know it! To both of you, thank you very much for standing by my side, not only through the defence but in many moments of my $\mathrm{PhD}$ journey.

Anke, you are the master of the confocal and I am extremely thankful to have learned so much from you. Thank you for being there when I had questions, and thank you for the support. Maria, thanks for your support in the lab and all your patience while showing me how to use all kinds of chemicals. I learned a lot from you. Thank you for making fun of me and calling me "Calimero" in my rainy days. But above all, thank you for always making me smile whenever I had to face a new experimental challenge in the lab. William, you are awesome. Thanks for making each experimental day an adventure. It is with you that I learned how important it is to always wear adequate protective gear! Things might (and will) explode around you. But I must say, it was lots of fun. Thanks for the long talks and the wine-in-the-Rhine, for the cooking tips, the LORT marathon, and the jokes. My time in Mainz would not have been half as fun without you around. I wish you the best in Finland! Aiting, I admire your commitment and strength. I must say I am extremely happy to have had you as a colleague, and I am sorry I did not get to be at your defence. However, I sincerely hope we get to meet again. Diego, I enjoyed our time together in the lab and during our different discussions. I wish you the best for what remains of your PhD. Regina, Andreas B., Andreas $H$. and Gabi, thank you for supporting and sharing your knowledge and experience with all AK-Butt members. Your work is vital to the group.

Ivan, thanks for the awesome wine tour experience, the long conversations about science and the support. It took me a while to recognize it, but I think I learned a lot from your attitude and overall character. I hope we get to share a bottle of wine again at some point. Fosé, thank you for helping me grow into my $\mathrm{PhD}$, it was a nice experience. Rianne, my first PoF-experiments were under your supervision and I am so glad it was you! You taught me so much! From physics to lab etiquette and analysis. I am really thankful that 
you took so much time to teach me. Thank you. Udo, I tease you, but I really like you and I love your socks! They're awesome. Thank you for your detailed feedback on parts of this thesis, for the science discussions, and for letting me use your set-up at times. I hope you know that you've got a friend in me. Vatsal, thank you for the scientific discussions and the tea parties! They were vital in the process of me writing this document. I must say I deeply appreciate your attitude towards science, the rigour of your questions and explanations. I wish you the best in what is left of your PhD. Alvaro, you run so fast I could almost not keep up with you. It's amazing! I really enjoyed being your Bata-partner. Carola, I think everything turned out for the best. I am happy I got to know you and I am very glad we got to have a lot of different discussions, from how to keep the labs safe and tidy to politics and photography. Thank you for actively seeking to bring PoFers together and for your active input in the group (especially in the labs). Utkarsh, you always had memes that made me laugh, good advice, and comforting words. Thank you for all the times I went to annoy you at your office and you let me. Sander, we met briefly on your last postdoc day which happened to be my first day at PoF. Since then, and I have no idea how, we managed to keep in touch and discuss many many topics. Thank you for being available for all kinds of questions, be it experimental, numerical, or about manuscripts. I really appreciate your enthusiasm when tackling all kinds of problems. Thank you, I have learned a lot from you. Maaike, I have nothing but gratitude for your smile and your love for science. You are amazing, and your curiosity and kindness are limitless. Lijun, probably you do not remember but we shared a train ride from Mainz to Enschede, and while talking to you I felt your passion for science and that reminded me a lot of my own motivation for doing my work. Thank you for sharing that with me. Pim W., thank you for letting me annoy you guys in your office and thank you for all the nice discussions. Myrthe, I still remember you singing in the labs! I was truly happy to see your unwavering cheerfulness and drive. I admire that in you. Thank you so much for that and all the discussions we had. Dennis $v G$., we did not get to play Catan! It is a shame! But hopefully, there is time for that now. Thank you for your efforts in keeping the labs safe and clean. I appreciate it a lot. Giulia, I wish you the best for what is left or your PhD. Have lots of fun! Yoan, Marvin, TA-ing with you was a very nice experience and I learned a lot from you (and the students). Thank you! Tineke, Rudolf, Rutger, Femke en de meisjes, bedankt voor de tijd die we samen hebben doorgebracht, en bedankt dat jullie me geholpen hebben Nederlands te leren! Ik hoop mijn Nederlands in de toekomst nog te verbeteren. My PoF office-mates, Daniel, Ricardo, Yanshen, Bernardo, I wish we could have shared a bit more, but thank you for the very interesting discussions and laughs we have shared! Also, Bernardo, your headphones leak, and your taste in music is great!! I will miss singing along to Soda Stereo and Café Tacvba while you did not realize it. Gert-Wim, I missed you! Thank you for always being available to help and discuss different experimental solutions. I truly admire your ability to create wonderful things. Martin, thank you for helping me out with several parts that needed to be adjusted in the workshop! foanita, you are so helpful and efficient! I have no idea how you do it! Thank you for answering so many questions, and thank you for always taking the time to help us. Bas, you've got a great taste in music! Thank you for your help all the times I did bad things to hard disks or whenever I got weird errors in the computer. I wish you the best!! 
I would be so happy if I could name all the PoFers, AK-Butt members, friends, family who I have not yet named. But I am certain that this would end up being longer than any chapter I could ever write. So, I will just say that even if I forgot to name you (or have named you briefly), I still carry you in my heart and I wish you all the best. To the reader of this document, thank you for taking the time to read it. It condenses four years of learning, and I hope I could convey the exciting, beautiful, at times difficult process that has been this $\mathrm{PhD}$.

En el '94, Alberto Cortez escribió A mis amigos. Y para mí, el sentimiento de esta canción es fácilmente ampliable a mi familia. El texto dice:

A mis amigos les adeudo la ternura, y las palabras de aliento y el abrazo. El compartir con todos ellos la factura que nos presenta la vida, paso a paso.

A mis amigos les adeudo la paciencia, de tolerarme las espinas más agudas, los arrebatos del humor, la negligencia, las vanidades, los temores y las dudas. Un barco frágil de papel parece a veces la amistad. Pero jamás puede con él la más violenta tempestad. Porque ese barco de papel tiene aferrado a su timón por capitán y timonel un corazón.

Papá, mamá, a ustedes les adeudo todo lo que esta canción dice y mucho más, incluso mi vida. Siempre me motivaron a dar lo mejor de mi, a tomar decisiones y sobre todo a aprender. Muchas gracias por todos sus esfuerzos, por su apoyo, por la libertad que siempre me han dado para tomar mis decisiones y por estar ahí cada vez que los he buscado. Gracias por todo lo que me han enseñado-y continuan a enseñarme-con cada palabra y con cada paso que dan. Espero que sepan que estoy muy orgullosa de ser su hija y de tenerlos en mi vida. Los quiero mucho! Mis mejores amigas, Angela, Elizabeth, gracias por darme su amistad. Sé que hay veces en las que pensamos diferente, pero siempre me alegra tenerlas ahí para aprender de ustedes. Gracias por acompañarme en este proceso y por escucharme tantas veces en las que las he necesitado. Espero que sepan que yo también estoy acá para ustedes. A ustedes, mi familia, les adeudo todo. Y como dice la canción, ni siquiera la más violenta tempestad podría con este barco.

A la familia García, Caicedo, González, y Muñoz, de los cuales he aprendido tanto; muchas gracias por todas las lecciones que me han dado a través de los años. Sin duda todos ustedes han ayudado a formar mi visión del mundo y les agradezco profundamente por eso. 


\section{About the author}

Diana Marcela García González was born in Bogotá, Colombia. After Elizabeth and Angela, she is the daughter of Oswaldo García Caicedo and Aguedita González González. As a child, she loved to spend time with her sisters, listen to her father play the guitar and go outside to play in the tropical rain.

In 2008, she enrolled in the Physics bachelor program at the Universidad Nacional de Colombia. There, she fell in love with the program and especially all the experimental courses. In 2012, she took a physics break to volunteer at 'Insieme si può, Onlus' in Udine, Italy. After this enriching experience, she came back to finish her Physics studies. She teamed up with Prof. Roberto Martínez in the quest to build a small wind tunnel and this led her to present their work at the 2013 APS DFD in Pittsburgh, USA. In this adventure, she met some PoFers, and their love for science and experiments would motivate her even more to pursue her master's degree at the Physics of Fluids Group at the University of Twente. She obtained a scholarship from the University of Twente and got her master's degree in Applied Physics under the guidance of Prof. Devaraj van der Meer.

In 2017, after her master studies, she started her PhD under the guidance of HansJürgen Butt, Michael Kappl, and Jacco Snoeijer in a joint $\mathrm{PhD}$, shared between the Max Planck Institute for Polymer Research in Mainz, Germany and the University of Twente in Enschede, The Netherlands. In her spare time, she loves to take pictures, sport, and dance. 


\section{Sobre el autor}

Diana Marcela García González nació en Bogotá, Colombia, hija de Oswaldo García Caicedo y Aguedita González González. De niña, le encantaba pasar tiempo con sus hermanas, escuchar a su padre tocar la guitarra y salir a jugar bajo la lluvia tropical.

En 2008, se matriculó en la carrera de Física de la Universidad Nacional de Colombia. Allí se enamoró del programa y especialmente de todos los cursos experimentales. En 2012, se tomó un descanso de la física para ser voluntaria en 'Insieme si può, Onlus' en Udine, Italia. Después de esta enriquecedora experiencia, volvió para terminar sus estudios de Física. Se asoció con el profesor Roberto Martínez en la búsqueda de la construcción de un pequeño túnel de viento y esto la llevó a presentar su trabajo en el APS DFD 2013 en Pittsburgh, Estados Unidos. En esta aventura, conoció a algunos miembros del grupo de física de fluidos de Twente (PoFers), y su amor por la ciencia y los experimentos la motivarían aún más para cursar su máster en la Universidad de Twente. En el 2015, Diana obtuvo una beca de la Universidad de Twente y a través de ella obtuvo su máster en Física Aplicada bajo la dirección del profesor Devaraj van der Meer.

En 2017, después de sus estudios de maestría, comenzó su doctorado bajo la dirección de Hans-Jürgen Butt, Michael Kappl y Jacco Snoeijer en un doctorado conjunto, compartido entre el Instituto Max Planck para la Investigación de Polímeros en Mainz, Alemania y la Universidad de Twente en Enschede, Países Bajos. En su tiempo libre, le gusta tomar fotos, hacer deporte y bailar. 
